ORNL/TM-2015/3

\title{
Case Study of the ARRA-Funded GSHP Demonstration at the University at Albany
}

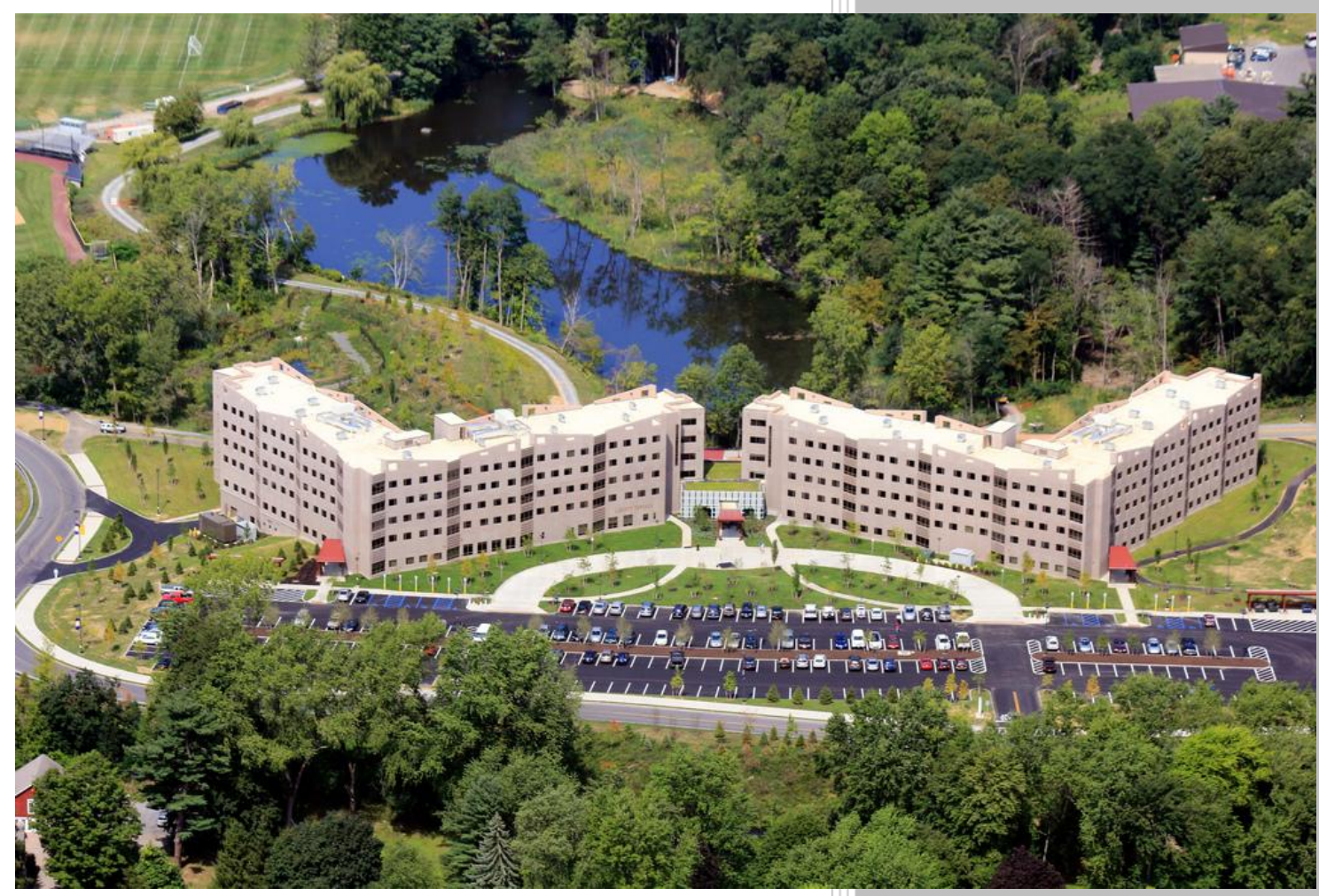

Xiaobing Liu Mini Malhotra

Zeyu Xiong

Adam Walburger

February 2015 


\section{DOCUMENT AVAILABILITY}

Reports produced after January 1, 1996, are generally available free via the U.S. Department of Energy (DOE) Information Bridge.

Web site http://www.osti.gov/bridge

Reports produced before January 1, 1996, may be purchased by members of the public from the following source.

National Technical Information Service

5285 Port Royal Road

Springfield, VA 22161

Telephone 703-605-6000 (1-800-553-6847)

TDD 703-487-4639

Fax 703-605-6900

E-mail info@ntis.gov

Web site http://www.ntis.gov/support/ordernowabout.htm

Reports are available to DOE employees, DOE contractors, Energy Technology Data Exchange (ETDE) representatives, and International Nuclear Information System (INIS) representatives from the following source.

Office of Scientific and Technical Information

P.O. Box 62

Oak Ridge, TN 37831

Telephone 865-576-8401

Fax 865-576-5728

E-mail reports@osti.gov

Web site http://www.osti.gov/contact.html

This report was prepared as an account of work sponsored by an agency of the United States Government. Neither the United States Government nor any agency thereof, nor any of their employees, makes any warranty, express or implied, or assumes any legal liability or responsibility for the accuracy, completeness, or usefulness of any information, apparatus, product, or process disclosed, or represents that its use would not infringe privately owned rights. Reference herein to any specific commercial product, process, or service by trade name, trademark, manufacturer, or otherwise, does not necessarily constitute or imply its endorsement, recommendation, or favoring by the United States Government or any agency thereof. The views and opinions of authors expressed herein do not necessarily state or reflect those of the United States Government or any agency thereof. 
Energy and Transportation Science Division

\title{
CASE STUDY OF THE ARRA-FUNDED GSHP DEMONSTRATION AT THE UNIVERSITY OF ALBANY
}

\author{
Xiaobing Liu \\ Mini Malhotra \\ Zeyu Xiong \\ Adam Walburger* \\ *CDH Energy Corp.
}

Date Published: February 2015

\author{
Prepared by \\ OAK RIDGE NATIONAL LABORATORY \\ Oak Ridge, Tennessee 37831-6283 \\ managed by \\ UT-BATTELLE, LLC \\ for the \\ U.S. DEPARTMENT OF ENERGY \\ under contract DE-AC05-00OR22725
}





\section{ACKNOWLEDGMENTS}

This work was sponsored by the U.S. Department of Energy, Building Technology Office. Special thanks to the inspirations and inputs from Indu Lnu and her colleagues at the University at Albany. 



\begin{abstract}
High initial costs and lack of public awareness of ground-source heat pump (GSHP) technology are the two major barriers preventing rapid deployment of this energy-saving technology in the United States. Under the American Recovery and Reinvestment Act (ARRA), 26 GSHP projects have been competitively selected and carried out to demonstrate the benefits of GSHP systems and innovative technologies for cost reduction and/or performance improvement. This report highlights the findings of a case study of one of the ARRA-funded GSHP demonstration projects - a distributed GSHP system at a new 500-bed apartment-style student residence hall at the University at Albany. This case study is based on the analysis of detailed design documents, measured performance data, published catalog data of heat pump equipment, and actual construction costs. Simulations with a calibrated computer model are performed for both the demonstrated GSHP system and a baseline heating, ventilation, and airconditioning (HVAC) system to determine the energy savings and other related benefits achieved by the GSHP system. The evaluated performance metrics include the energy efficiency of the heat pump equipment and the overall GSHP system, as well as the pumping performance, energy savings, carbon emission reductions, and cost-effectiveness of the demonstrated GSHP system compared with the baseline HVAC system. This case study also identifies opportunities for improving the operational efficiency of the demonstrated GSHP system.
\end{abstract}





\section{TABLE OF CONTENTS}

Page

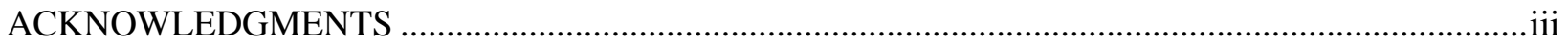

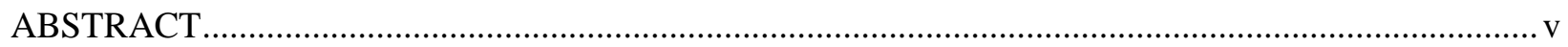

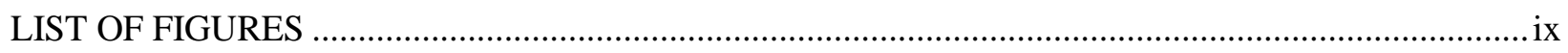

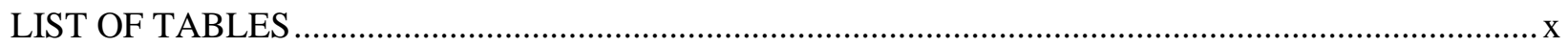

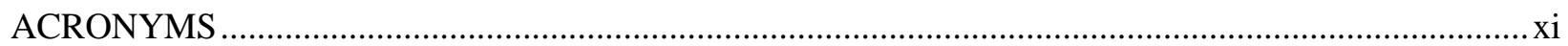

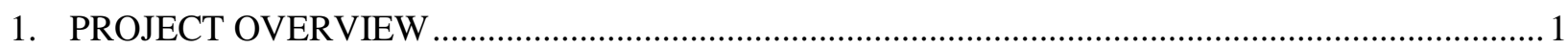

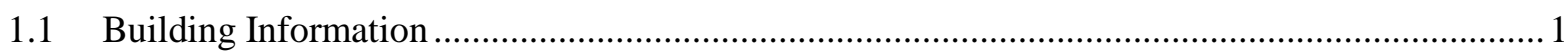

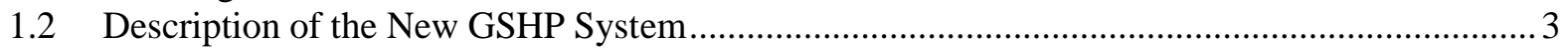

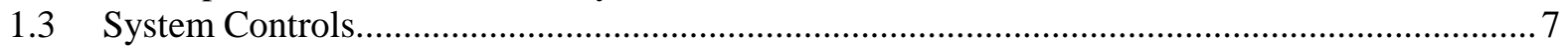

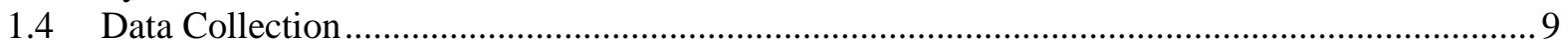

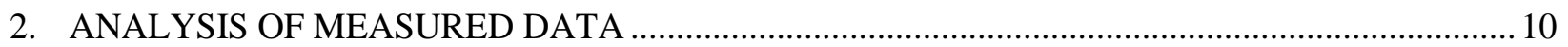

2.1 Temperatures and Flow Rate in the Primary and Secondary Loops........................................ 10

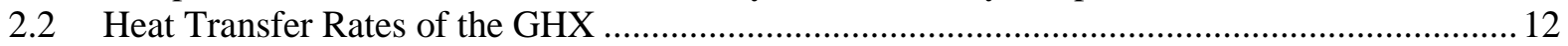

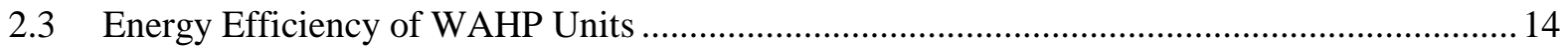

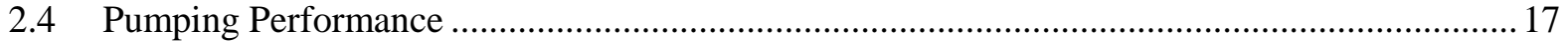

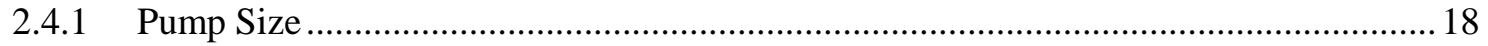

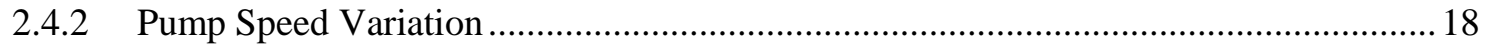

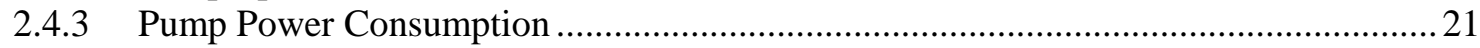

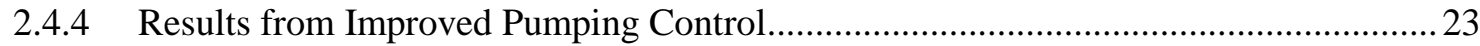

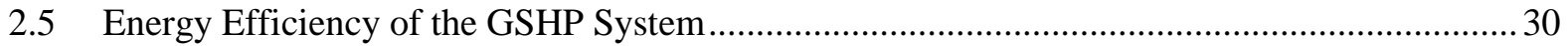

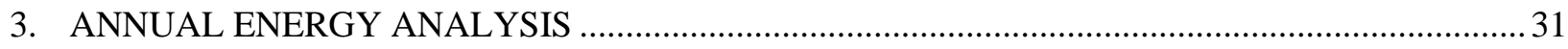

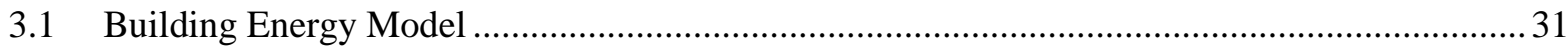

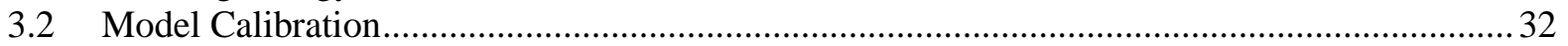

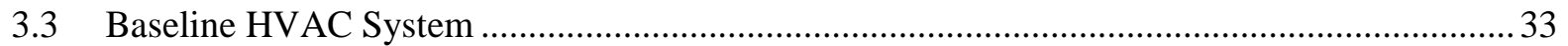

3.4 Comparison between Demonstrated GSHP System and Baseline PTHP System ...................... 34

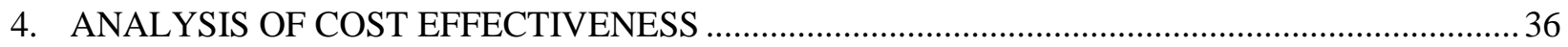

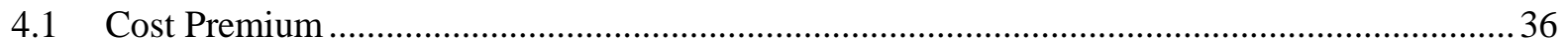

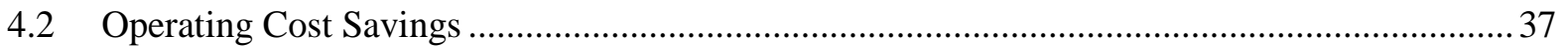

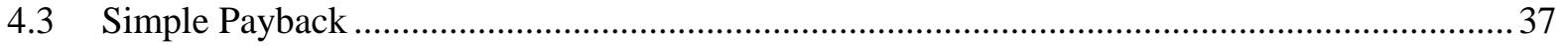

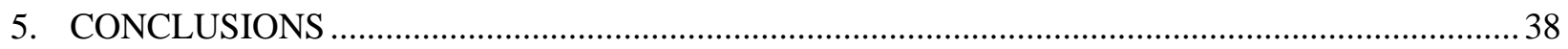

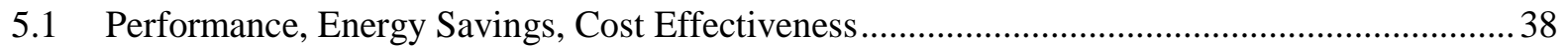

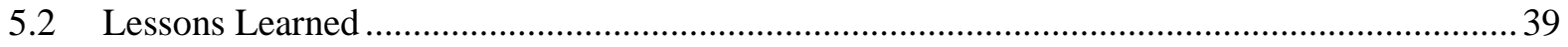

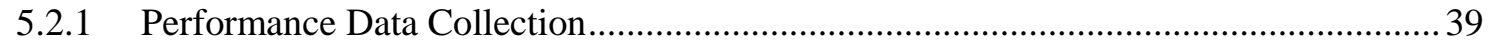

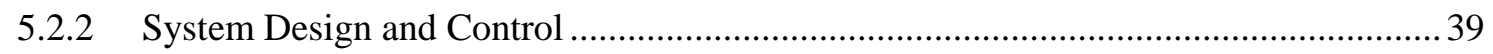

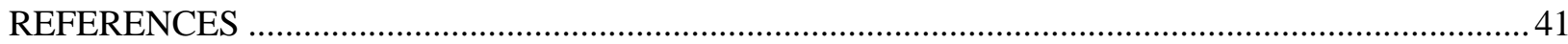

APPENDIX A. List of the Capacity and Efficiency of Installed WAHP Units.........................................42

APPENDIX B. Original Specification for Pumping Control..................................................................... 49

APPENDIX C. Additional Data from On-site Measurements .................................................................50 



\section{LIST OF FIGURES}

Figure $\quad$ Page

1. Liberty Terrace residence hall at the University at Albany........................................................ 1

2. Geographic location of the GSHP demonstration site at the University at Albany........................... 2

3. Aerial photo showing the location of the new student housing and the bore field for the

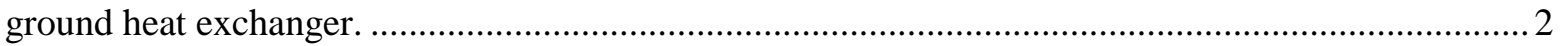

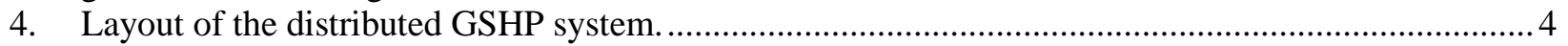

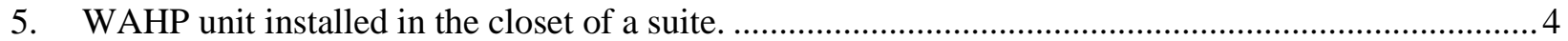

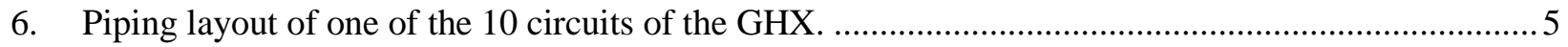

7. GSHP system schematic, showing monitored data points. ............................................................

8. Pumps in (left) the primary loop and (right) the secondary loop.....................................................6

9. Outdoor air ventilation equipment installed at the roof of Liberty Terrace. ...................................... 7

10. A differential pressure sensor installed in the ceiling of a suite/apartment on the fifth floor..............9

11. The building loop (secondary loop) and ground loop (primary loop) supply fluid temperature.

12. Time series chart for the temperature differential in the primary and secondary loops along

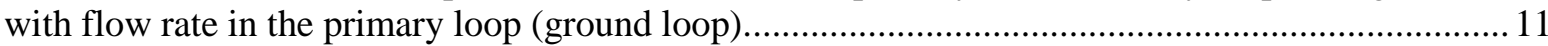

13. Distribution of the temperature differential in the primary loop...................................................... 12

14. Primary-loop flow rate and secondary-loop supply temperature ................................................... 12

15. Time series chart for the heat transfer rates of the GHX............................................................. 13

16. Scatter chart showing relationship between the heat transfer rates of the GHX and the

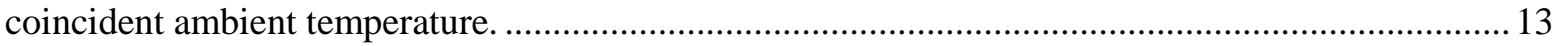

17. Estimated combined heating and cooling outputs of all the WAHPs. ........................................... 15

18. Time series chart for calculated combined heat pump power consumption in heating and cooling modes.

19. Calculated combined heat pump power consumption in heating and cooling modes against

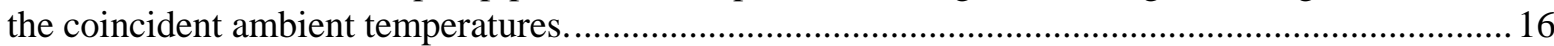

20. Calculated COP at each time interval during the period of data measurement................................ 17

21. Calculated EER at each time interval during the period of data measurement. ............................... 17

22. Speed of the three circulation pumps in the primary (ground) loop. .............................................. 19

23. Average speed of primary-loop pumps vs. primary loop temperature differential (data shown in this chart are the average in each 15-min interval). ................................................................. 19

24. Average speed of primary-loop pumps vs. combined power consumptions of all WAHPs..............20

25. Speed of the two circulation pumps in the secondary loop........................................................... 20

26. Average speed of secondary-loop pumps vs. combined power consumption of all the

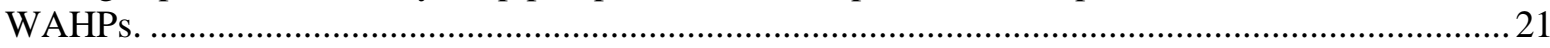

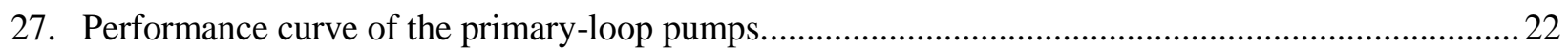

28. Calculated power consumptions of primary-loop pumps and the WAHPs (data shown in this chart are the power consumptions in each 15-min interval). ....................................................22

29. Flow rate in the primary loop from October 2012 through August 2014 ........................................24

30. Primary-loop pump speed during the week of August 1-7, 2013 ................................................24

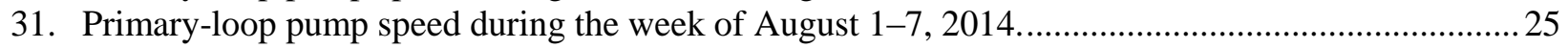

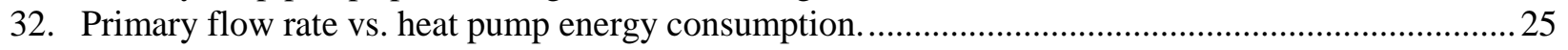

33. Primary flow rate vs. ground loop temperature difference. .........................................................26

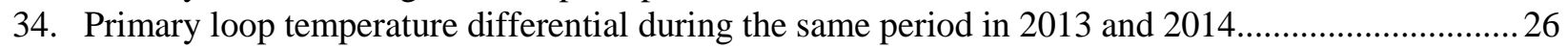

35. Primary-loop pumping energy use vs. ambient temperature....................................................22

36. Secondary loop supply temperatures during the same period in 2013 and 2014 .........................28

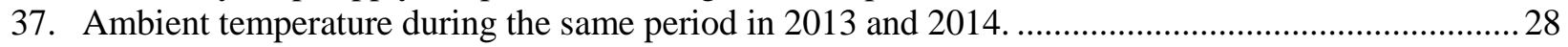

38. Comparison of cooling outputs of WAHPs during the same period in 2013 and 2014...................29 
39. Comparison of secondary loop supply temperatures during the same period in 2013 and 2014.

40. Total building power consumptions during the same period in 2013 and 2014.

41. Images of Liberty Terrace: (a) actual building and (b) a three-dimensional rendering of the eQUEST energy model of the building.

42. Measured and predicted hourly heating and cooling loads.

43. Measured and predicted monthly heating and cooling loads.

44. Schematic of a typical packaged terminal heat pump.

45. Simulation results for electric end use of the baseline PTHP system and the as-built GSHP system, as well as two alternative GSHP systems.

\section{LIST OF TABLES}

\section{Table}

1. GSHP system monitoring points....

2. Principal design parameters of the simulated baseline PTHP system ............................................ 34

3. Energy consumptions and carbon emissions of the as-built GSHP and the baseline PTHP system (pumping power of the GSHP system is measured before the primary-loop pump control is fixed).....

4. Conversion factors for source energy consumption and carbon emissions in New York State.

5. Itemized installed cost of the demonstrated GSHP system 


\section{ACRONYMS}

$\begin{array}{ll}\text { COP } & \text { coefficient of performance } \\ \text { DHW } & \text { domestic hot water } \\ \text { DOAS } & \text { dedicated outdoor air system } \\ \text { DOE } & \text { US Department of Energy } \\ \text { EER } & \text { energy efficiency ratio } \\ \text { ERV } & \text { energy recovery ventilator } \\ \text { EWT } & \text { entering water temperature } \\ \text { GHX } & \text { ground heat exchanger } \\ \text { GSHP } & \text { ground source heat pump } \\ \text { HSPF } & \text { heating seasonal performance factor } \\ \text { HVAC } & \text { heating, ventilation, and air conditioning } \\ \text { NREL } & \text { National Renewable Energy Laboratory } \\ \text { OA } & \text { outdoor air } \\ \text { ORNL } & \text { Oak Ridge National Laboratory } \\ \text { PTHP } & \text { packaged terminal heat pump } \\ \text { RTU } & \text { rooftop unit } \\ \text { SEER } & \text { seasonal energy efficiency ratio } \\ \text { WAHP } & \text { water-to-air heat pump }\end{array}$





\section{PROJECT OVERVIEW}

University at Albany, a part of the State University of New York, was competitively selected by the U.S. Department of Energy (DOE) in 2009 to receive a \$2.7 million grant from the American Recovery and Reinvestment Act (ARRA) to demonstrate a ground-source heat pump (GSHP) at its new residence hall, Liberty Terrace, which is a 500-bed apartment-style facility (Fig. 1). The demonstrated GSHP system provides individual climate control to each of the apartments and the common area of the building. Characteristics of the building and the GSHP system are contained in the following sections.

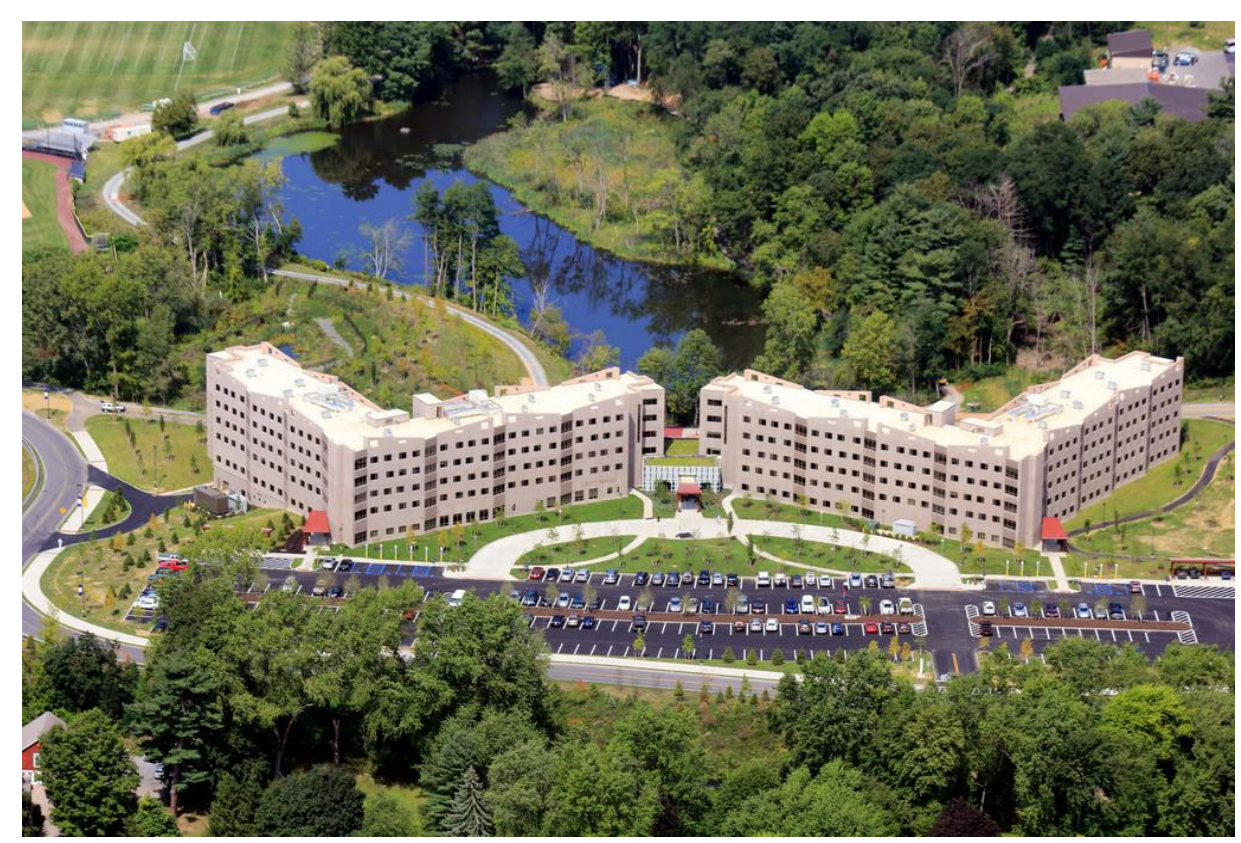

Fig. 1. Liberty Terrace residence hall at the University at Albany.

(Courtesy of University at Albany)

\subsection{Building Information}

Albany, New York, is located in the humid continental climate zone. Summers in Albany can be hot and humid, with temperatures of $90{ }^{\circ} \mathrm{F}$ or hotter on average 9 days per year. Winters can be very cold with fluctuating conditions; temperatures drop to $0{ }^{\circ} \mathrm{F}$ or below on average 9 nights per year. Record temperature extremes have ranged from $-28^{\circ} \mathrm{F}$ on January 19,1971 , to $104{ }^{\circ} \mathrm{F}$ on July 4,1911 . Albany receives 38.6 inches of rainfall annually, with 138 days of at least 0.01 in. of precipitation each year. Snowfall is significant, totaling 61.7 in. annually. ${ }^{1}$ Figure 2 shows the geographic location of the demonstration site.

\footnotetext{
${ }^{1}$ http://en.wikipedia.org/wiki/Albany,_New_York
} 


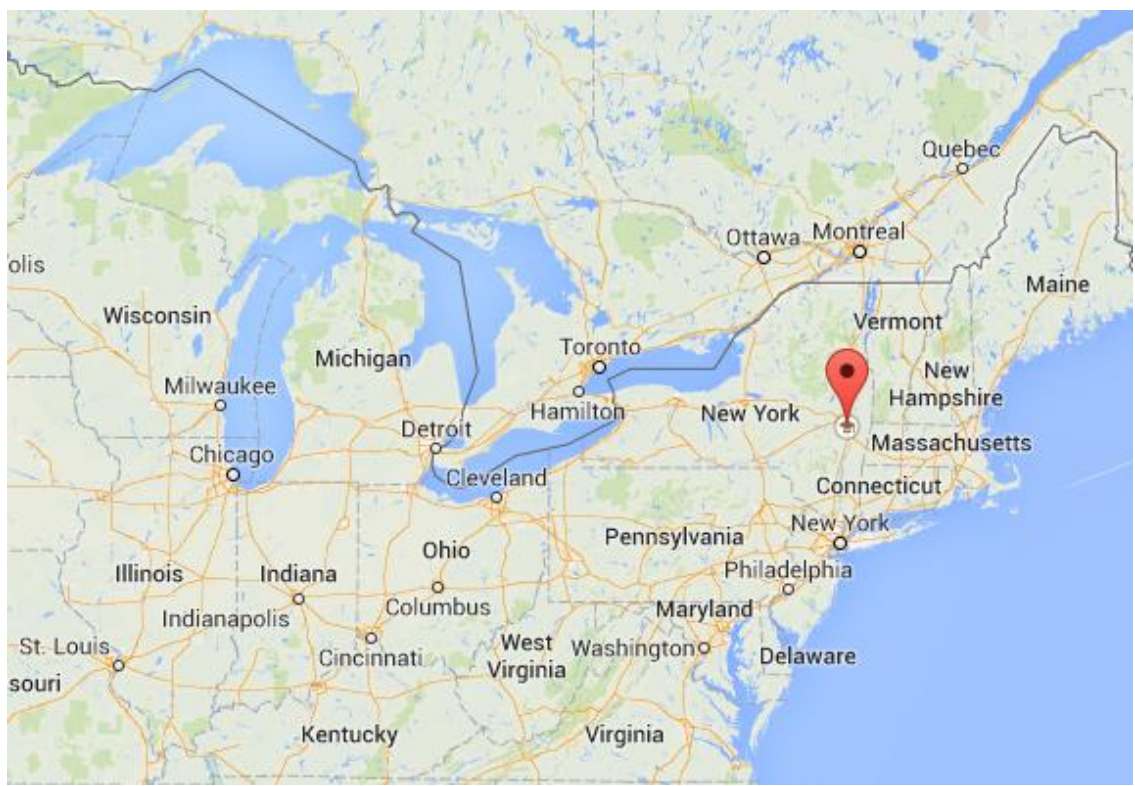

Fig. 2. Geographic location of the GSHP demonstration site at the University at Albany.

Figure 3 displays an aerial photo of the Liberty Terrace residence hall and the site of installation of the ground heat exchanger (GHX) of the GSHP system. Liberty Terrace includes 125 identical apartments. Each apartment consists of four single-bed bedrooms, two bathrooms, a kitchen, and a living/dining area. In addition, Liberty Terrace has a few meeting spaces, an exercise room, a lounge area, and other shared amenities for students, including laundry facilities on each floor. The total floor space conditioned by the GSHP system is $184,533 \mathrm{ft}^{2}$.

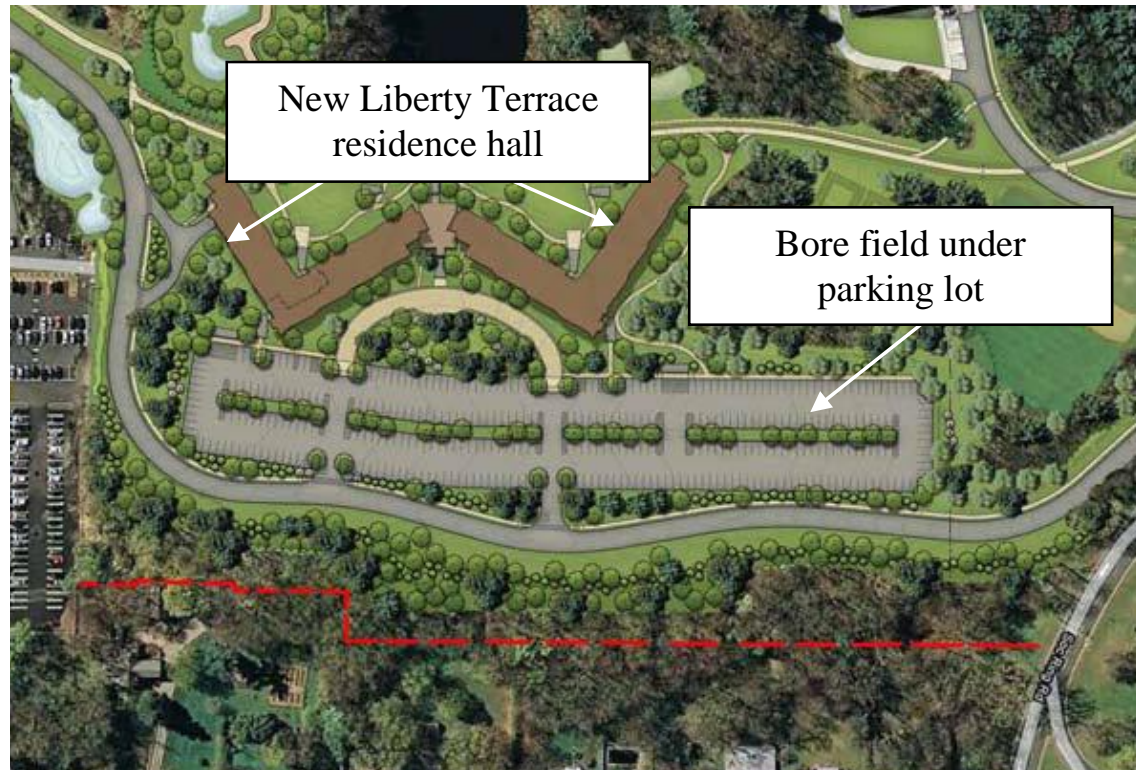

Fig. 3. Aerial photo showing the location of the new student housing and the bore field for the ground heat exchanger. 
The Liberty Terrace building has been certified as a LEED Gold building. In addition to the GSHP system, Liberty Terrace has also implemented the following other energy-saving features ${ }^{2}$.

- Energy-efficient windows and doors

- Constructed from pre-cast insulated concrete panels

- Use of recycled and local-source materials

- Green roofing and a white roof

- Rain gardens

- Permeable pavement

- Maximization of daylight

- High efficiency lighting and Energy Star labeled appliances

A campus benchmarking conducted by the university indicates that Liberty Terrace has $63.6 \mathrm{kBtu} / \mathrm{ft}^{2} /$ year energy consumption, which is approximately $50 \%$ lower than the conventional buildings in the campus (Indu 2014).

\subsection{Description of the New GSHP System}

The demonstrated GSHP system is in a distributed configuration, which is very common for GSHP applications in the United States. With this distributed configuration, each zone of the building is conditioned with an individual water-to-air heat pump (WAHP) unit, and all the WAHP units are connected to a common two-pipe water loop, which is connected to a GHX, as illustrated in Fig. 4. A central pump station is used to circulate a $20 \%$ ethanol-water solution through the WAHP units and the GHX.

In total there are 189 McQuay WAHP units, with a combined cooling capacity of approximately 355 tons, installed throughout the building, that is, in each suite and the common areas. Each of the 125 identical suites is conditioned by a 2-ton WAHP unit, which is installed in a closet along the corridor of the apartment (Fig. 5). ${ }^{3}$ The WAHP units conditioning the common areas are installed above the ceiling. Each of the WAHP units has a one-stage compressor that cycles on and off to meet the fluctuating heating and cooling demands in the zone it conditions. No backup electric heaters installed with the WAHP units. ${ }^{4}$ Appendix A lists the location, capacity, and efficiency (at design conditions) of each of the 189 WAHP units.

\footnotetext{
${ }^{2}$ http://www.albany.edu/housing/libertyenv.shtml

${ }^{3}$ The facility manager of Liberty Terrace indicated that the heat pump mechanical closets should have been positioned to be accessible from the hallway, not from the students' living space, so that maintenance staff could access the heat pump for service (i.e., filter changes) without having to enter the students' living space.

${ }^{4}$ The only electric resistance heat in the building is in the stairwells and vestibules on each floor. In addition, there are radiant heat panels in the bathrooms at the basement and at the top (5th) floor of the building to provide better comfort during extremely cold weather.
} 


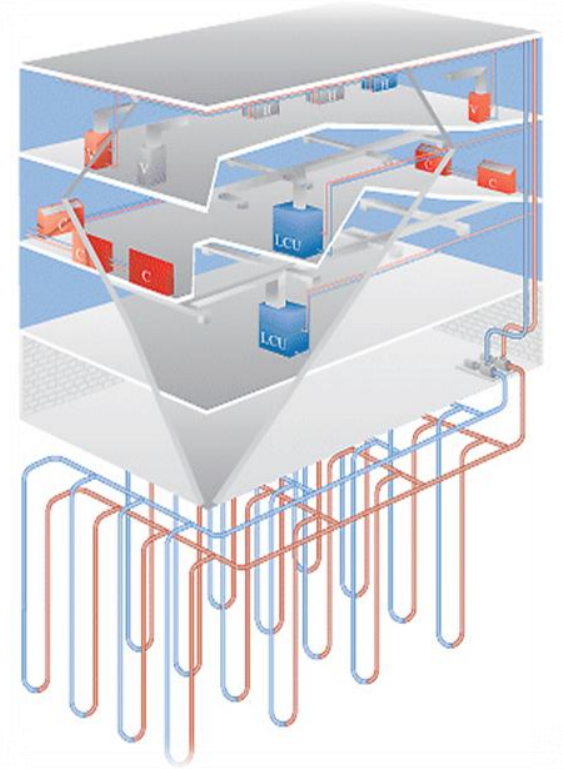

Fig. 4. Layout of the distributed GSHP system. (Source: ClimateMaster)

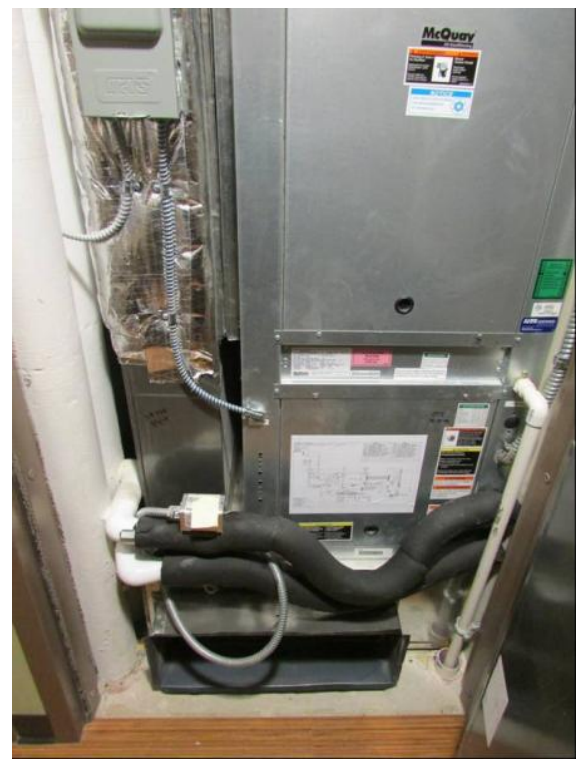

Fig. 5. WAHP unit installed in the closet of a suite.

The GHX consists of 150 vertical bores, each $450 \mathrm{ft}$ deep, for a total of 67,500 bore-feet and a total piping length of $135,000 \mathrm{ft}$. The vertical bores are spaced $20 \mathrm{ft}$ apart and are arranged in 10 circuits. The GHX is located under an adjacent parking lot (as shown in Fig. 3); the well headers are collected in a vault outside the building and run underground to the building's mechanical room. Fig. 6 shows the piping layout of one of the 10 circuits. An in-situ test for the thermal properties of the ground formation was conducted on April 15, 2010. The test results indicated that the effective ground thermal conductivity along the depth of the vertical bore is $1.18 \mathrm{Btu} / \mathrm{h}-\mathrm{ft}-{ }^{\circ} \mathrm{F}$. The estimated thermal diffusivity for this formation is $0.85 \mathrm{ft}^{2} /$ day. 
The undisturbed ground temperature is estimated to be within 52.5 to $54^{\circ} \mathrm{F}$, based on the initial temperature data at the startup of the test.

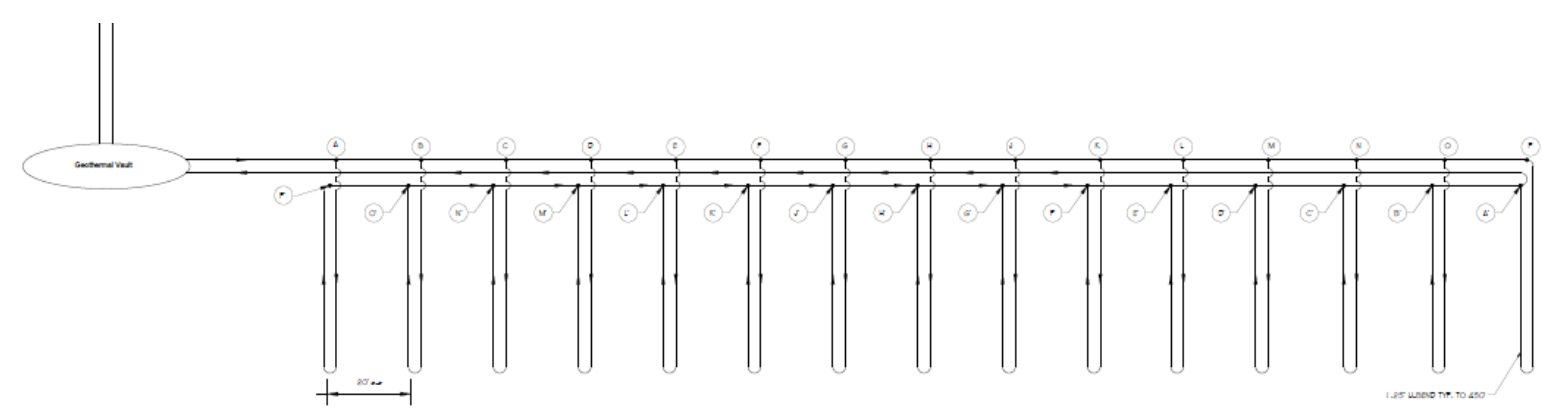

Fig. 6. Piping layout of one of the 10 circuits of the GHX.

A primary and secondary loop configuration is used in this GSHP system. A 20\% ethanol-water solution is circulated by pumps in the primary and secondary loops. Figure 7 displays a schematic of the GSHP system with monitoring points labeled.

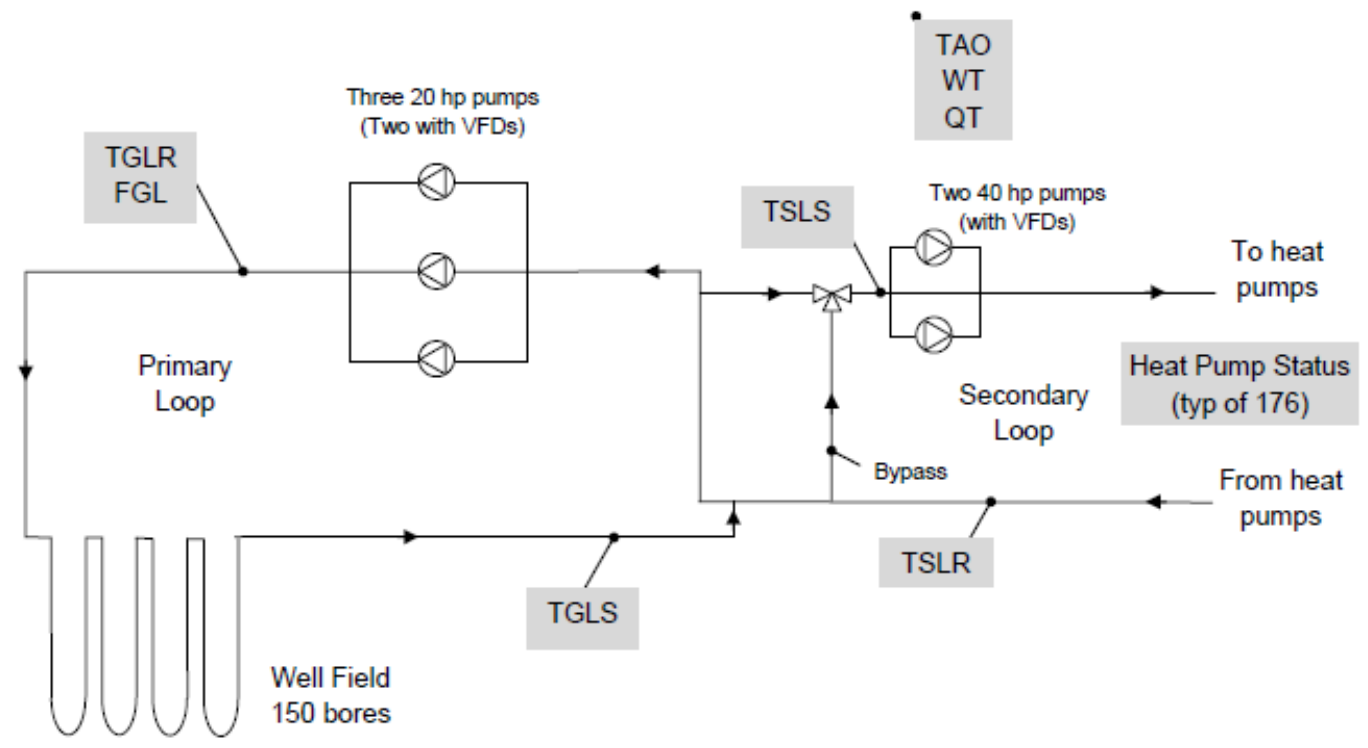

Fig. 7. GSHP system schematic, showing monitored data points.

Circulation in the primary loop-between the common two-pipe water loop in the building and the GHX - is provided by three $20 \mathrm{hp}$ Armstrong pumps located in the mechanical room in the building's basement. Each pump is sized at $50 \%$ of the total peak flow $(1000 \mathrm{gpm})$ to meet peak heating and cooling loads. All of these pumps operate in parallel. Two redundant $40 \mathrm{hp}$ Armstrong pumps provide circulation in the secondary loop - the common two-pipe loop that connects all the WAHPs. Each pump is sized at $100 \%$ of the total peak flow, and the two pumps operate in parallel alternatively. Photos of the pumps are shown in Fig. 8. 

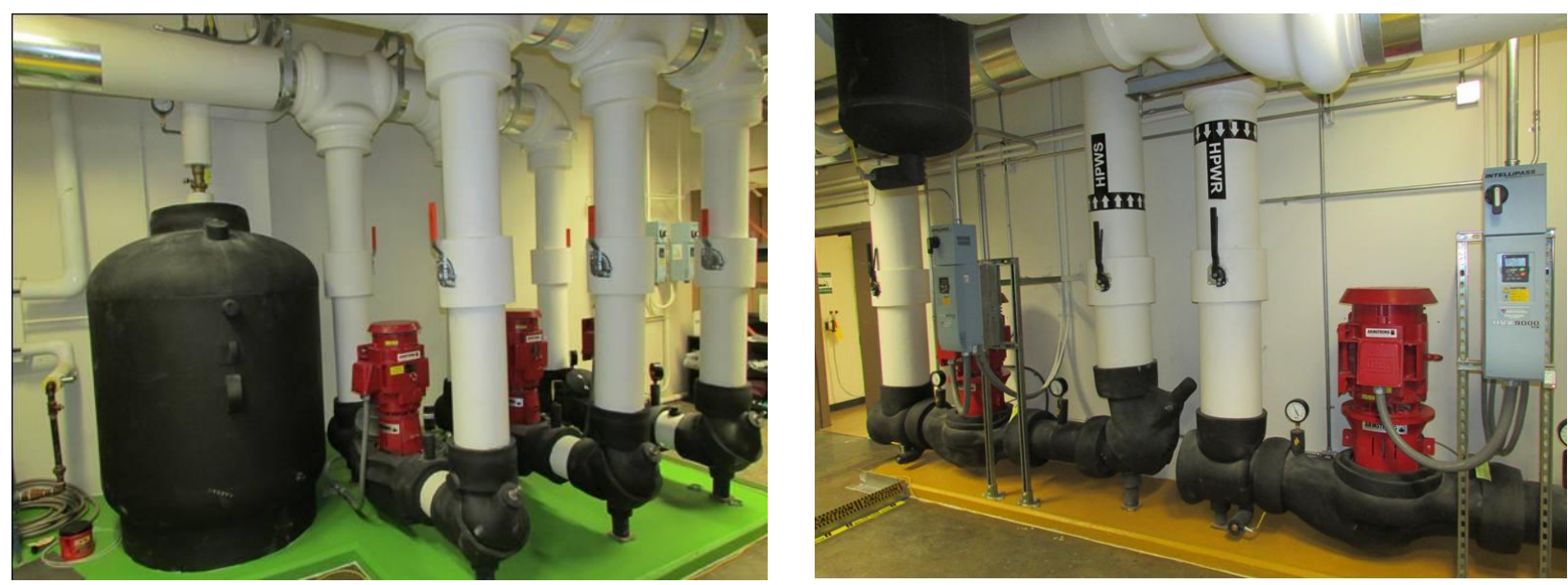

Fig. 8. Pumps in (left) the primary loop and (right) the secondary loop.

The outdoor air (OA) ventilation in the common areas of the building is provided by four dedicated OA systems, including two 15 ton and one 20 ton water source rooftop units (as shown in Fig. 9a), and a $100 \%$ OA water source heat pump installed at the mechanical room in the basement of the building (as shown in Fig. 9b). Each of these OA systems is equipped with an energy recovery ventilator (ERV). The combined OA supply is about 16,225 CFM. All these OA systems use the GHX as heat sink and source. These units use two-stage compressors that modulate heating/cooling output based on the loads for conditioning the OA. Besides, there are 27 Renewaire ERVs (with a combined capacity of 20,540 CFM) installed on the roof of the building (as shown in Fig. 9c). These ERVs run at constant speed all year round. Each of the ERVs delivers OA to a group of five WAHP units serving the five apartments below it and vertically connected through a draft/duct.

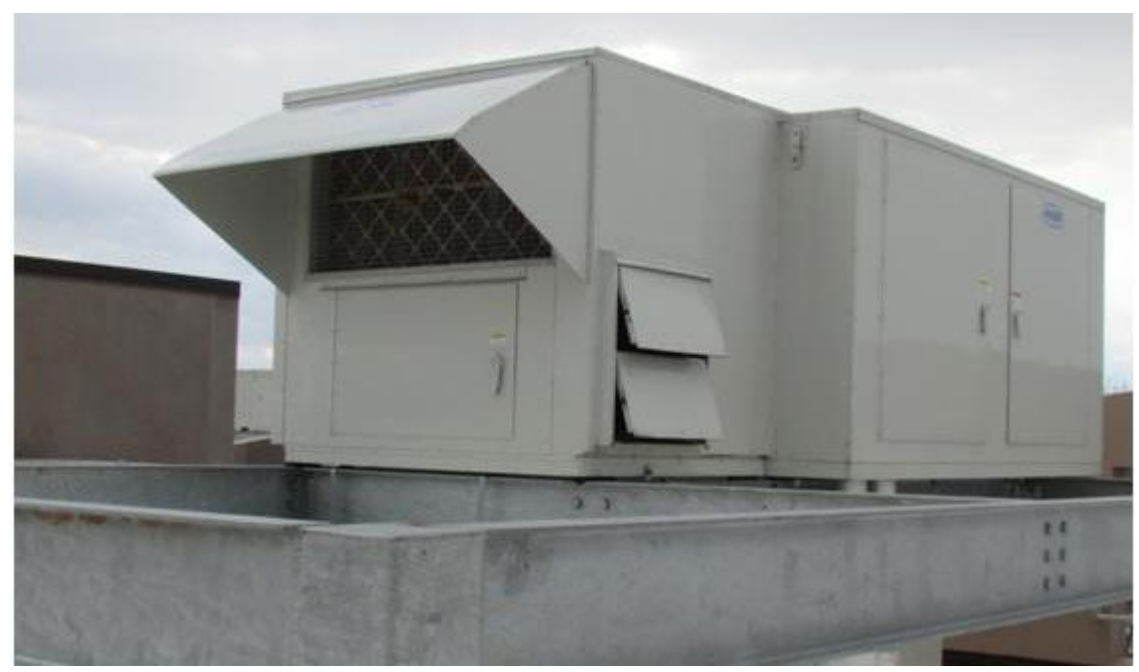

(a) One of the three water source rooftop units for OA ventilation at common areas 


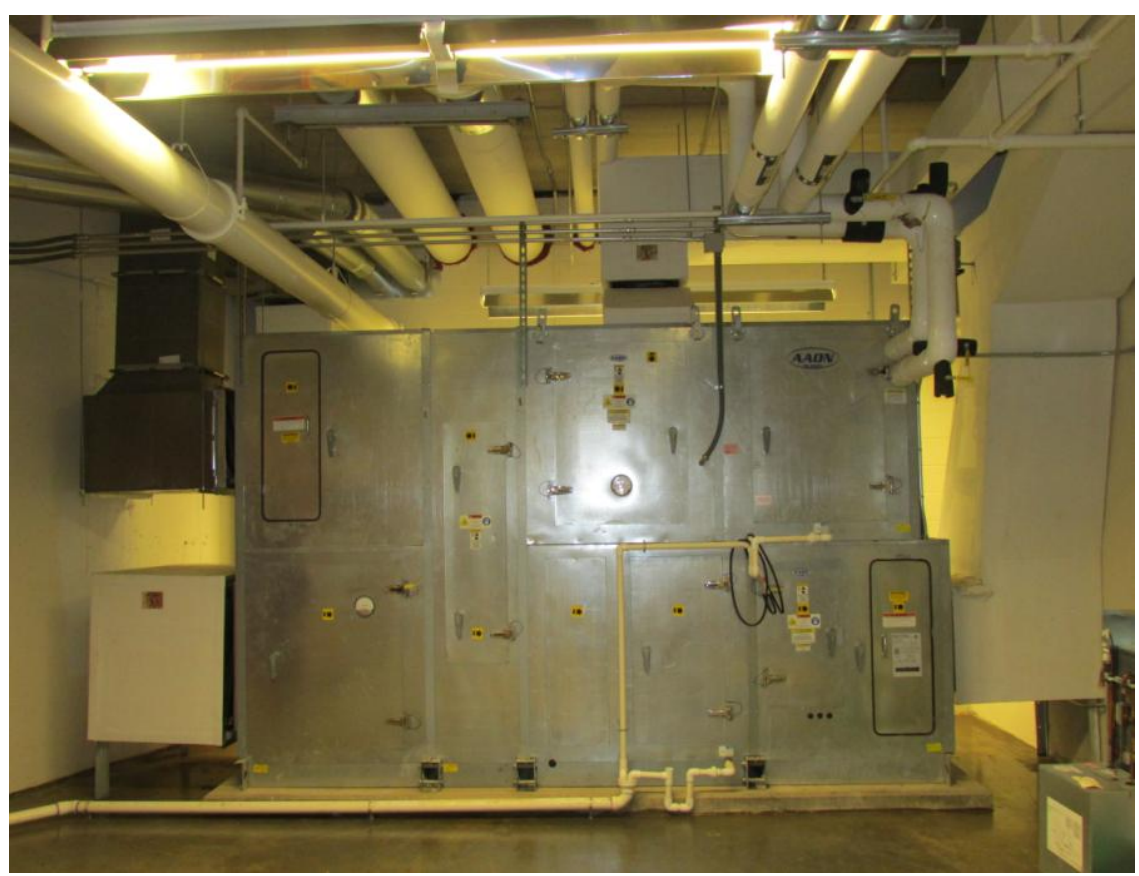

(b) The fourth DOAS installed at the mechanical room in the basement

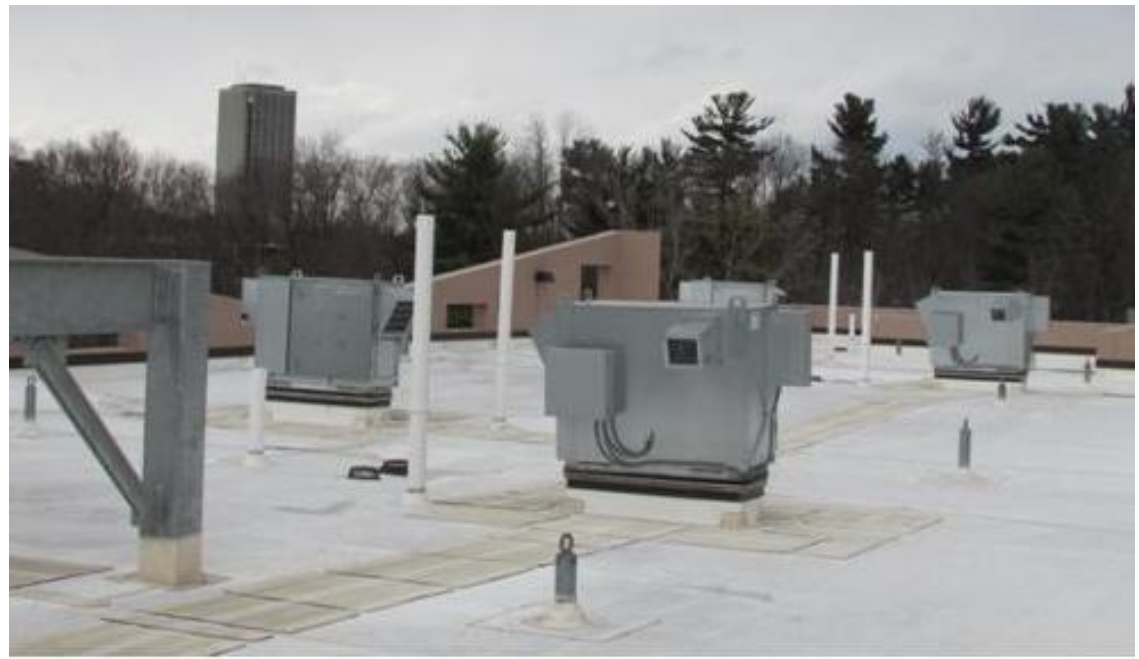

(c) Four of the 27 ERV units installed on the rooftop for OA ventilation at apartments below

Fig. 9. Outdoor air ventilation equipment installed at the roof of Liberty Terrace.

Domestic hot water (DHW) is provided by two conventional natural gas water heaters and recirculated through a hydronic loop.

\subsection{System Controls}

It was found during the site visit that the actually implemented control of the GSHP system is somewhat different from the original design intention. The observed actual control is described below, along with the control strategies documented in the original design intention. 


\section{WAHP Units}

Each WAHP unit turns on and off to satisfy the fluctuating heating or cooling demand in the zone it conditions. These WAHP units switch from heating to cooling mode if the space temperature rises to $77^{\circ} \mathrm{F}$, and from cooling to heating mode if the space temperature falls to $66^{\circ} \mathrm{F}$. Originally, fan of the WAHP ran continuously all day long regardless of whether the WAHP was providing heating or cooling. Since February 13, 2013, the fan operation mode was changed so that it runs only when the compressor of the WAHP is turned on. This change was made to solve student's complaints about cold air blowing into their living space in winter. The facility manager of the university measured the outdoor air volume delivered to the suite after changing the fan operation mode. The measurement showed sufficient outdoor air volume with cycling fans of the WAHP units.

The default set point for space temperature is $70^{\circ} \mathrm{F}$ in winter and $74^{\circ} \mathrm{F}$ in summer. Residents were given $\pm 2^{\circ} \mathrm{F}$ adjustment range from the set point. The occupancy in common areas is identified with motion sensors. The space temperature set points in common areas will be set back automatically $\left(65^{\circ} \mathrm{F}\right.$ for heating, $76^{\circ} \mathrm{F}$ for cooling) when these zones are not occupied. There is neither an occupancy sensor nor an occupancy schedule for the suites, and as a result, there is no space temperature setback even when a suite is unoccupied, although the design document stated that "In unoccupied mode, space temperature setback will start the unit to prevent temperature extremes of less than 60 degrees or greater than 85 degrees." A setback control for the suites could have reduced energy consumption in this building.

\section{Primary Loop Circulation Pump}

During the initial data collection period (October 2013 through January 2014), the primary-loop pump was controlled to maintain the secondary loop supply fluid temperature at $60^{\circ} \mathrm{F}$. As shown in Fig. 7 , there is a 3-way valve between the primary and the secondary loops. The control system modulates this 3-way valve based on the secondary loop supply temperature. When the secondary loop supply temperature is not at the specified temperature, the 3-way valve closes the bypass (between the supply and return lines of the secondary loop) to allow mixing between the fluid in the primary and the secondary loops. When the secondary loop supply temperature is at the set point, the 3-way valve opens the bypasses so that water flow is only circulated in the secondary loop. In the meanwhile, the primary-loop pump speed is reduced to its minimum (around 20\% of full speed). As discussed later, this control strategy resulted in excessive pumping in the primary loop and degraded the operational energy efficiency of the entire GSHP system.

\section{Secondary Loop Circulation Pump}

The pumps in the secondary loop are controlled to maintain a 6 psi pressure differential at two WAHP units, which are at the fifth floor and the most distant to the secondary-loop pump. Figure 10 shows a differential pressure sensor installed in the ceiling of a suite/apartment on the fifth floor. Most of the WAHP units have a 2-way solenoid valve, which is opened to allow water flow to enter the WAHP unit when the thermostat associated with the WAHP calls for heating or cooling. The 2-way valve is closed at other times. The WAHP units on the first floor have 3-way valves and bypass piping to allow water to flow through. This bypass allows water flow circulation in the secondary loop even when no WAHP is called on.

\section{Outdoor Air Ventilation}

The four OA systems condition the OA and deliver it to the common areas in the building. Based on available measured data, the control strategy of the three AAON rooftop units (RTUs) is as follows. The virgin OA first mixes with return air from the building. The ratio between OA and return air varies depending on the $\mathrm{OA}$ temperature. When $\mathrm{OA}$ is lower than $50^{\circ} \mathrm{F}$, the OA ratio is less than 1 and it linearly decreases (to a minimum value) with a decrease of OA temperature. When OA temperature is between $50^{\circ} \mathrm{F}$ and $75^{\circ} \mathrm{F}$, the OA ratio becomes 1 and the RTUs provide $100 \%$ OA to the building. Since the OA is lower than the room temperature, it provides free cooling to the building. When $\mathrm{OA}$ is higher than $75^{\circ} \mathrm{F}$, 
the $\mathrm{OA}$ ratio is less than 1 again, and it decreases linearly with an increase of OA temperature to a minimum value. ${ }^{5}$ The RTUs switch from heating to cooling mode when the ambient temperature is higher than $60^{\circ} \mathrm{F}$. The 27 Renewaire ERVs run continuously and deliver OA to the WAHP unit installed in each suite.

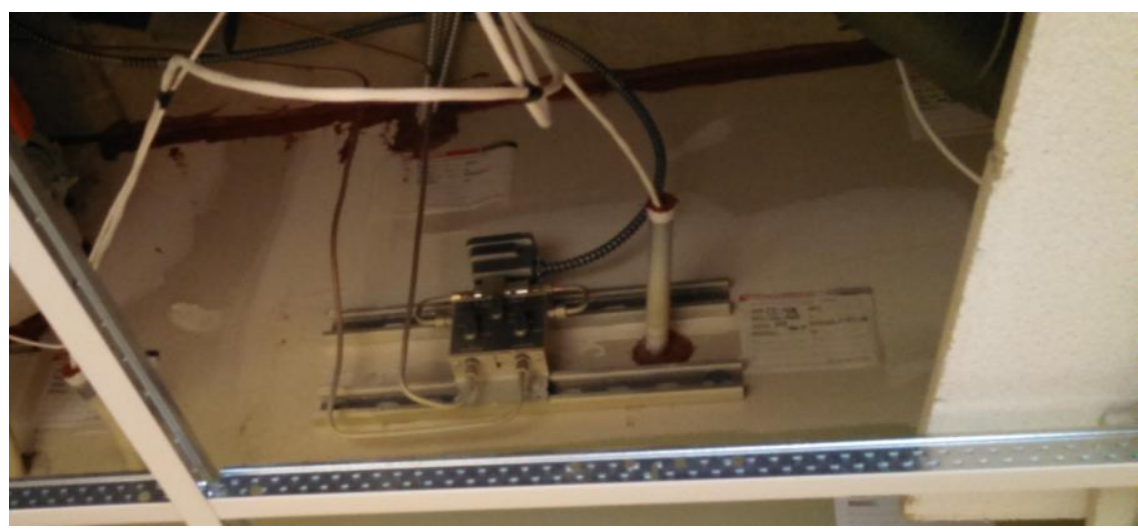

Fig. 10. A differential pressure sensor installed in the ceiling of a suite/apartment on the fifth floor.

\subsection{Data Collection}

Performance monitoring and data collection for the GSHP system is provided by the University at Albany using an on-site Siemens APOGEE direct digital control system. The system polls the sensors continually and provides 15-min totals or averages of each sensor reading depending on the sensor type; the heat pump statuses are sampled every $15 \mathrm{~min}$. The measured data are recorded in a column oriented, comma delimited file (CSV format) and stored on a server (Walburger and Perriello 2013). The site has its own meter to measure natural gas consumption (for DHW), which is not included in this case study since it is independent from the GSHP system. The available data points are listed in Table 1, which shows that less than $4 \%$ of the measured data were missing.

Table 1. GSHP system monitoring points

\begin{tabular}{|l|c|c|c|c|}
\hline Data points & Units & Type & $\begin{array}{c}\text { Missing data } \\
\text { (hours) }\end{array}$ & $\begin{array}{c}\text { Missing data } \\
\text { (percentage) }\end{array}$ \\
\hline Ground loop supply temperature & ${ }^{\circ} \mathrm{F}$ & Measured & 183.75 & $1.6 \%$ \\
\hline Ground loop return temperature & ${ }^{\circ} \mathrm{F}$ & Measured & 183.75 & $1.6 \%$ \\
\hline Ground loop flow & $\mathrm{gpm}$ & Measured & 169 & $1.4 \%$ \\
\hline Ground loop pump, 1 speed & $\%$ speed & Measured & 417.5 & $3.6 \%$ \\
\hline Ground loop pump, 2 speed & $\%$ speed & Measured & 417.5 & $3.6 \%$ \\
\hline Ground loop pump, 3 speed & $\%$ speed & Measured & 417.5 & $3.6 \%$ \\
\hline Ambient temperature & ${ }^{\circ} \mathrm{F}$ & Measured & 169 & $1.4 \%$ \\
\hline Building secondary loop supply temperature & ${ }^{\circ} \mathrm{F}$ & Measured & 183.75 & $1.6 \%$ \\
\hline Building secondary loop return temperature & ${ }^{\circ} \mathrm{F}$ & Measured & 183.75 & $1.6 \%$ \\
\hline Building secondary loop pump, 1 speed & $\%$ speed & Measured & 183.75 & $1.6 \%$ \\
\hline Building secondary loop pump, 2 speed & $\%$ speed & Measured & 183.75 & $1.6 \%$ \\
\hline Heat pump cooling status (1-189) & - & Measured & 170 & $1.2 \%$ \\
\hline Heat pump heating status (1-189) & - & Measured & 170 & $1.2 \%$ \\
\hline
\end{tabular}

${ }^{5}$ Available measured data showed that the minimum OA ratio during heating mode was around $40-45 \%$, but not enough data were available to characterize the RTUs' operation condition during cooling mode. 
Most of the available data were collected from October 2012 through January 2014 (1.3 years). The heat pump status data is available from October 2012 to April 2014. The energy uses of all the circulation pumps were not directly measured and have been estimated using correlations between the pumping power and the associated pump speed, which were derived from on-site measurements (listed in Appendix C). Details of the derivations are explained later in the data analysis section.

\section{ANALYSIS OF MEASURED DATA}

Performance data of the GSHP system collected during the full year of 2013 is analyzed in this section. The goals of this analysis are to (1) assess the efficiency of the GSHP unit and the overall GSHP system, (2) assess the operation of the pumping system, and (3) identify faults/abnormalities in GSHP system operation and determine potential improvements for it.

\subsection{Temperatures and Flow Rate in the Primary and Secondary Loops}

Figure 11 displays the measured supply fluid temperatures of both the building loop (secondary loop) and the ground loop (primary loop) from January 1, 2013, to December 31, 2013. The supply fluid temperatures in the two loops are very close $\left(<1^{\circ} \mathrm{F}\right.$ difference), except when the pumps in the primary loop were turned off for maintenance. Excluding the abnormal spikes, the secondary loop supply fluid temperature ranged from $47.5^{\circ} \mathrm{F}$ to $77.5^{\circ} \mathrm{F}$, with an average temperature of $60.4^{\circ} \mathrm{F}$, while the ambient temperature varied from $-2.2^{\circ} \mathrm{F}$ to $96.1^{\circ} \mathrm{F}$ during the same period.

The temperature differential between the supply and return of both the primary and the secondary loops is plotted against time in Fig. 12. The maximum temperature differences of the primary and secondary loops are $6.6^{\circ} \mathrm{F}$ and $10.6^{\circ} \mathrm{F}$, respectively. Figures 12 and 13 show that, during most times of the year, the temperature differential in the primary loop was between $1^{\circ} \mathrm{F}$ and $2^{\circ} \mathrm{F}$ and the flow rate in the primary loop varied from $975 \mathrm{gpm}$ to $1200 \mathrm{gpm}$. Such a narrow range of flow rate and the very low temperature differential resulted from the original control for the primary-loop pump. As described before, the original control for the primary-loop pump was to modulate its speed to maintain the secondary loop supply temperature at $60^{\circ} \mathrm{F}$. However, due to the large thermal resistance of the ground and the continuous heat rejection or extraction by the WAHPs, the GHX cannot condition the heat carrier fluid to the $60^{\circ} \mathrm{F}$ set point, which is even higher than the undisturbed ground temperature at the site of the building (52.5 to $54^{\circ} \mathrm{F}$ ) for most of the year, even when the primary-loop pump ran at its full speed. The primary-loop pump ran at the allowable minimum speed (10\% of the full speed) on only a few occasions when the secondary loop supply fluid temperature was at $60^{\circ} \mathrm{F}$. On these occasions (in May and November as shown in Fig. 14), the flow rate in the primary loop dropped to $100 \mathrm{gpm}$, which is about $10 \%$ of the design flow rate. 


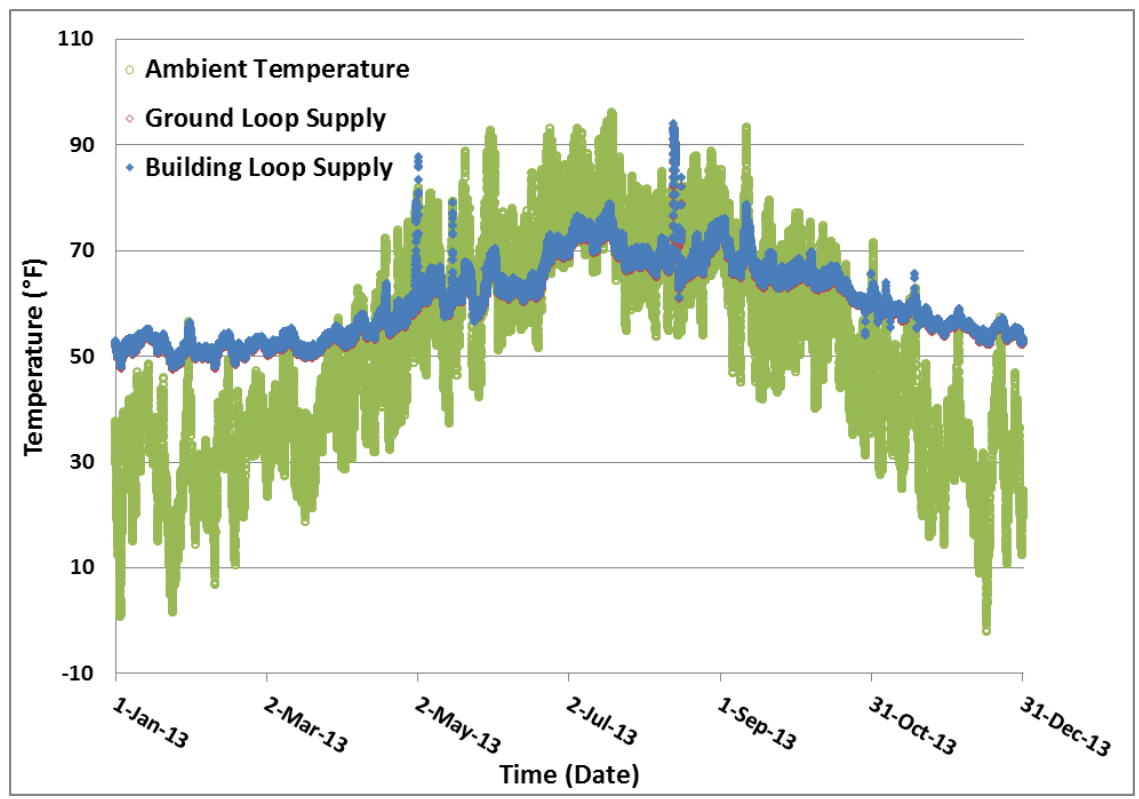

Fig. 11. The building loop (secondary loop) and ground loop (primary loop) supply fluid temperature.

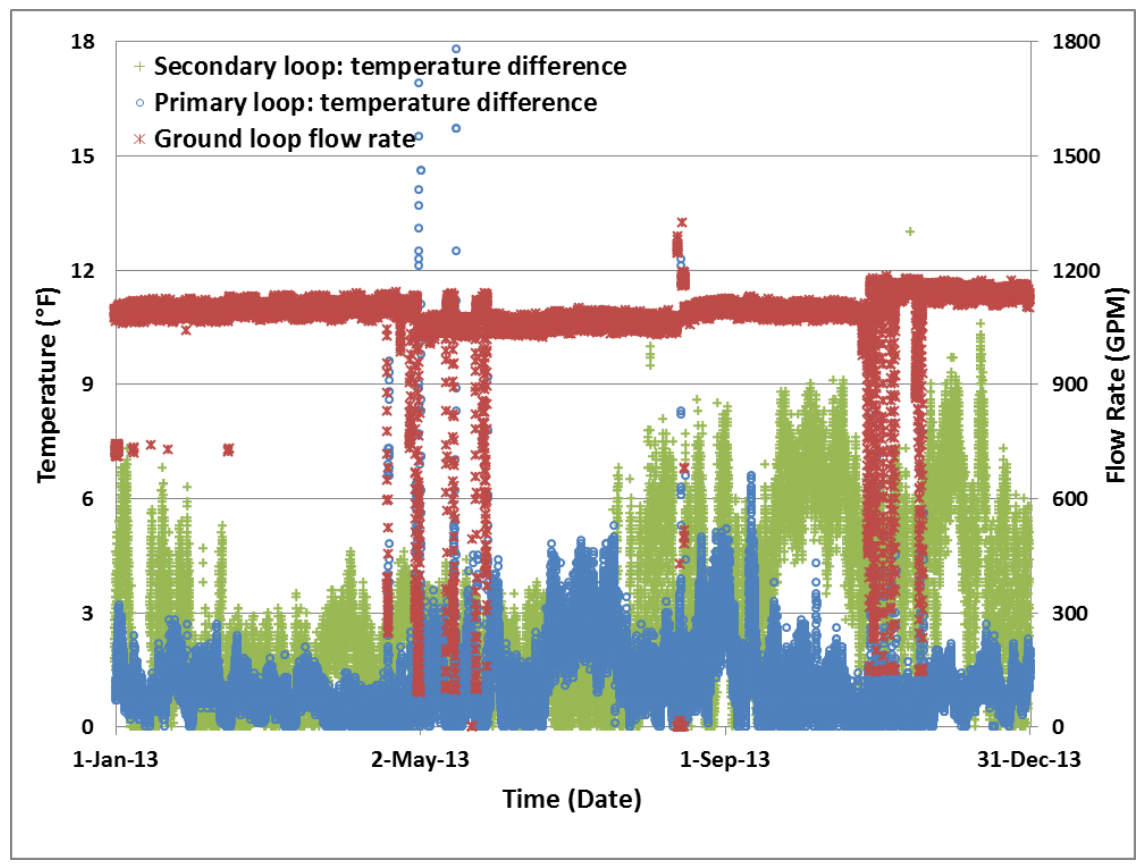

Fig. 12. Time series chart for the temperature differential in the primary and secondary loops along with flow rate in the primary loop (ground loop). 


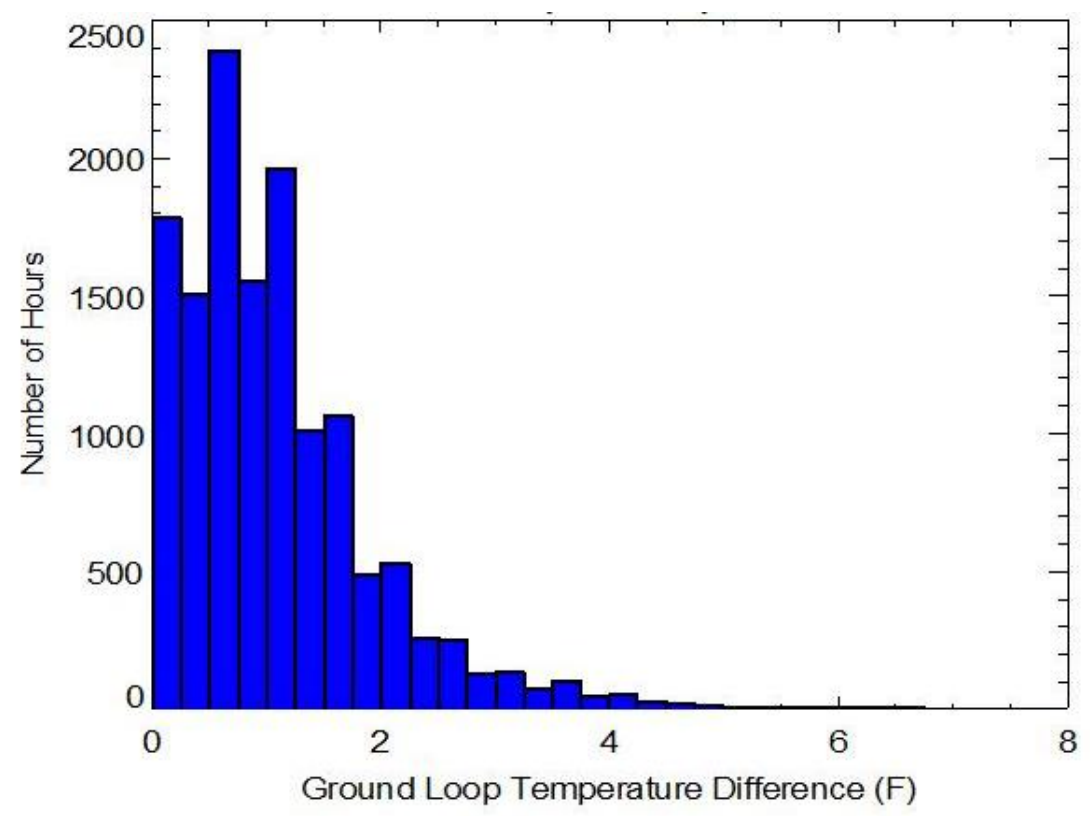

Fig. 13. Distribution of the temperature differential in the primary loop.

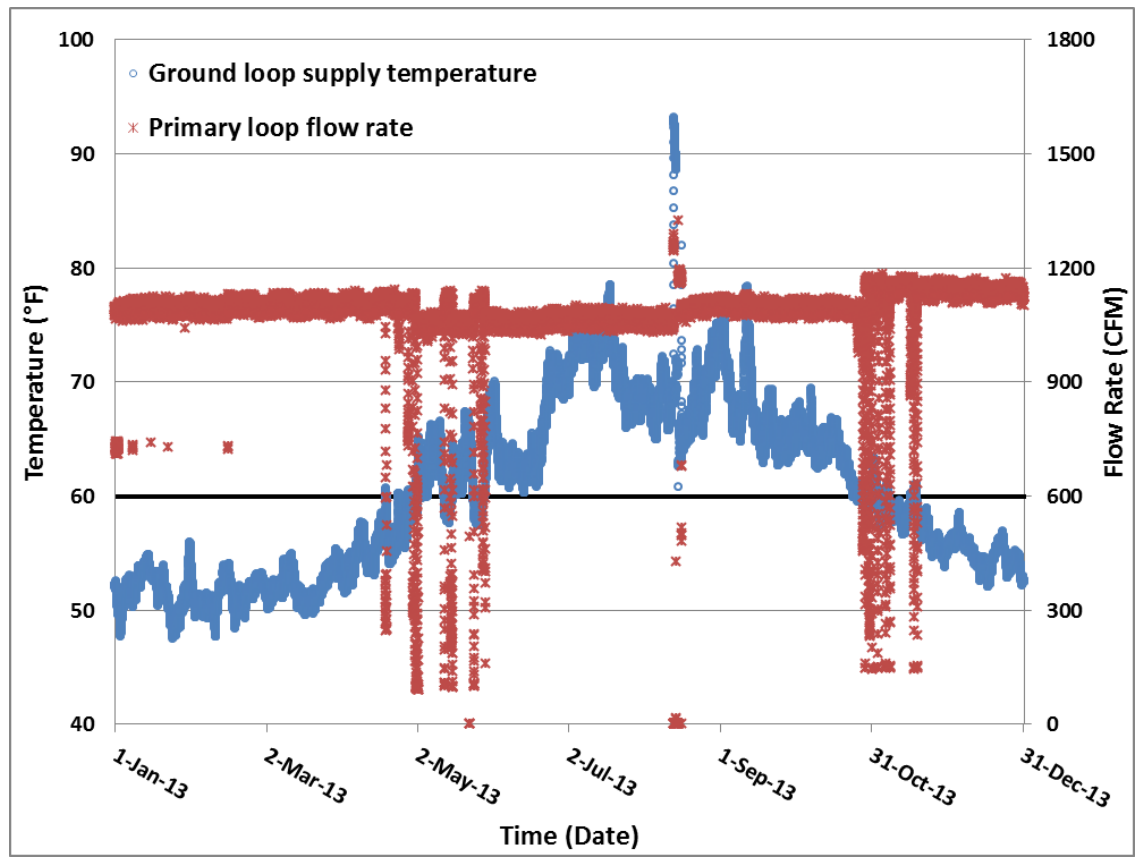

Fig. 14. Primary-loop flow rate and secondary-loop supply temperature.

\subsection{Heat Transfer Rates of the GHX}

The heat transfer rates at the GHX are calculated from the measured fluid temperatures and flow rates. The heat transfer rates are plotted against time in Fig. 15 and plotted against ambient temperature in Fig. 16. As these figures show, the maximum heat extraction rate is $1,502 \mathrm{kBtu} / \mathrm{h}$, while the maximum heat rejection rate is $3,561 \mathrm{kBtu} / \mathrm{h}$. From Fig. 16, it can be seen that the heat transfer rate of the GHX 
shows a nearly linear relationship with ambient temperature. During the entire year, a total of 3,324 million Btu of heat was rejected to the ground, with 1,773 million Btu extracted from the ground. The annual heat rejection is about two times the annual heat extraction.

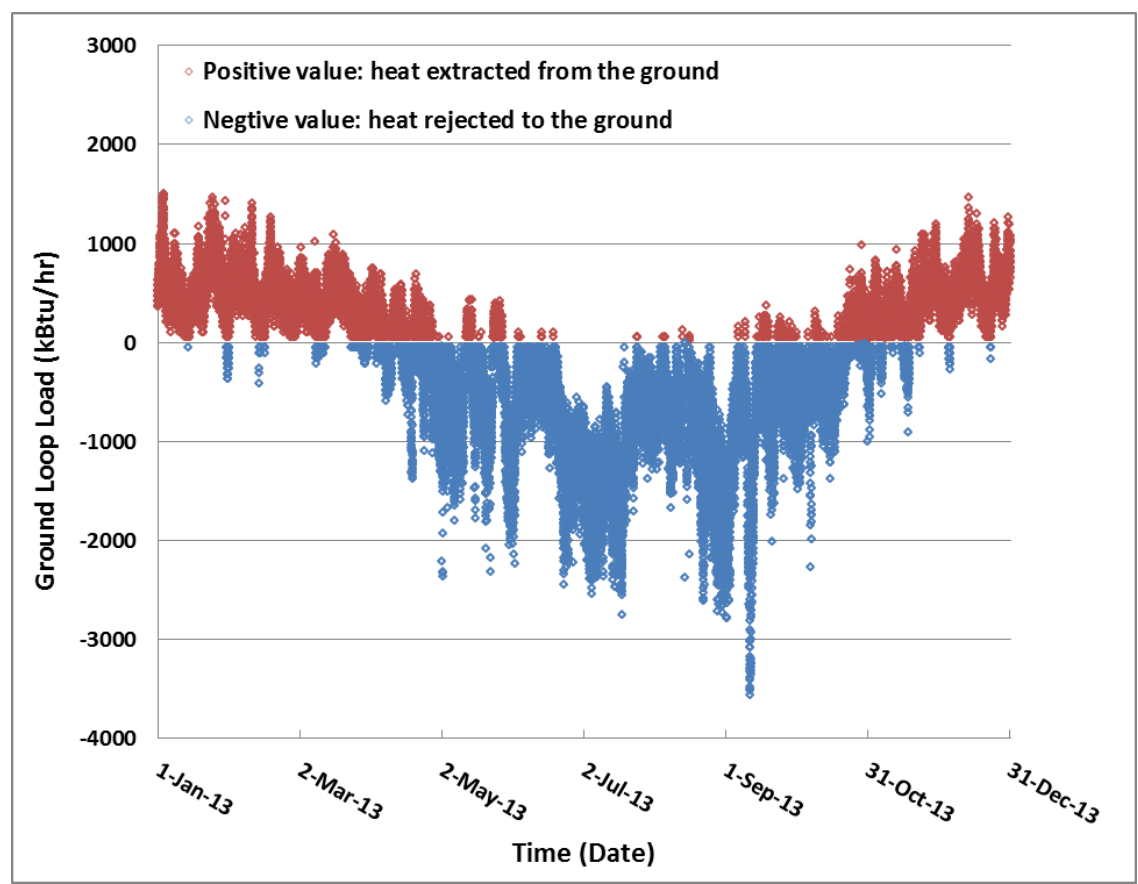

Fig. 15. Time series chart for the heat transfer rates of the GHX.

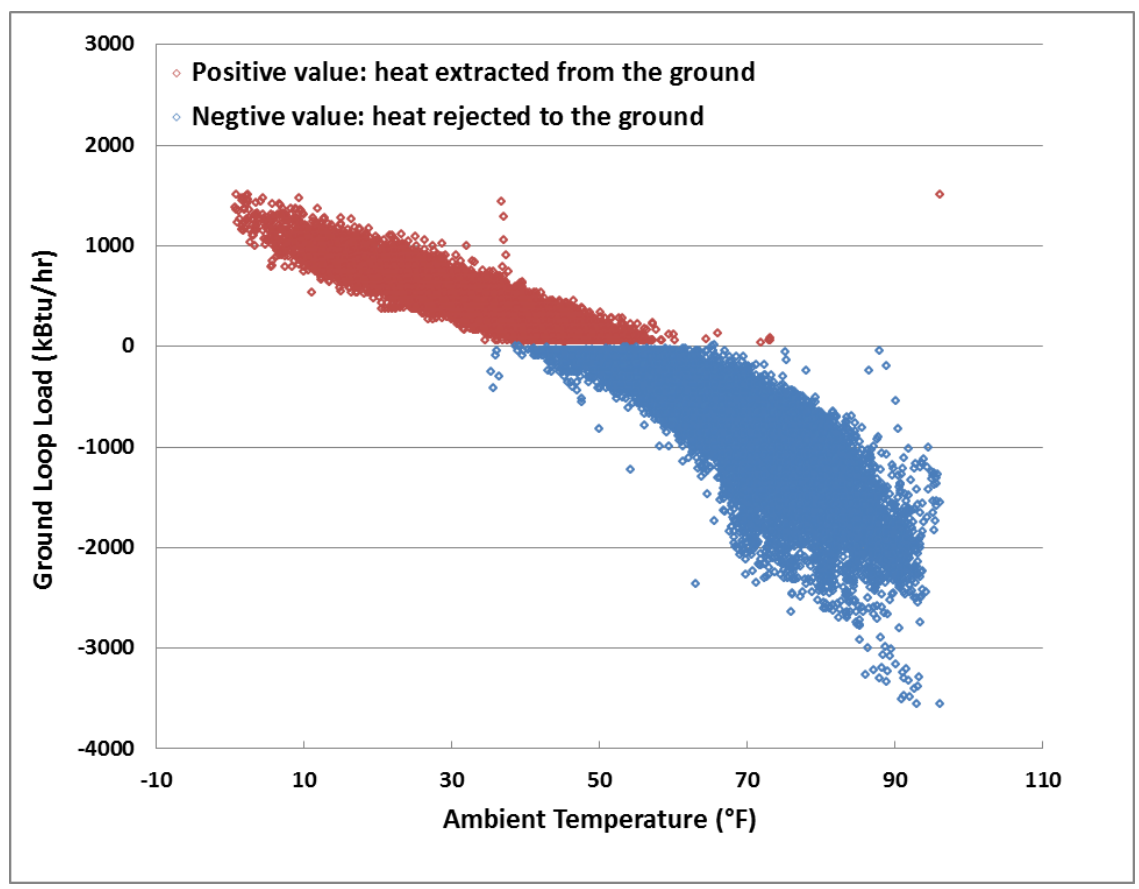

Fig. 16. Scatter chart showing relationship between the heat transfer rates of the GHX and the coincident ambient temperature. 


\subsection{Energy Efficiency of WAHP Units}

The on/off status and operation mode (heating or cooling) of each of the 189 McQuay WAHP units are recorded at each 15-min interval. They are the only measured data for the WAHP units. The heating and cooling outputs, as well as the associated power consumption of each WAHP, are calculated with available information on the on/off status and operation mode of each WAHP, the measured heat pump entering water temperature (EWT, which is the leaving water temperature from GHX), its performance curves as presented in the manufacturer's catalog data, and other related information, including entering air condition, and air and water flow rates of the WAHP. In these calculations, the entering air condition is assumed at $70^{\circ} \mathrm{F}$ dry bulb temperature and $60 \%$ relative humidity. The air and water low rates of each WAHP unit are assumed constant and as specified in the design documents (Appendix A). The HVAC air and water balancing report indicates that the actual air flow rates of the WAHPs were within $10 \%$ of the design values for most WAHPs and the water flow rate of each WAHP was balanced to the corresponding design value. The heating and cooling outputs of each WAHP are calculated as a function of the entering water temperature as expressed in Eqs. (1) and (2), respectively.

$$
\begin{aligned}
Q_{h} & =S H P_{h} \times \frac{15 \mathrm{~min}}{60 \mathrm{~min} / \mathrm{hour}} \times\left(B 1 \times E W T^{2}+B 2 \times E W T+B 3\right) \\
Q_{c} & =S H P_{c} \times \frac{15 \mathrm{~min}}{60 \mathrm{~min} / \mathrm{hour}} \times\left(A 1 \times E W T^{2}+A 2 \times E W T+A 3\right)
\end{aligned}
$$

where

$S H P_{h}$ and $S H P_{c}$ are on/off status (on=1, off=0) of a WAHP in heating and cooling modes, respectively;

$Q_{c}$ and $Q_{h}$ are the cooling and heating outputs of the WAHP during a 15-min time interval, in Btu; EWT is the entering water temperature, in ${ }^{\circ} \mathrm{F}$;

$A 1-B 3$ are curve-fit coefficients for the correlations between EWT and heating/cooling capacity of the WAHP, which are derived from manufacturer's catalog data.

Based on the measured EWT and the performance map of each WAHP presented in the manufacturer's catalog data, the COP (for heating mode) or EER (for cooling mode) of the 189 WAHP units are also estimated at every 15-min time interval with Eqs. (3) and (4). With the same assumptions discussed above, the COPs or EERs are calculated as functions of the EWT only.

$$
\begin{aligned}
& C O P=C 1 \times E W T^{2}+C 2 \times E W T+C 3 \\
& E E R=D 1 \times E W T^{2}+D 2 \times E W T+D 3
\end{aligned}
$$

where $C 1-D 3$ are curve-fit coefficients for the correlations between EWT and COP/EER derived from manufacturer's catalog data.

Based on the above calculated heating/cooling output and EER/COP of each WAHP, the associated power consumption of the WAHP in heating or cooling mode is calculated using Eqs. (5) or (6).

$$
W_{c}=\frac{Q_{c}}{E E R \times 1000}
$$




$$
W_{h}=\frac{Q_{h}}{\operatorname{COP} \times 3412}
$$

where $W_{c}$ and $W_{h}$ are the power consumptions of the WAHP in cooling and heating modes during each 15-min time interval, in Btu.

The calculated combined cooling and heating outputs of all the 189 WAHP units at each time interval are plotted in Fig. 17. As shown in Fig. 17, the maximum combined heating output is 2,139 kBtu/h and the maximum combined cooling output is $2,533 \mathrm{kBtu} / \mathrm{h}$ (211 cooling tons). However, the combined cooling capacity of the 189 WAHP units is approximately 355 tons. This indicates the building loads have significant diversity (i.e., only up to $60 \%$ of the installed cooling capacity of the WAHP units was utilized during the data collection period). This is not unreasonable for such a student housing building with many individually air-conditioned zones.

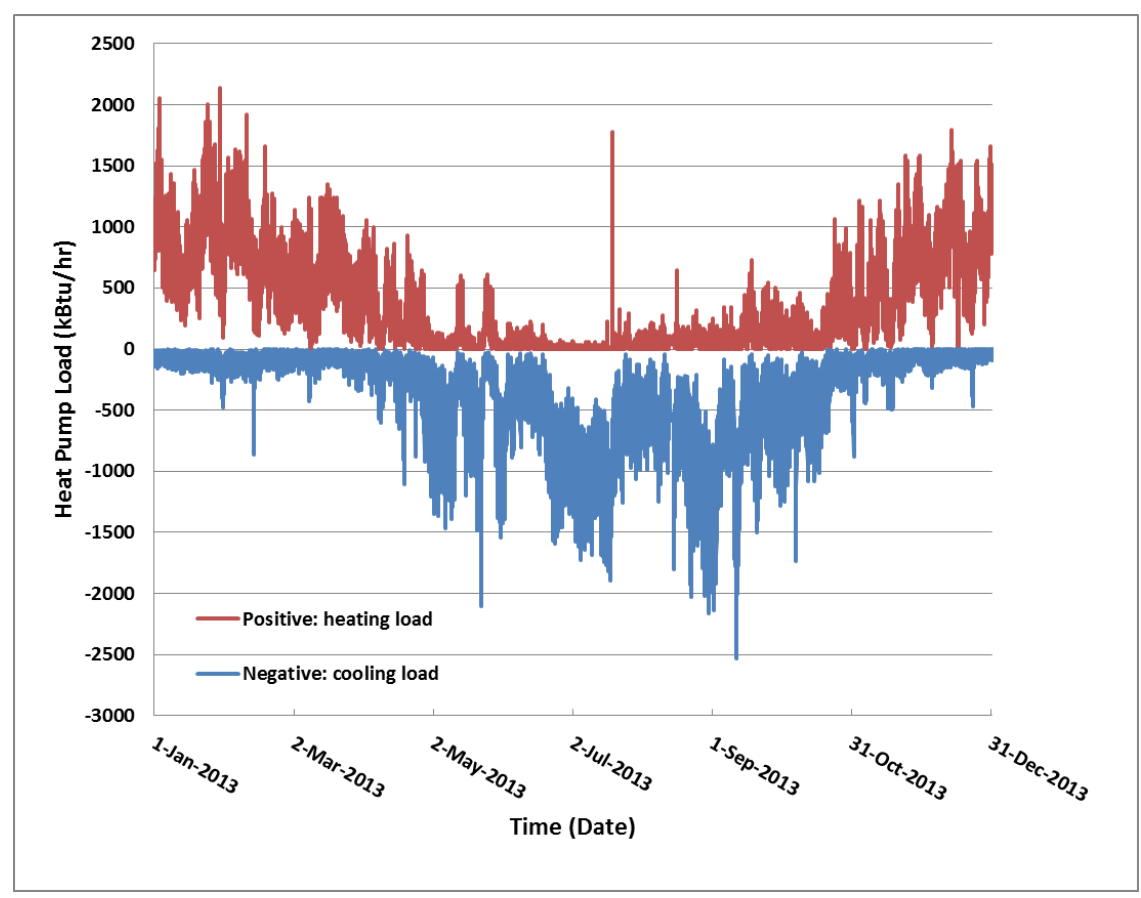

Fig. 17. Estimated combined heating and cooling outputs of all the WAHPs.

The calculated hourly combined power consumptions of all the WAHPs for cooling and heating operations are plotted against time and ambient temperature in Figs. 18 and 19, respectively. The peak hourly electricity use for cooling is $160 \mathrm{kWh}$, while the peak electricity use for heating is $137 \mathrm{kWh}$. As Fig. 19 shows, the power consumption of the WAHPs is clearly related to ambient temperature. The heating power consumption increased nearly linearly with the decrease of ambient temperature when the ambient temperatures were below $50^{\circ} \mathrm{F}$, and the cooling power consumption increased approximately quadratically with the increase of ambient temperature when the ambient temperatures were above $50^{\circ} \mathrm{F}$. In addition, Figs. 18 and 19 show the simultaneous heating and cooling of various WAHPs, especially in shoulder seasons (April to June and September to November) when the ambient air temperature is between $40^{\circ} \mathrm{F}$ and $70^{\circ} \mathrm{F}$. Figure 19 shows some cooling power consumption when the outside ambient temperature was lower than $50^{\circ} \mathrm{F}$. This occurred because WAHPs in some rooms (e.g., elevator room, server room, and mechanical room) operated in cooling mode all year long. However, Fig. 19 also shows small heating power consumption when the outside ambient temperature was higher than $90^{\circ} \mathrm{F}$. The exact 
reason for this counterintuitive operation is not clear. It is thought to be due to abnormal operation of the WAHPs (e.g., temporary switches between heating and cooling modes during maintenance and repair) and/or noises in the heat pump status data.

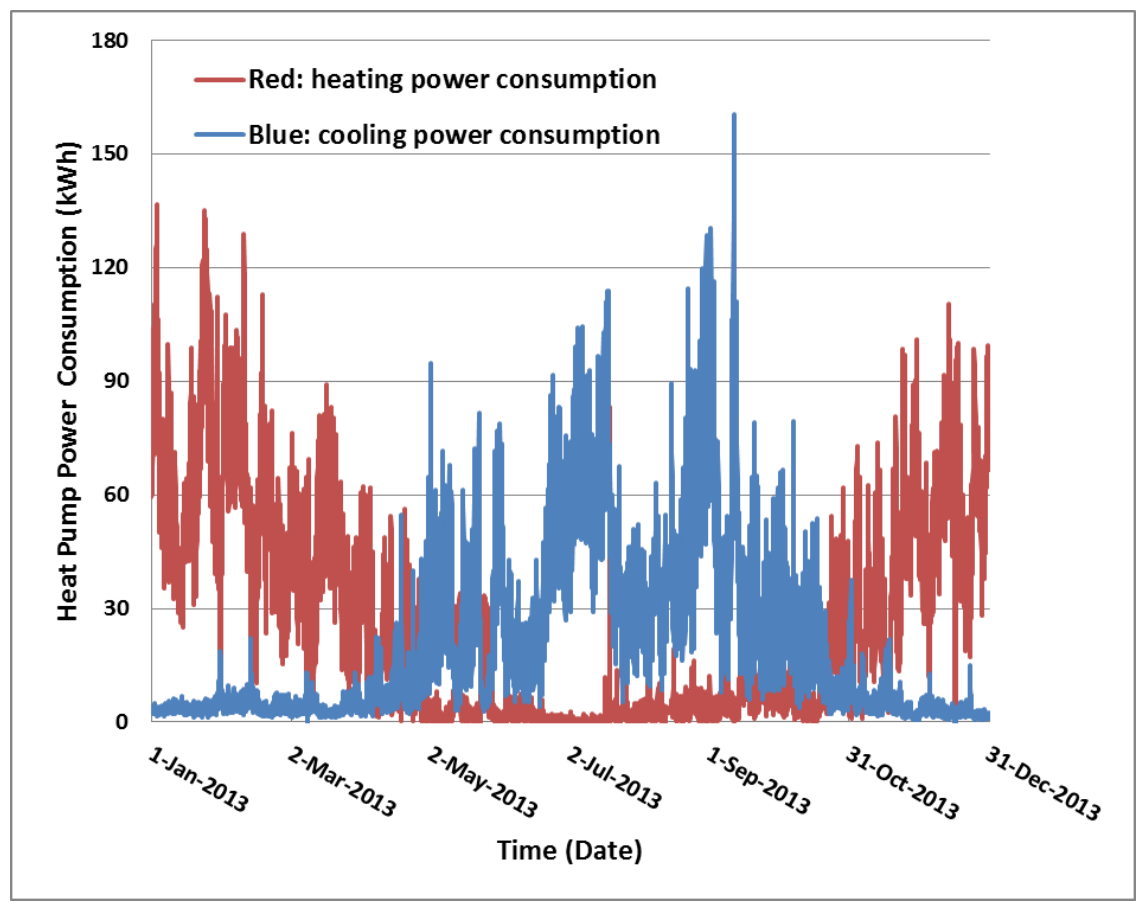

Fig. 18. Time series chart for calculated combined heat pump power consumption in heating and cooling modes.

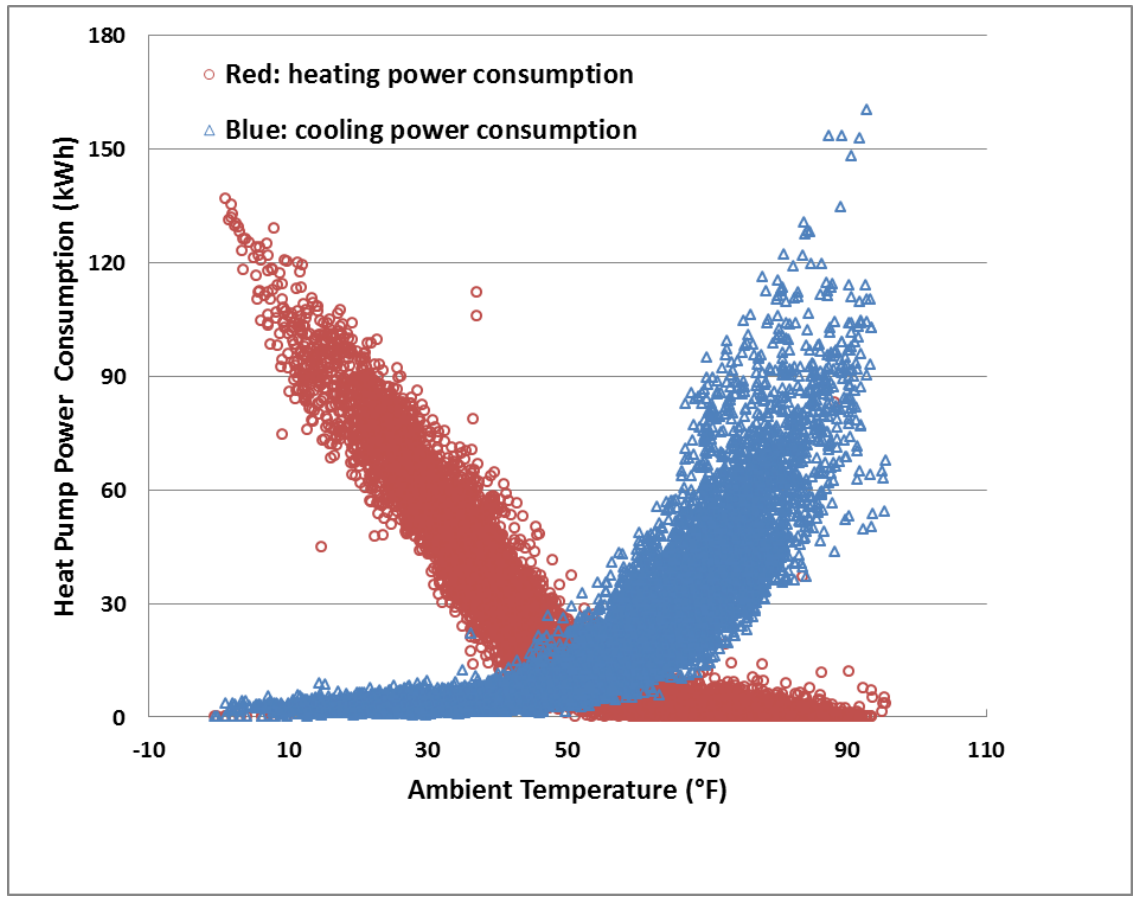

Fig. 19. Calculated combined heat pump power consumption in heating and cooling modes against the coincident ambient temperatures. 
The calculated average COP and EER of all 189 WAHPs at each time interval are plotted in Figs. 20 and 21, respectively. As shown, the average COPs range from 3.8 to 5.7 and the average EERs are within 12 to 29. The annual averages of the EER and COP during the one-year period are 19.7 and 4.3, respectively.

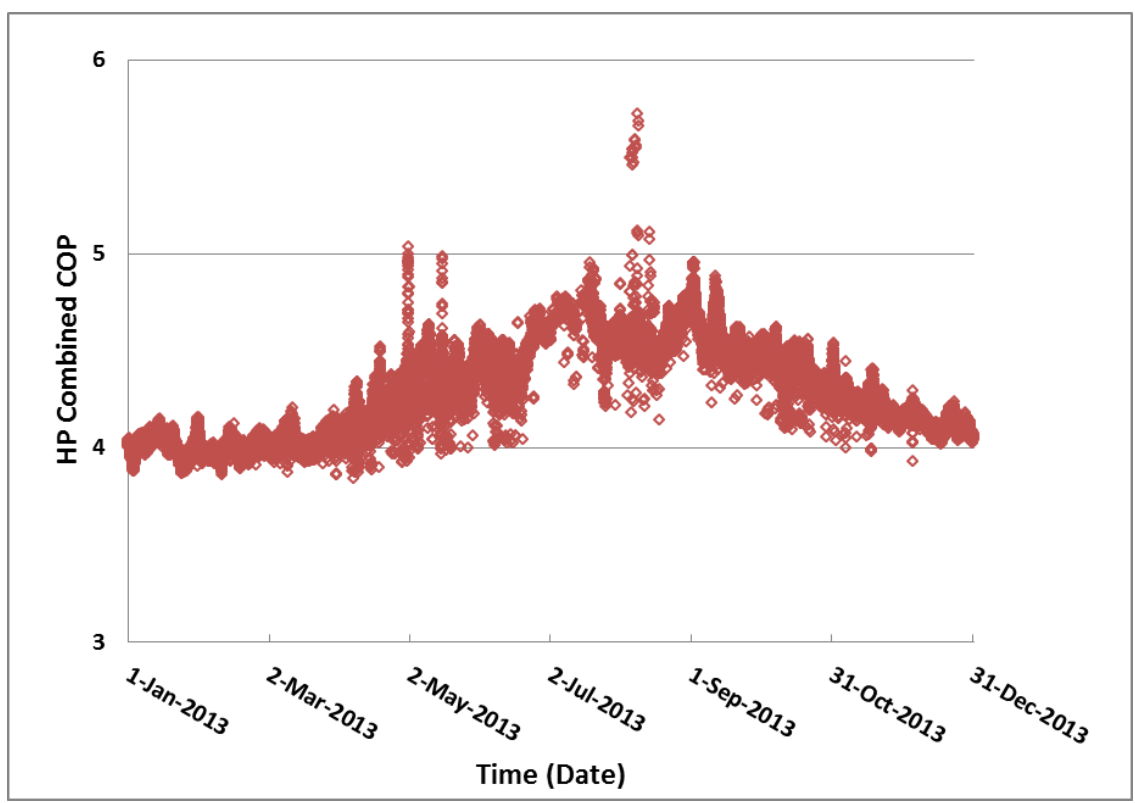

Fig. 20. Calculated COP at each time interval during the period of data measurement.

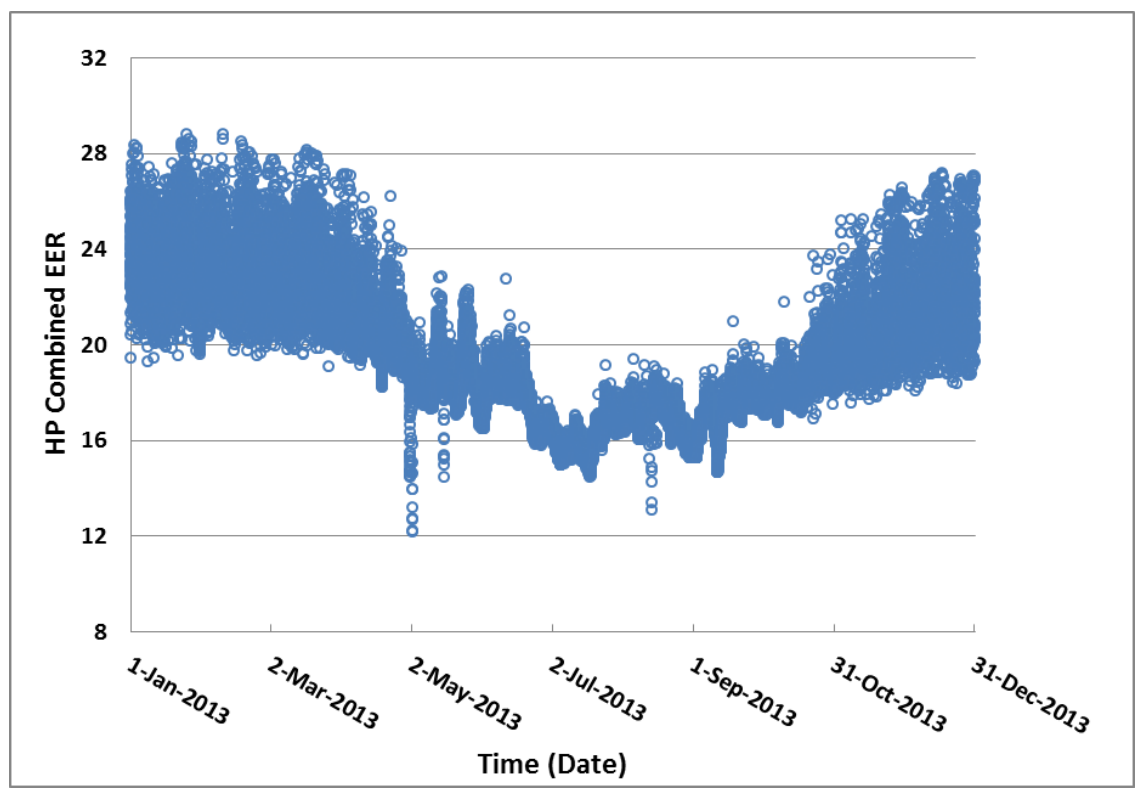

Fig. 21. Calculated EER at each time interval during the period of data measurement.

\subsection{Pumping Performance}

Pumping performance is evaluated on the basis of (1) pump size, (2) pump speed variation in response to heat pump operation, and (3) pump power consumption. 


\subsubsection{Pump Size}

Pump size is evaluated by the ratio between the nominal horsepower of all the pumps in operation and the total installed cooling capacity of the GSHP system. The total cooling capacity (including both the WAHPs and the DOASs) is 450 ton (at $77^{\circ} \mathrm{F} \mathrm{EWT}$ ), and the combined horsepower of the primary-loop pumps (two $20 \mathrm{hp}$ ) and the secondary-loop pump (one $40 \mathrm{hp}$ ) is $80 \mathrm{hp}$. The resulting pump size ratio is $17.8 \mathrm{hp} / 100$ tons, which would get an " $\mathrm{F}$ " if graded per the ASHRAE design guidance for commercial GSHP systems (Kavanaugh and Rafferty 1995).

\subsubsection{Pump Speed Variation}

Measured speeds (percentage of full speed) of the primary (ground) loop pumps are shown in Fig. 22. As shown, the three pumps alternated in running, and only two of the three pumps ran at any given time under normal operating conditions. Figure 22 shows the typical operation: Pump 1 ran at full speed and a second pump (Pump 2 or Pump 3) ran at a speed between 80 and 100\% of full speed. All three pumps ran concurrently for a 15-min period in August 2013 after the pumps had been shut down for two days.

The average speed of the primary-loop pumps is calculated using Eq. (7), based on the measured pump speeds $P S_{1}, P S_{2}$, and $P S_{3}$.

$$
P S_{\text {avg,prim }}=\frac{P S_{1}+P S_{2}+P S_{3}}{2}
$$

The average pump speed is plotted against the temperature differential of the primary loop in Fig. 23, and against the combined power consumptions (in each 15-min interval) of all the WAHPs in Fig. 24. As shown in Fig. 23, the average pump speed is within $80 \%$ to $100 \%$ of full speed during most of the year and does not appear related to the primary loop temperature differential; however, the pump speed did drop to about $10 \%$ occasionally and the primary loop temperature differential increased to $10^{\circ} \mathrm{F}$ then. As discussed earlier, this occurred when the secondary loop supply temperature reached the set point $\left(60^{\circ} \mathrm{F}\right)$. Figure 24 shows that for the WAHPs, no relation exists between average pump speed and combined power consumption. 

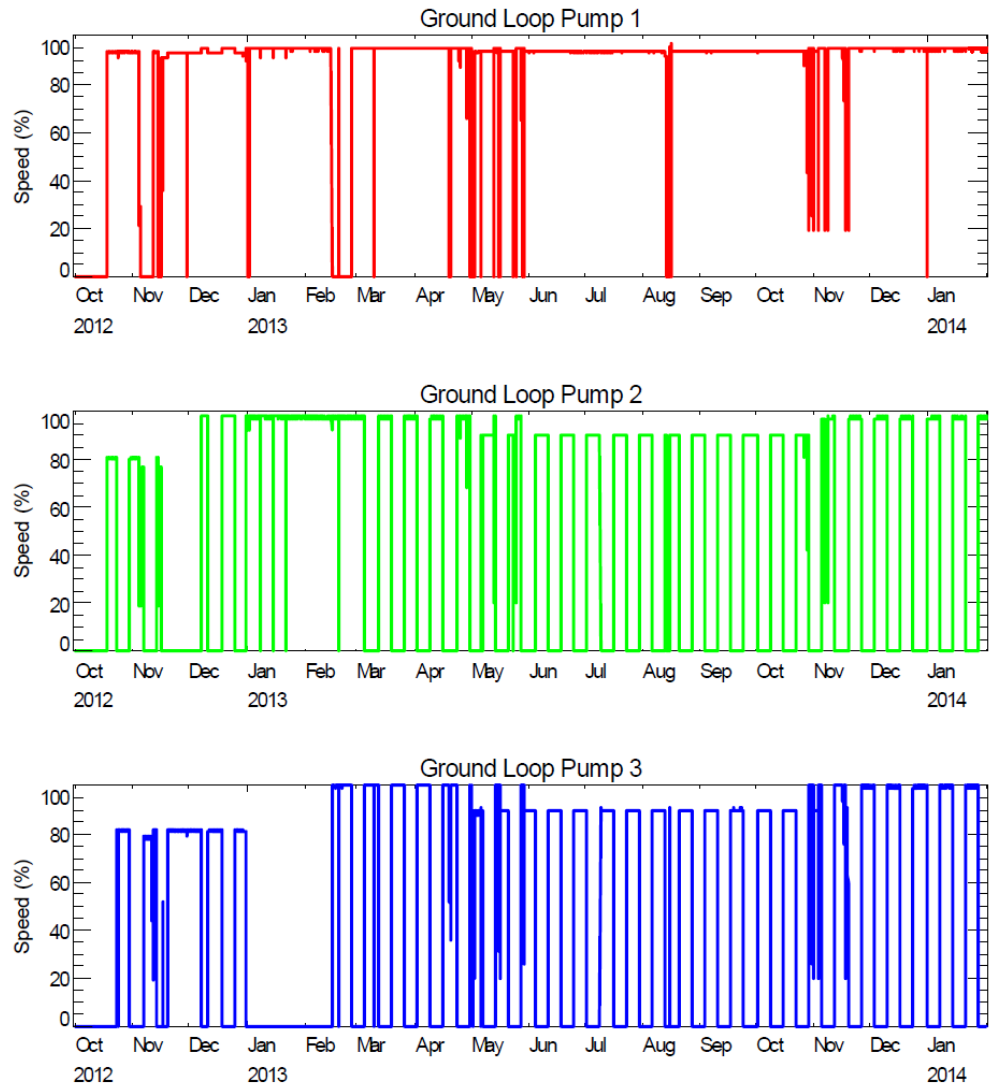

Fig. 22. Speed of the three circulation pumps in the primary (ground) loop.

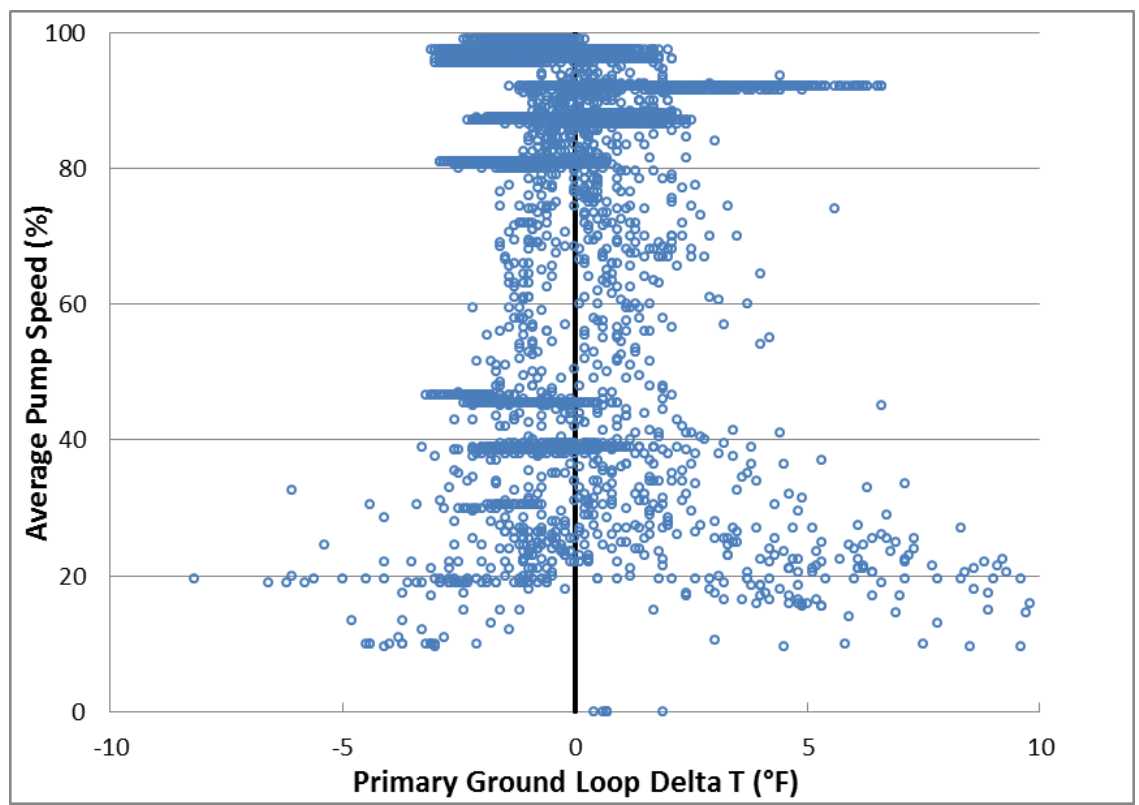

Fig. 23. Average speed of primary-loop pumps vs. primary loop temperature differential (data shown in this chart are the average in each 15 -min interval). 


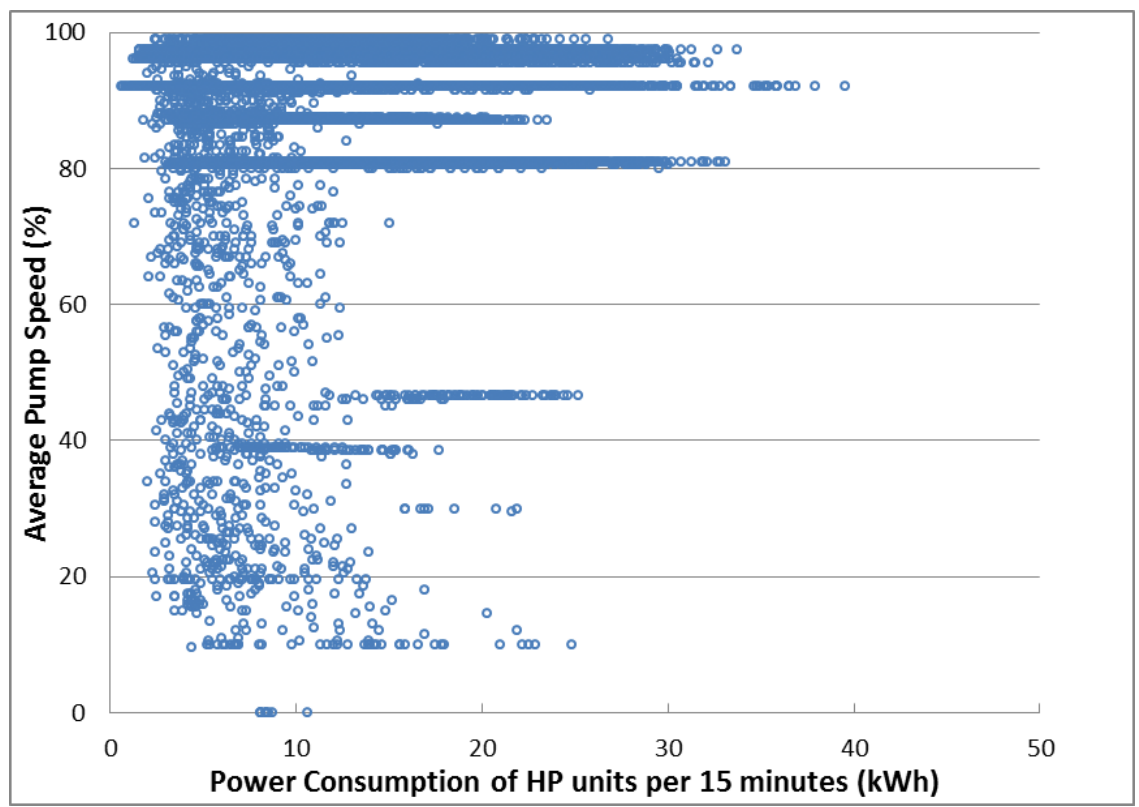

Fig. 24. Average speed of primary-loop pumps vs. combined power consumptions of all WAHPs.

Measured speeds (percentage of full speed) of the secondary-loop pumps are shown in Fig. 25. As shown, the two pumps alternated in running at speeds within $60 \%-90 \%$ of full speed. According to the design documents, these pumps are controlled to maintain a constant pressure differential ( $6 \mathrm{psi})$ at the secondary loop.
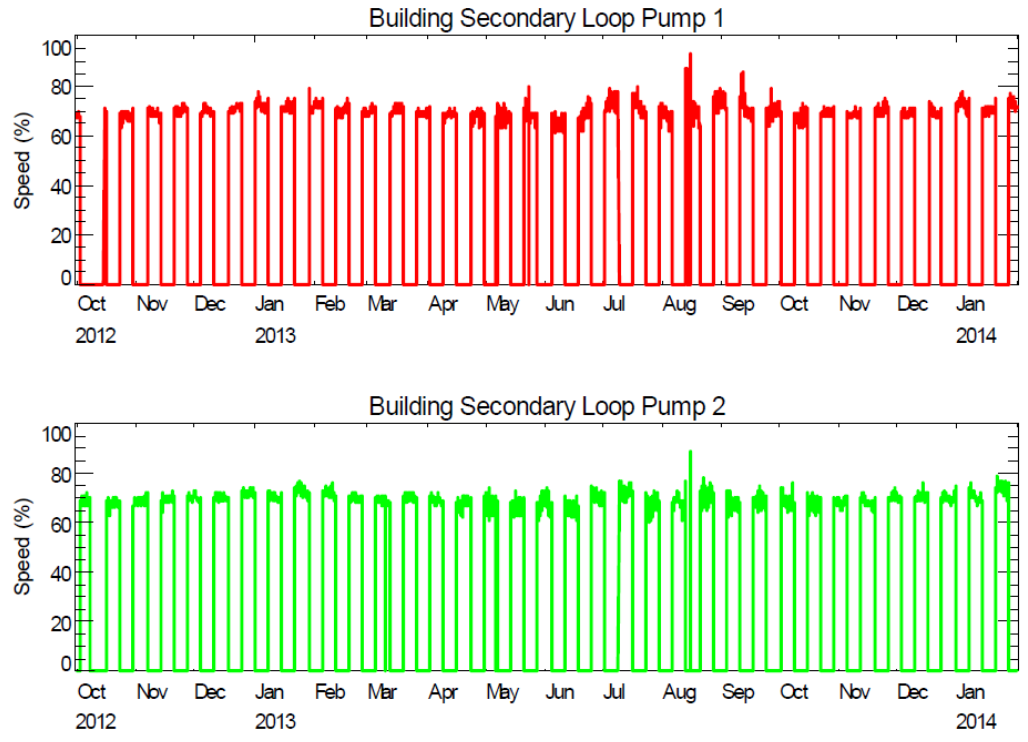

Fig. 25. Speed of the two circulation pumps in the secondary loop.

The average speed of the secondary-loop pumps is calculated using Eq. (8) based on the measured speeds of the two pumps. 


$$
P S_{\text {avg }, \text { sec }}=P S_{4}+P S_{5}
$$

The average pump speed is plotted against the combined power consumption of the WAHPs in Fig. 26. As shown, the average speed of the secondary-loop pumps shows a nearly linear relationship with the combined power consumption of the WAHPs. The measured minimum average speed of secondary-loop pumps is around $60 \%$, which resulted in a minimum loop flow rate approximately at $600 \mathrm{gpm}$ when the combined power consumptions of the WAHPs approached zero. Typically, a variable speed pumping system will have a $20 \%$ bypass of the design flow ( $200 \mathrm{gpm}$ for this system) when the demand for flow is low. The high minimum water flow rate in the secondary loop indicates either an excessive bypass flow (through the 3-way valves installed in the WAHPs in the first floor), or a large number of the 2-way valves in the WAHP units being stuck in the open position.

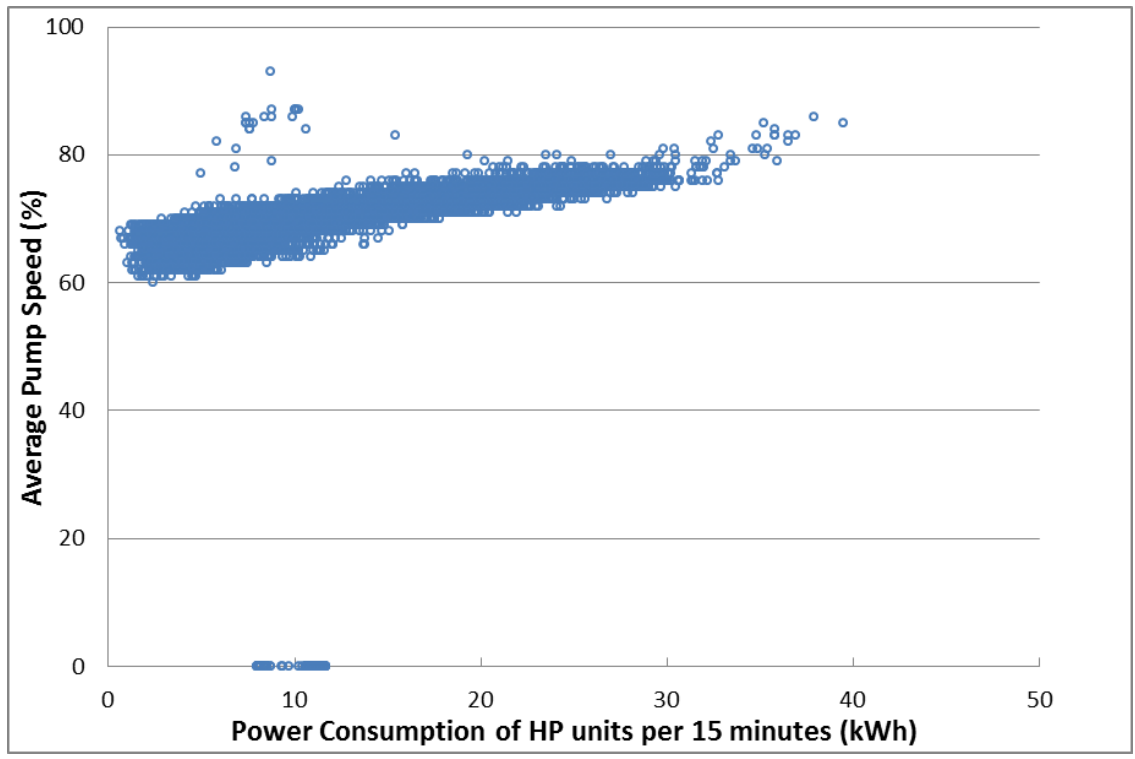

Fig. 26. Average speed of secondary-loop pumps vs. combined power consumption of all the WAHPs.

\subsubsection{Pump Power Consumption}

Pump power was not measured by the building energy management system of the university. Power draws of two primary-loop pumps running at several different speeds were measured during a site visit by the authors of this study. Based on the measured data (shown in Fig. 27 and listed in Appendix B), a correlation between pump speed and power draw was derived and expressed with Eq. (9).

$$
W_{\text {pump }}=P F \times W_{N P} \times(P S)^{3}
$$

where

$W_{\text {pump }}$ is pump power draw, in $\mathrm{kW}$;

$W_{N P}$ is the nameplate power of the primary-loop pump, which is $20 \mathrm{hp}(14.9 \mathrm{~kW})$;

$P F$ is the factor between the pump power at $100 \%$ pump speed and the nameplate pump power; it is 1.03 in this case;

$P S$ is the pump speed, in $\%$. 
With Eq. (9) and the measured pump speed, power consumptions of the primary-loop pumps at each 15min interval during the year were calculated and are presented in Fig. 28 along with the calculated power consumption of all the WAHPs. It can be seen that the power consumption of the primary-loop pump is higher than that of the WAHPs at some times, especially during the shoulder seasons.

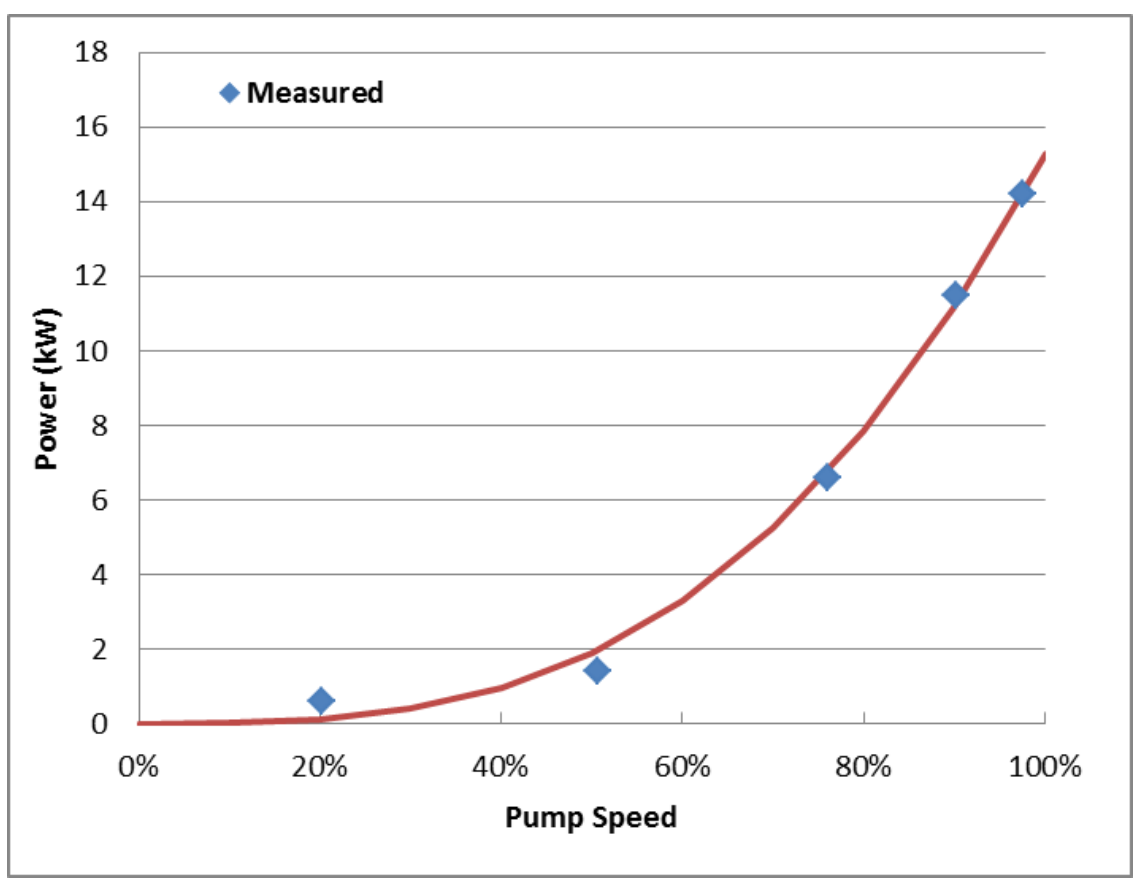

Fig. 27. Performance curve of the primary-loop pumps.

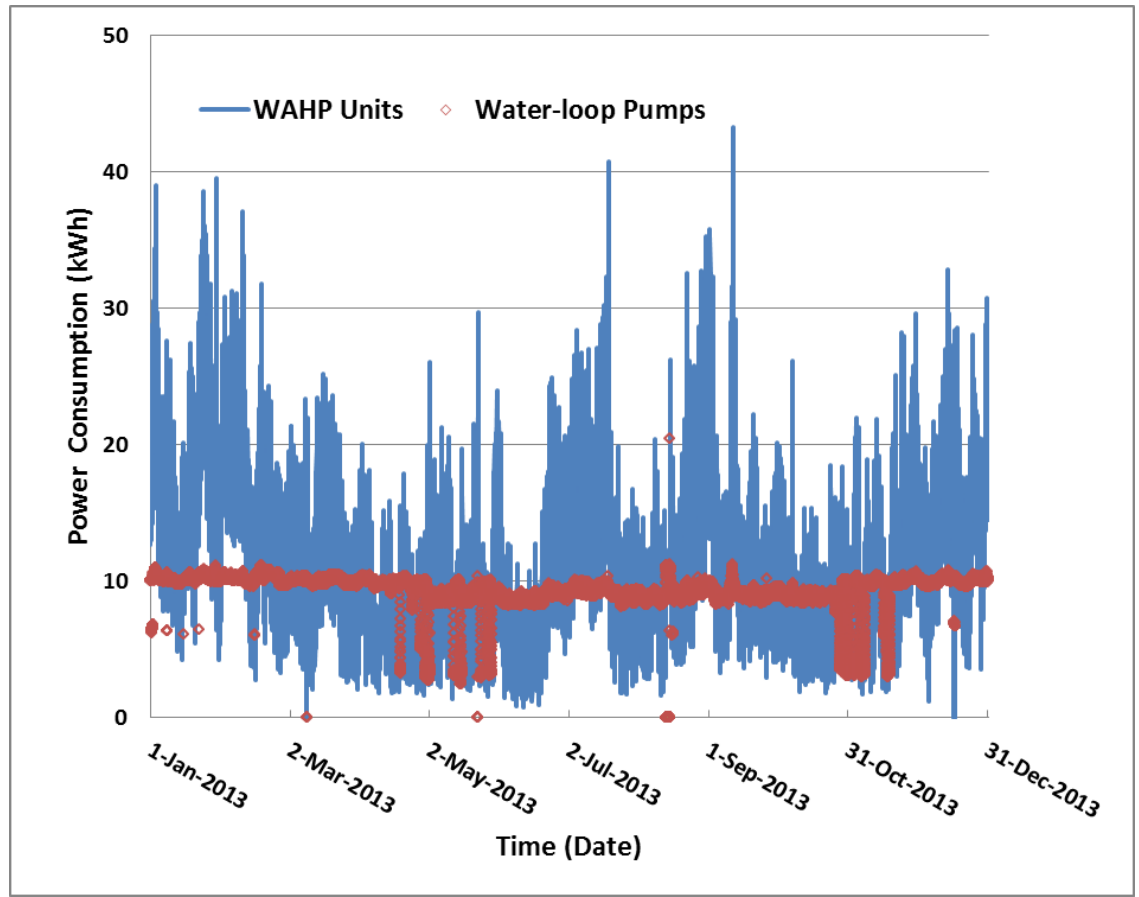

Fig. 28. Calculated power consumptions of primary-loop pumps and the WAHPs (data shown in this chart are the power consumptions in each 15-min interval). 
Since the pumps in the secondary loop are the same model as those in the primary loop, the same $P F$ is assumed. However, because the two secondary-loop pumps are pressure-controlled, an exponent of 2.5 is used to replace the exponent of 3 in Eq. (9), as expressed in Eq. (10). With Eq. (10) and the measured pump speeds, the power consumption of the secondary-loop pumps at each time interval is calculated.

$$
W_{\text {pump }}=P F \times W_{N P} \times(P S)^{2.5}
$$

where $W_{N P}$ is the nameplate power of the secondary-loop pump, which is $40 \mathrm{hp}(29.8 \mathrm{~kW})$.

The annual cumulative power consumptions of the primary-loop and secondary-loop pumps are 220,844 and $107,848 \mathrm{kWh}$, respectively. The total power consumption of these circulation pumps during the year is $328,692 \mathrm{kWh}$, which is only $19 \%$ less than the calculated annual cumulative power consumption of the WAHPs $(405,923 \mathrm{kWh})$.

\subsubsection{Results from Improved Pumping Control}

As described before, the primary-loop pumps were originally controlled to maintain the secondary-loop supply temperature at $60^{\circ} \mathrm{F}$, which had resulted in nearly constant full-speed operation of these pumps. After identifying this issue, a new control sequence for the primary-loop pumps was implemented on June 20, 2014. The new control sequence involves two steps as described below. The 3-way valve (Fig. 7) is positioned to fully close the bypass between the supply and return of the secondary loop.

Step 1. System operating mode determination

- If the secondary loop return temperature is at least $1^{\circ} \mathrm{F}$ higher than the secondary loop supply temperature, the GSHP system is considered as running in cooling mode.

- If the secondary loop return temperature is at least $1^{\circ} \mathrm{F}$ lower than the secondary loop supply temperature, the GSHP system is considered as running in heating mode.

- If the secondary loop temperature differential is less than or equal to $1^{\circ} \mathrm{F}$, the GSHP system is considered as running in floating mode.

Step 2. Pump speed control

- In cooling mode: the primary-loop pumps modulate to maintain the secondary loop supply temperature at $1^{\circ} \mathrm{F}$ above the primary loop supply temperature.

- In heating mode: the primary-loop pumps modulate to maintain the secondary loop supply temperature at $1^{\circ} \mathrm{F}$ below the primary loop supply temperature.

- In floating mode: the primary-loop pumps run at minimum speed.

Performance data after implementing the new pumping control were collected from June 23 through August 17, 2014 (a 56-day period). It was found that the new control reduced the flow rate in the primary loop significantly. As shown in Fig. 29, the flow rate dropped from the nearly constant 1000 gpm down to within 180 to $550 \mathrm{gpm}$. The average flow rate during the 56-day period is $341 \mathrm{gpm}$, which is only $33 \%$ of the average flow rate prior to implementing the new control. Figures 30 and 31 compare the pump speeds before and after the new control. Figure 30 shows the pump speeds during a week (August 1-7) in 2013 before implementing the new control. In this week, Pump 1 ran continuously at 94\% speed, while Pump 2 and Pump 3 alternated at $90 \%$ speed. The pump speeds did not appear responsive to the operation of the WAHPs (indicated by the power consumption of the WAHPs). However, for the same week in 2014 (Fig. 31), Pump 1 and Pump 3 alternated, with pump speed varying from $30 \%$ to $60 \%$ in response to the operation of WAHPs, and Pump 2 was completely off. 


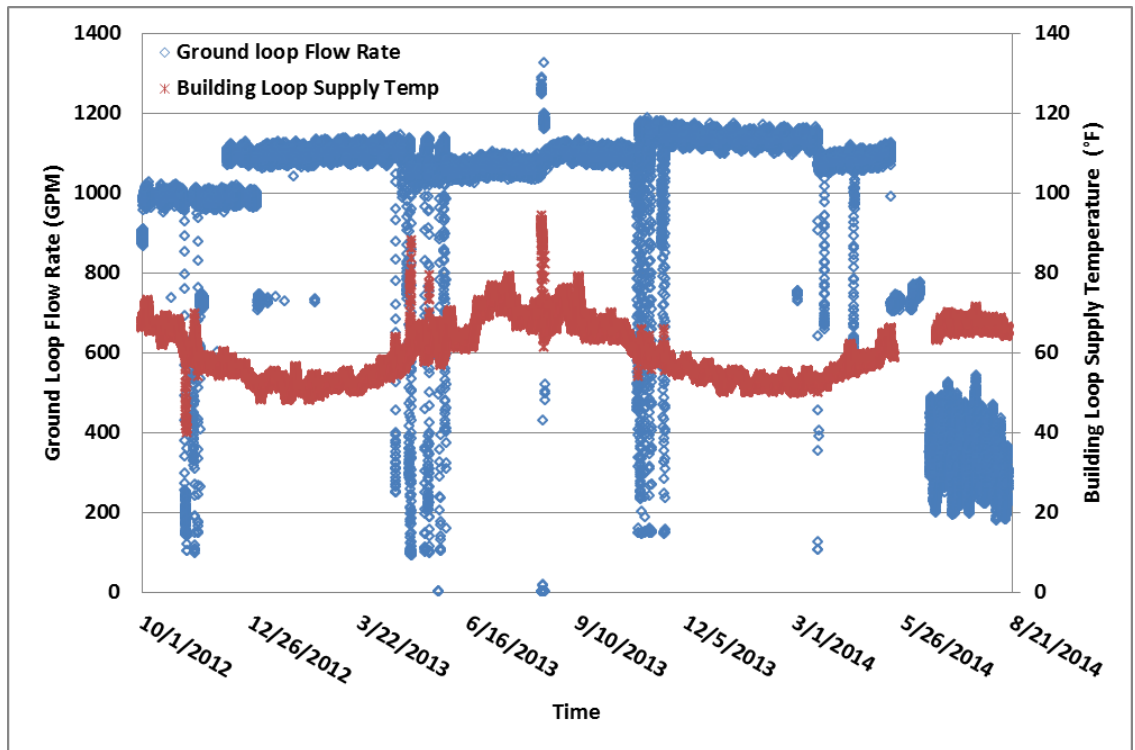

Fig. 29. Flow rate in the primary loop from October 2012 through August 2014.

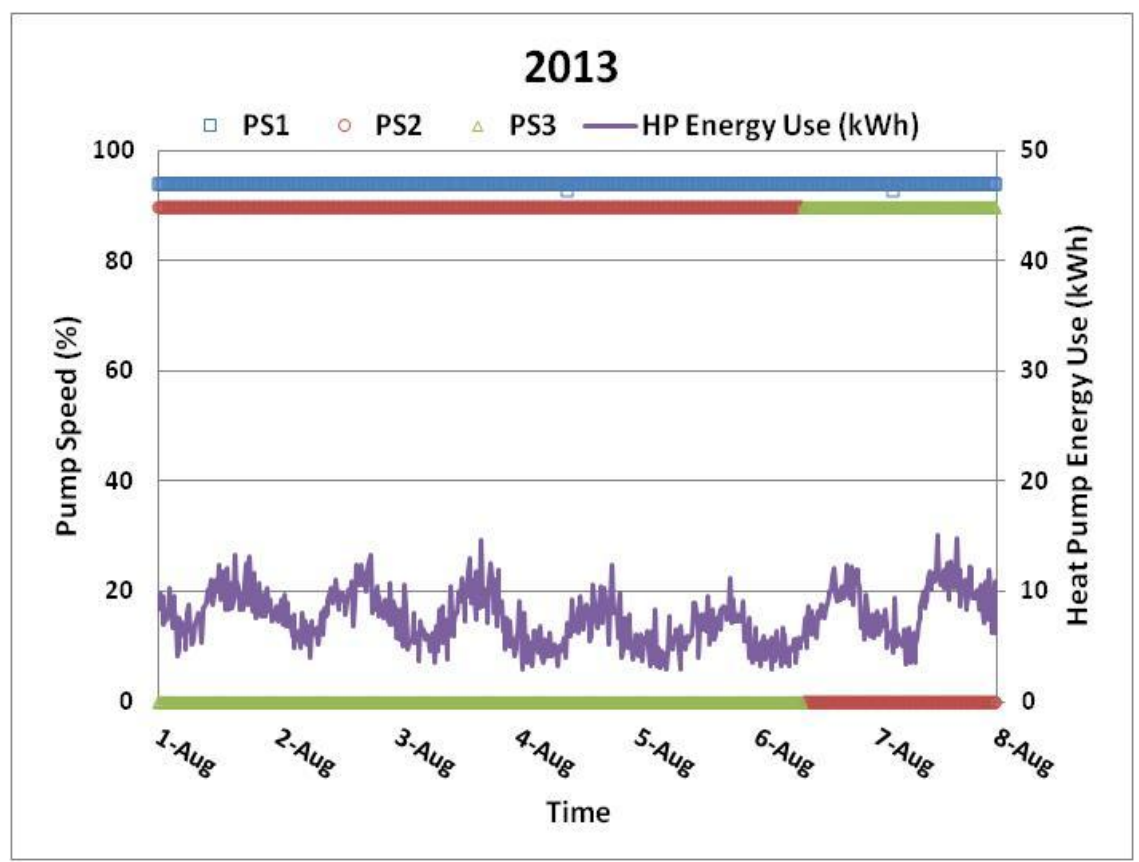

Fig. 30. Primary-loop pump speed during the week of August 1-7, 2013. 


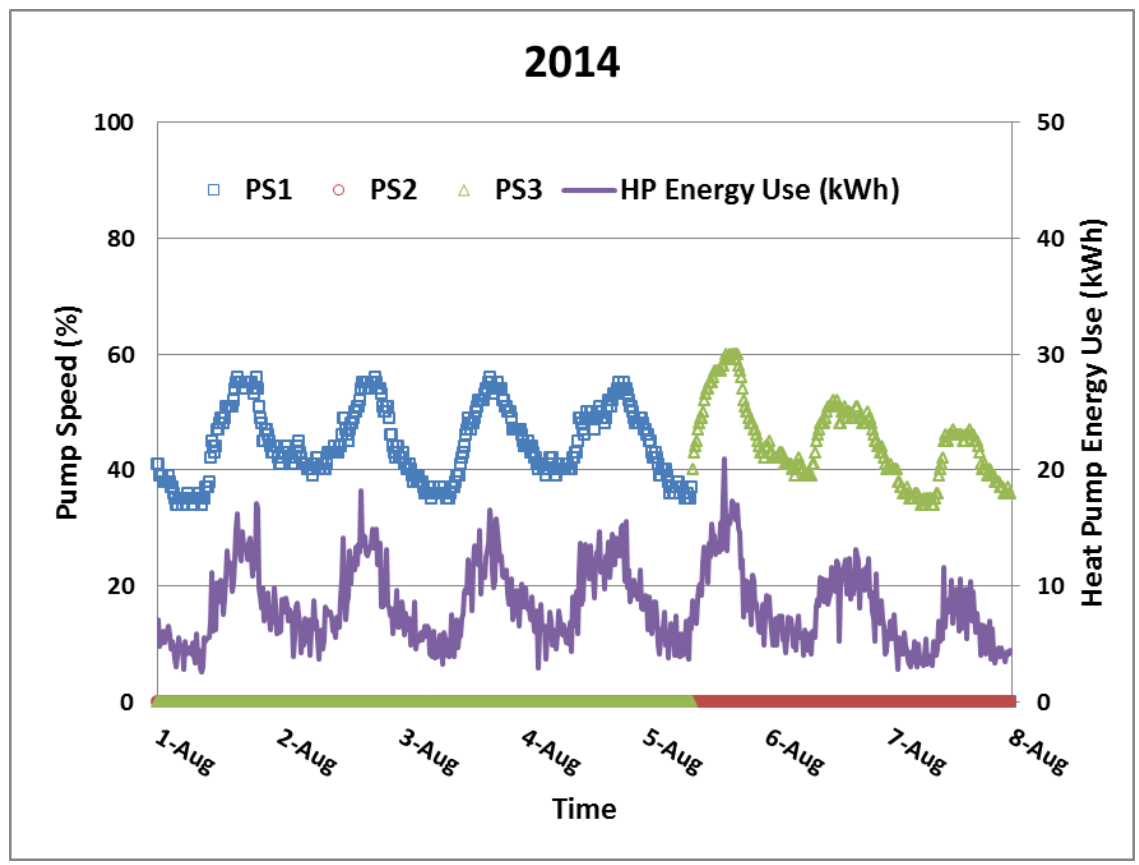

Fig. 31. Primary-loop pump speed during the week of August 1-7, 2014.

As a result of the more responsive operation of the pumps, the flow rate in the primary loop was nearly linearly related to both the power consumptions of the WAHPs (Fig. 32) and the temperature differential of the primary loop (Fig. 33).

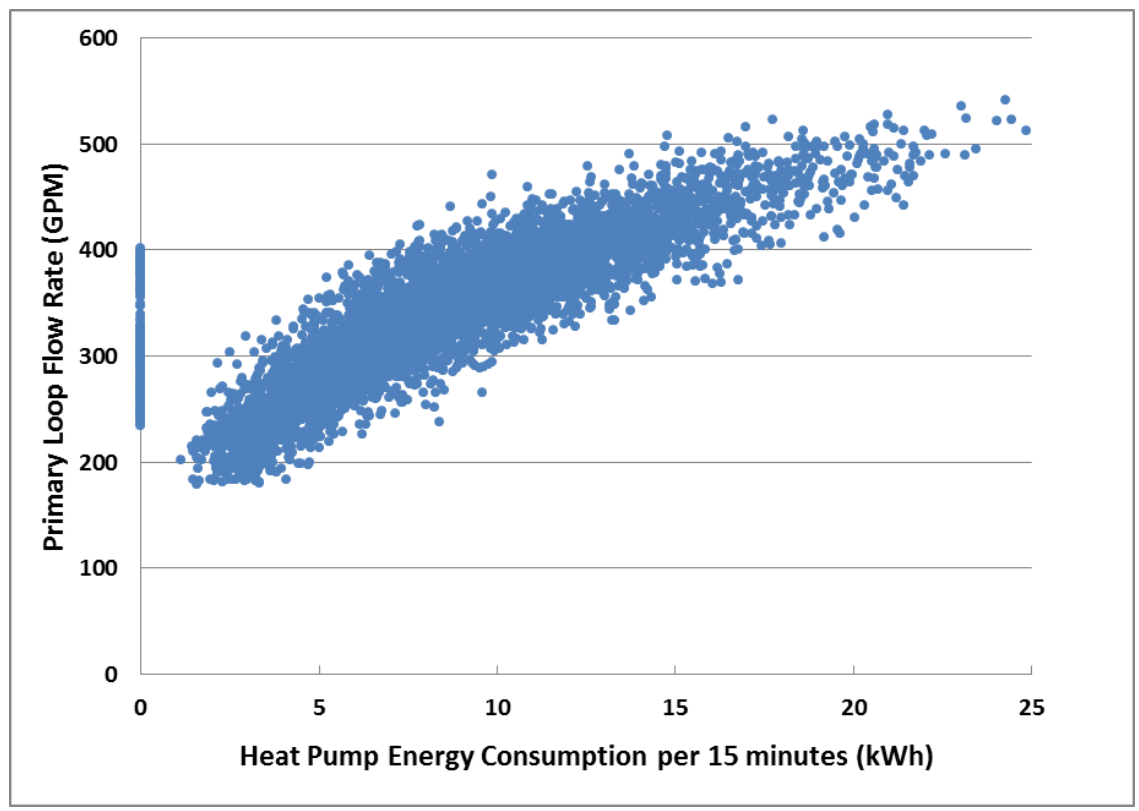

Fig. 32. Primary flow rate vs. heat pump energy consumption. 


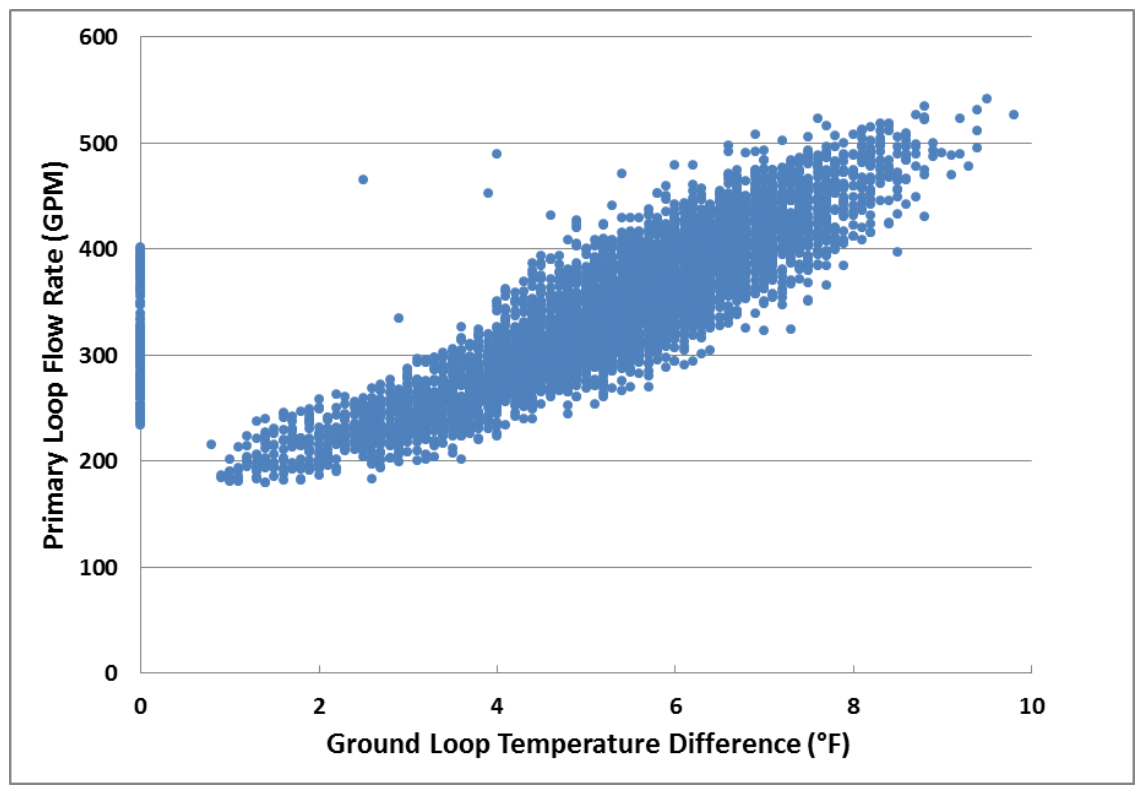

Fig. 33. Primary flow rate vs. ground loop temperature difference.

The lower flow rate resulted in larger temperature differential between the supply and return of the primary loop as shown in Fig. 34, which compares the temperature differential of the primary loop in the same period (June 23 to August 17) in 2013 and 2014. The average temperature differential in 2013 is around $2^{\circ} \mathrm{F}$, with a maximum value of $5.3^{\circ} \mathrm{F}$, but is around $5^{\circ} \mathrm{F}$ during the same period in 2014 , with a maximum value of $9.8^{\circ} \mathrm{F}$.

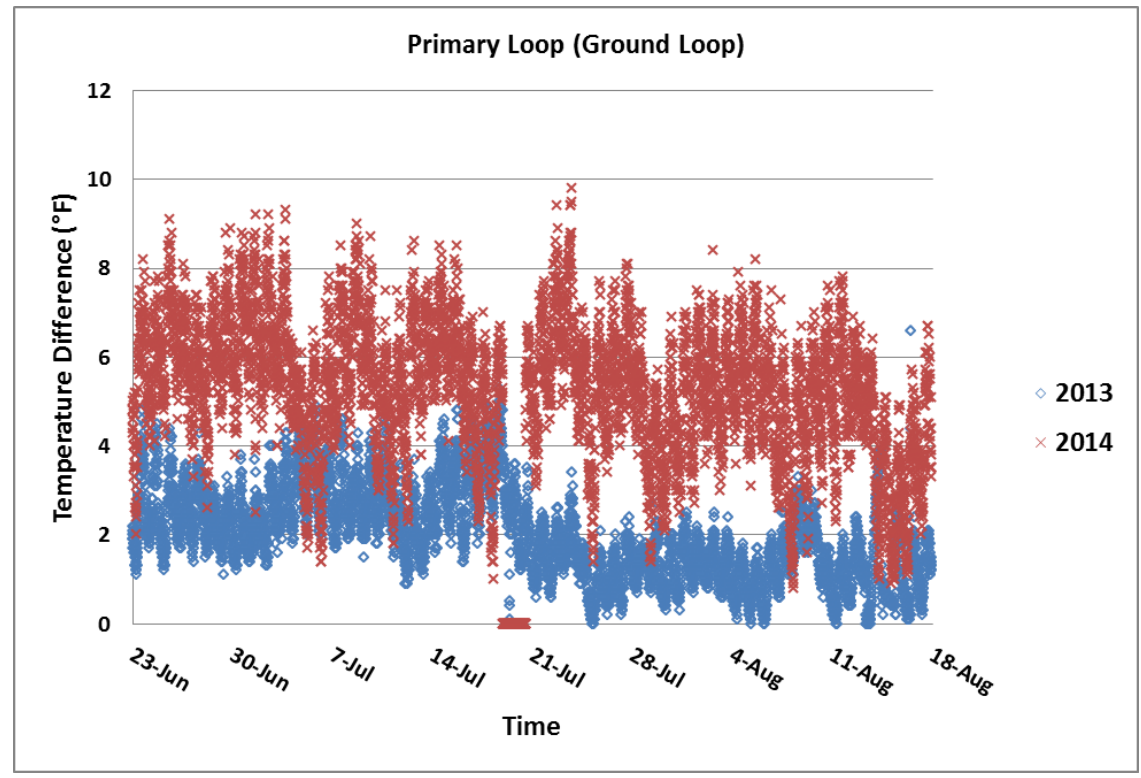

Fig. 34. Primary loop temperature differential during the same period in 2013 and 2014.

Power consumption of the primary-loop pumps before and after implementing the new control is calculated with the same method described before and shown in Fig. 35. The cumulative power 
consumption of the primary-loop pumps in the 56-day period was reduced by $\mathbf{9 3 \%}$ from $30,790 \mathrm{kWh}$ (in 2013) to only $2,093 \mathrm{kWh}$ (in 2014).

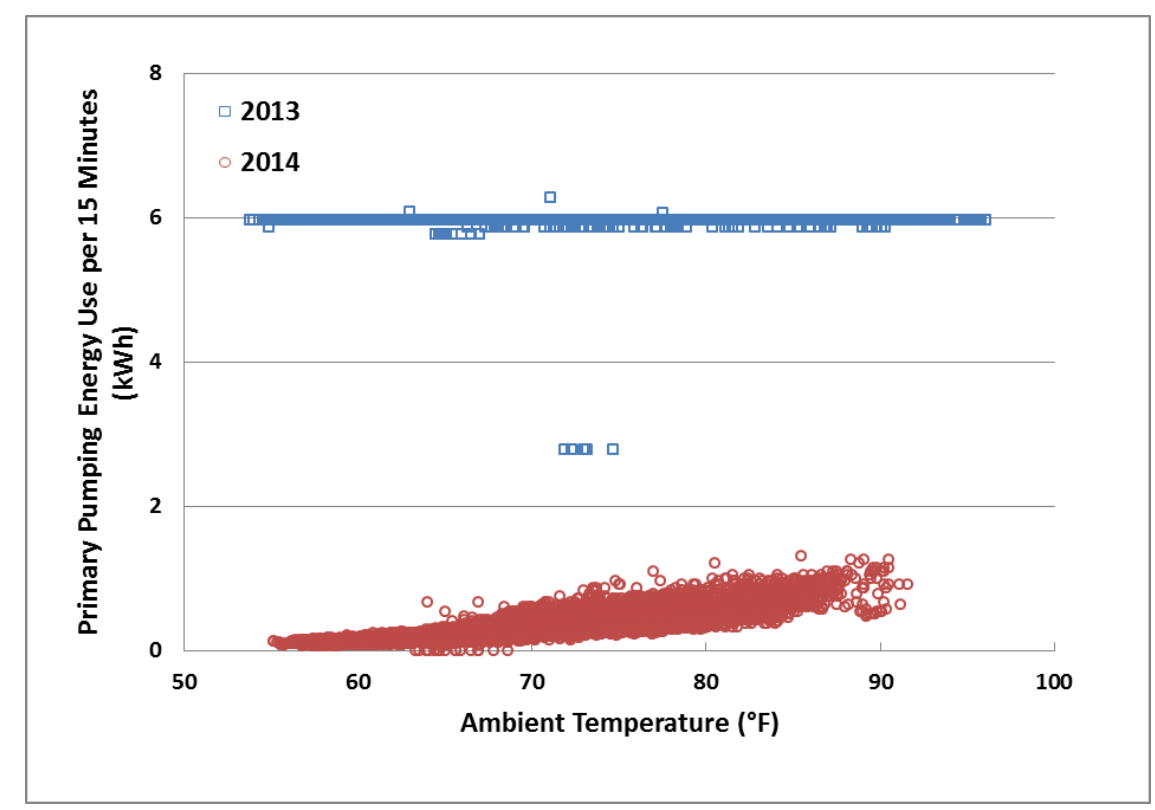

Fig. 35. Primary-loop pumping energy use vs. ambient temperature.

Of interest is how the new control affects the energy consumption of the WAHPs, and the overall GSHP system. The operating efficiency of the WAHPs is determined by the EWT, which is the secondary loop supply temperature. The reduced flow rate in the primary loop could affect the EWT in two different ways. On one hand, it reduces the heat transfer rate between the primary and secondary loops, which leads to increased EWT in the cooling season and decreased EWT in the heating season. But, on the other hand, the lower pump energy use means less heat from the pump is transferred to the ground, which results in lower EWT in both the cooling and heating seasons.

Figure 36 shows that the EWTs during the 56-day period in 2014 were lower than those in the same period in 2013. However, as shown in Fig. 37, the ambient temperatures in July 2014 were lower than those in July 2013. The lower ambient temperature in 2014 may have also contributed to the lower EWT. 


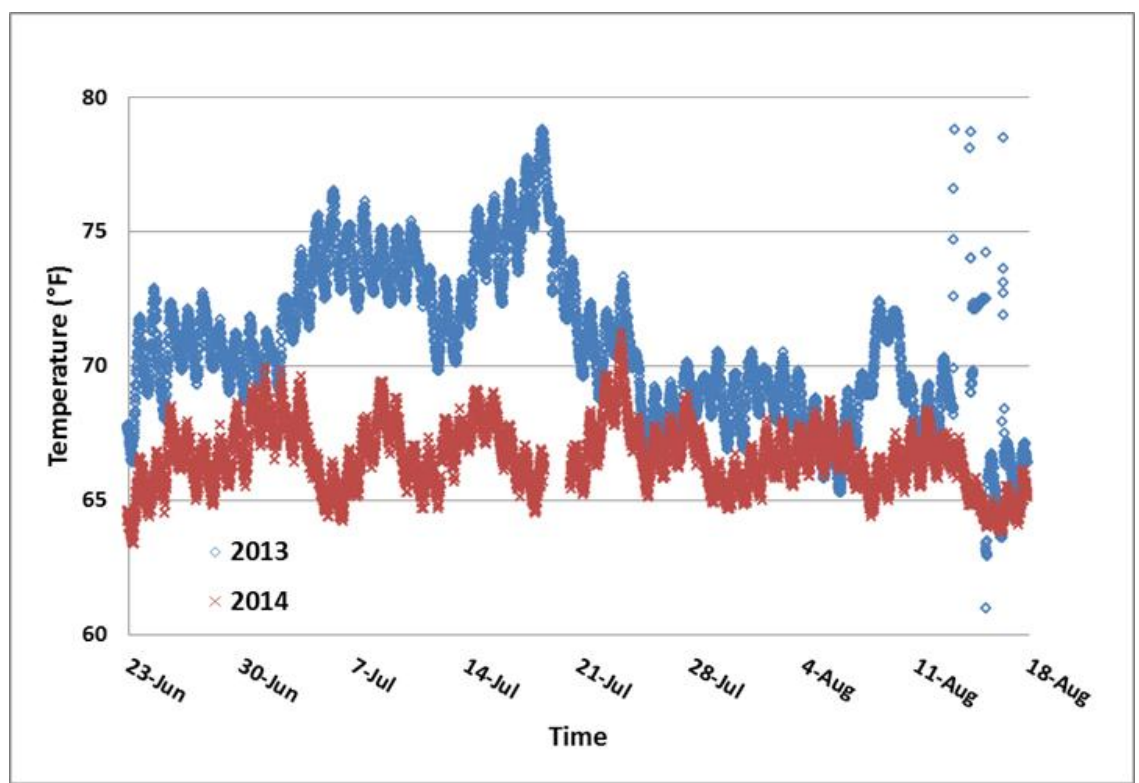

Fig. 36. Secondary loop supply temperatures during the same period in 2013 and 2014.

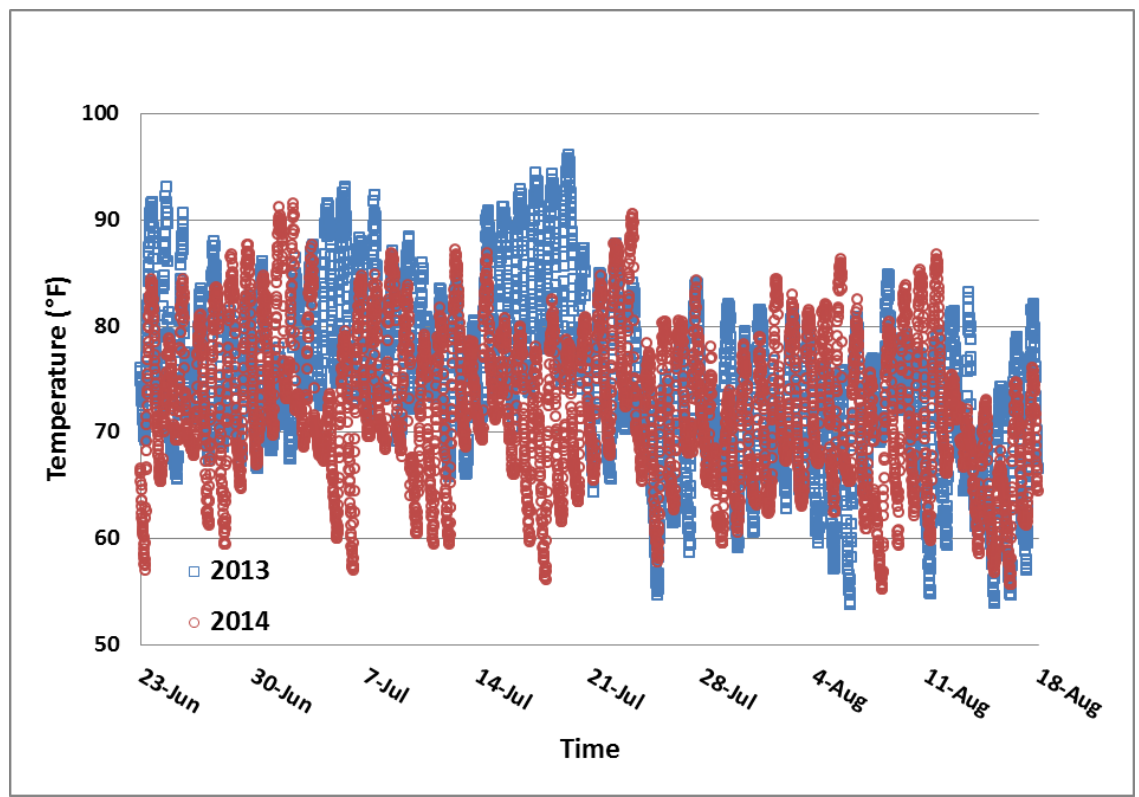

Fig. 37. Ambient temperature during the same period in 2013 and 2014.

To understand the impacts of the varying weather on the EWT, the heating/cooling outputs of the WAHPs and the EWTs in the same 56-day period in 2013 and 2014 were compared in Figs. 38 and 39, respectively. These figures show the cooling output of the WAHPs or the EWTs against the coincident ambient temperatures. Each data point in these figures is the average of WAHP outputs or EWTs within a $1^{\circ} \mathrm{F}$ bin of ambient temperatures. As can be seen in Fig. 38, the cooling outputs of the WAHPs are very similar in 2013 and 2014. However, the EWTs in 2014 are about $5^{\circ} \mathrm{F}$ lower than those in 2013, even when ambient temperatures are identical. This indicates that the lower EWTs in 2014 are the result of the new pumping control. 


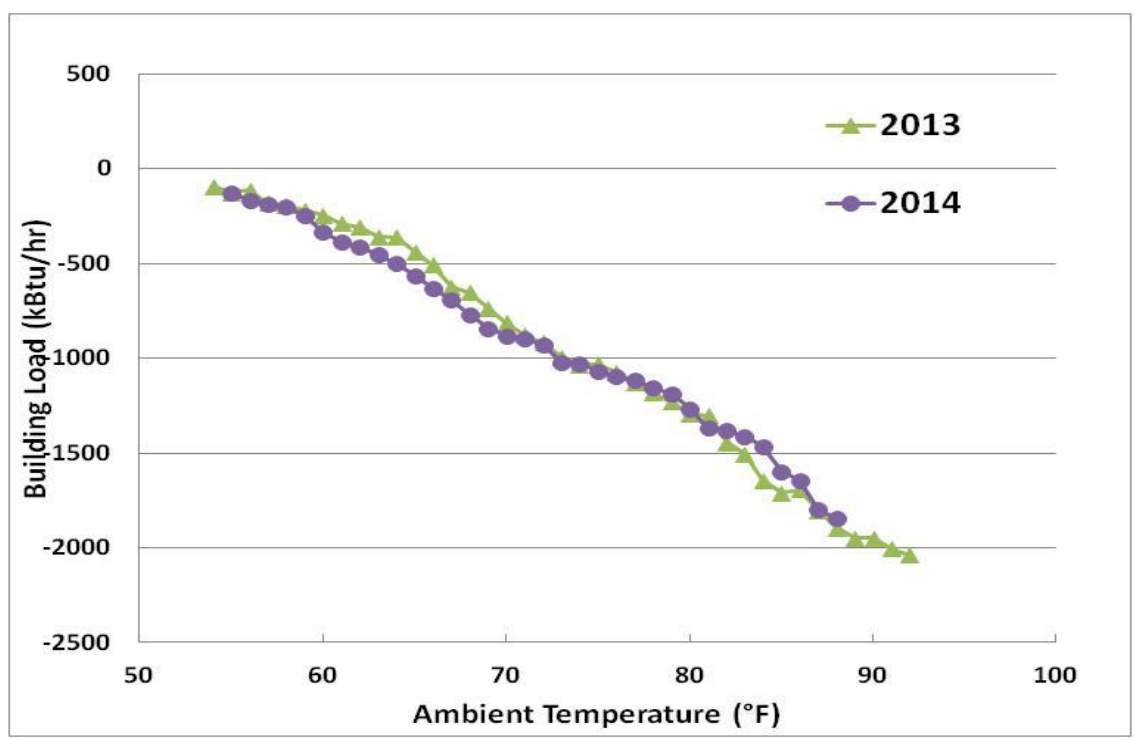

Fig. 38. Comparison of cooling outputs of WAHPs during the same period in 2013 and 2014.

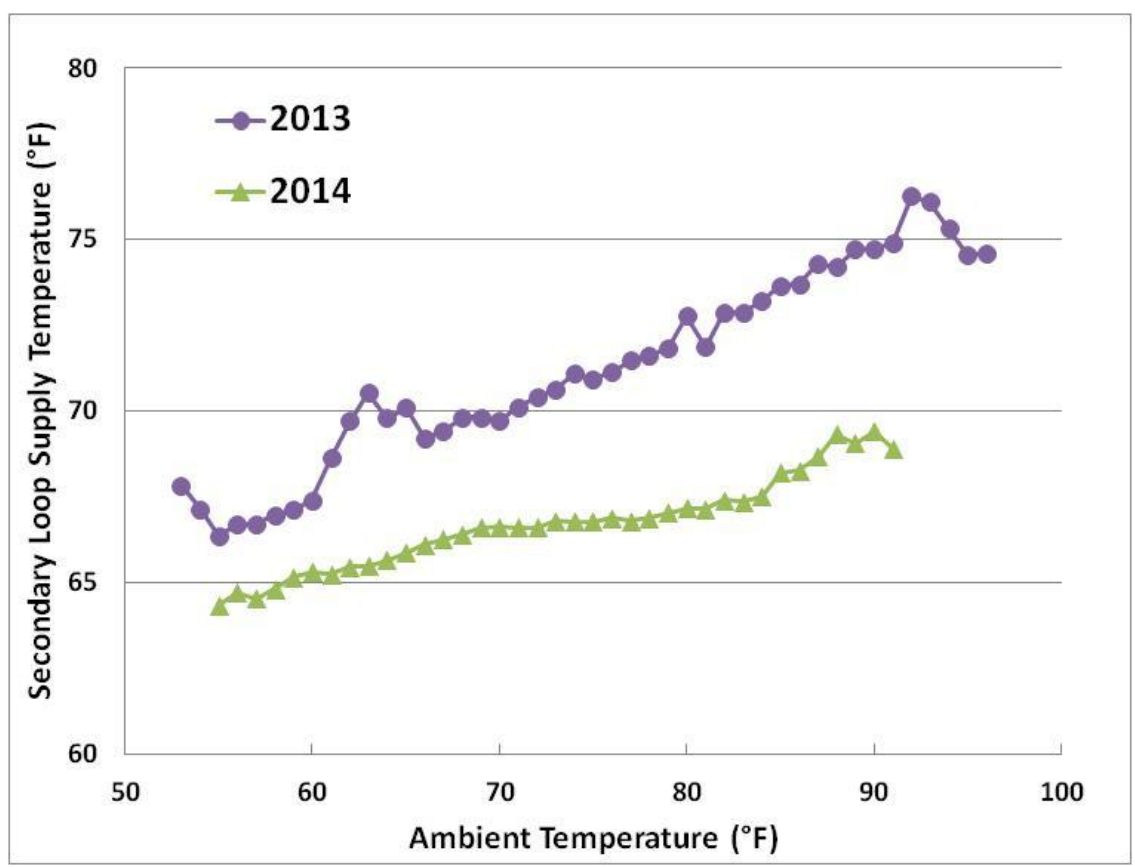

Fig. 39. Comparison of secondary loop supply temperatures during the same period in 2013 and 2014.

As a result of the reduced pumping power and the improved operating efficiency of the WAHPs, the power consumption of the entire building is reduced as shown in Fig. 40. Each data point in Fig. 40 is the average of building total power consumptions (during a 15 -min interval) within a $1^{\circ} \mathrm{F}$ bin of the ambient temperature. The cumulative power consumption of the building during the 56-day period was reduced by $15 \%$, from $331,052 \mathrm{kWh}$ (in 2013) to $280,224 \mathrm{kWh}$ (in 2014). The reduction in primary-loop pumping power $(28,697 \mathrm{kWh})$ contributes to $56 \%$ of the reduction in building enery use. The rest comes from the efficiency gains at the WAHPs due to the lower EWT. The $5^{\circ} \mathrm{F}$ reduction in EWTs (Fig. 39) resulted in 
$7 \%$ efficiency gain at WAHPs. The average EER of all the WAHPs during the 56-day period increased from 16.1 (in 2013) to 17.3 (in 2014). The COP of the GSHP system in 2014 is 3.8, which is $31 \%$ higher than that for the same period in 2013.

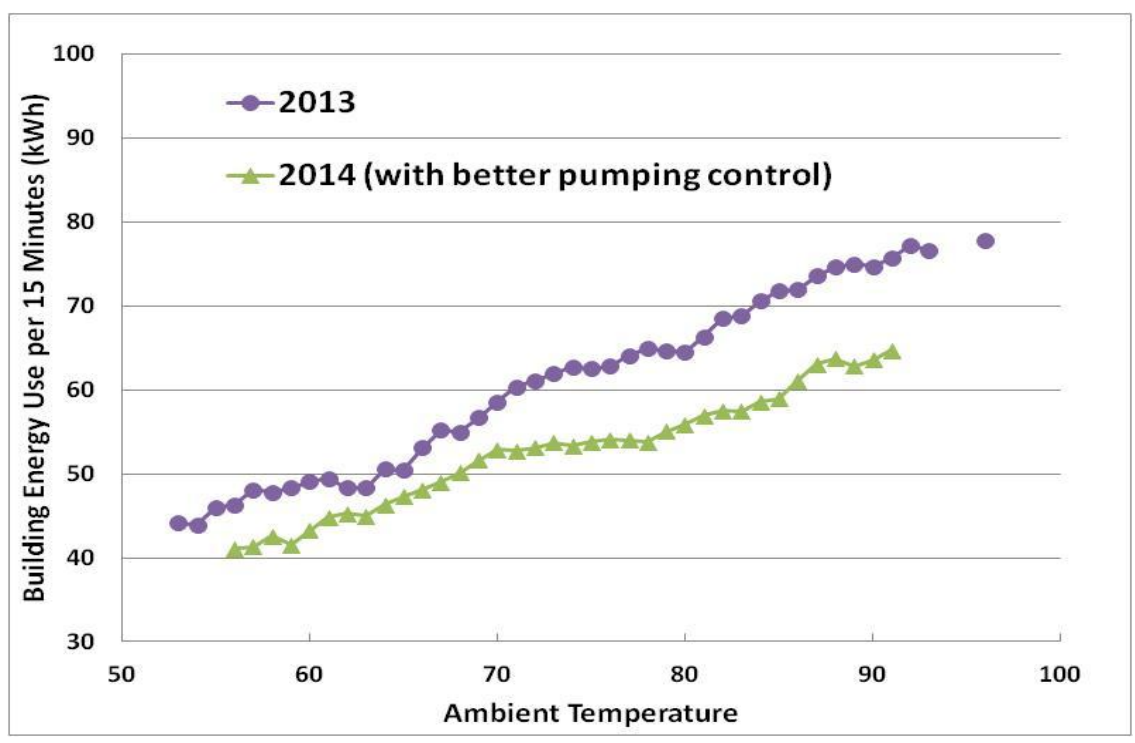

Fig. 40. Total building power consumptions during the same period in 2013 and 2014.

\subsection{Energy Efficiency of the GSHP System}

Given the very limited measured data from the DOASs and their relatively small contributions to the power consumption of the GSHP system (less than $10 \%$ as estimated based on the available data), DOASs are not included in the calculation of the COP (for heating efficiency) and EER (for cooling efficiency) of the GSHP system. The COP and EER of the GSHP system are computed from the calculated data of cooling/heating output of the WAHP units and the associated power consumption, as well the pumping power consumed by the WAHP units ( $84 \%$ of the measured total pumping power). This pumping power consumption is further allocated to the heating and cooling operation based on the ratio between the power consumptions of the WAHP units in heating and cooling modes, respectively. The calculations are expressed in Equations (11) and (12) below:

$$
\begin{gathered}
C O P_{\text {sys }}=\frac{\sum_{i=1}^{n} Q_{H P_{-} h}(i)}{\left[\sum_{i=1}^{n} P_{H P_{-} h}(i)+0.84\left(P_{P r}+P_{S e}\right) * R_{-} h\right] * 3.413} \\
E E R_{\text {sys }}=\frac{\sum_{i=1}^{n} Q_{H P_{-} c}(i)}{\sum_{i=1}^{n} P_{H P_{c}}(i)+0.84\left(P_{P r}+P_{S e}\right) *\left(1-R_{-} h\right)}
\end{gathered}
$$

where

$Q_{H P_{-} h}$ and $Q_{H P_{-} C}$ are the heating and cooling output of a WAHP, respectively, in kBtu;

$P_{H P_{-} h}$ and $P_{H P_{-} c}$ are the power consumption of a WAHP, respectively, in $\mathrm{kWh}$;

$P_{P r}$ and $P_{S e}$ are the power consumption of primary and secondary pumps, respectively, in kWh;

$R \_h$ is the ratio of the heat pump power consumptions in heating mode. 
For the year 2013, the system COP and EER are calculated as 2.5 and 10.1, respectively, which are significantly lower than the WAHP units' average COP of 4.3 and EER of 19.7. It is due to the pumping power consumption, especially the primary loop pump, as discussed before.

\section{ANNUAL ENERGY ANALYSIS}

Simulations with a calibrated computer model for Liberty Terrace residence hall were conducted to predict the performance of a baseline HVAC system. The energy simulation model, its calibration against available measured data, and the baseline HVAC system are discussed in the following sections, followed by a comparison of full-year performance between the two systems.

\subsection{Building Energy Model}

An eQUEST energy model, which was originally developed by the design team for Liberty Terrace, was obtained from the facility manager at the University at Albany. This model is further refined and calibrated against the available measured data. eQUEST is a widely used building energy simulation program. It is powered by the latest development of the DOE-2 program and has improved capability to simulate various GSHP systems (Liu and Hellström 2008).

Figure 41 shows a three-dimensional rendering of the eQUEST energy model of the building. The eQUEST model was developed based on the geometry and thermal zoning of the real building. Characteristics of the building envelope (i.e., exterior wall, windows, roof, and floor) and space conditions of each thermal zone (i.e., living suites, corridors, lobby, and other common spaces) were specified per the original design of the building. It was found that the space conditions for the service zones (including elevators, mechanical and electrical rooms, and data rooms) were not consistent with the measured data and they were adjusted during the calibration process (described in the next section). The characteristics of the demonstrated GSHP system, including the capacity and efficiency of each WAHP unit, size and layout of the GHX, and OA ventilation, were specified in great detail in the eQUEST model. OA ventilation through ERV was specified for each living suite, which represents the actual system for the living suites. In real building, the OA ventilation in corridors and most common spaces was provided by four DOASs. However, since the delivered OA is at the room temperature and does not affect the heating and cooling loads of the WAHPs, no OA ventilation is simulated for the corridors and common spaces. Due to a limitation of the eQUEST program, a central variable speed pump in a two-pipe water loop is modeled instead of the primary-and-secondary looping and pumping configuration in the actual system. The simulated GSHP system provides space heating and space cooling to the entire building and it is an all-electric system. 


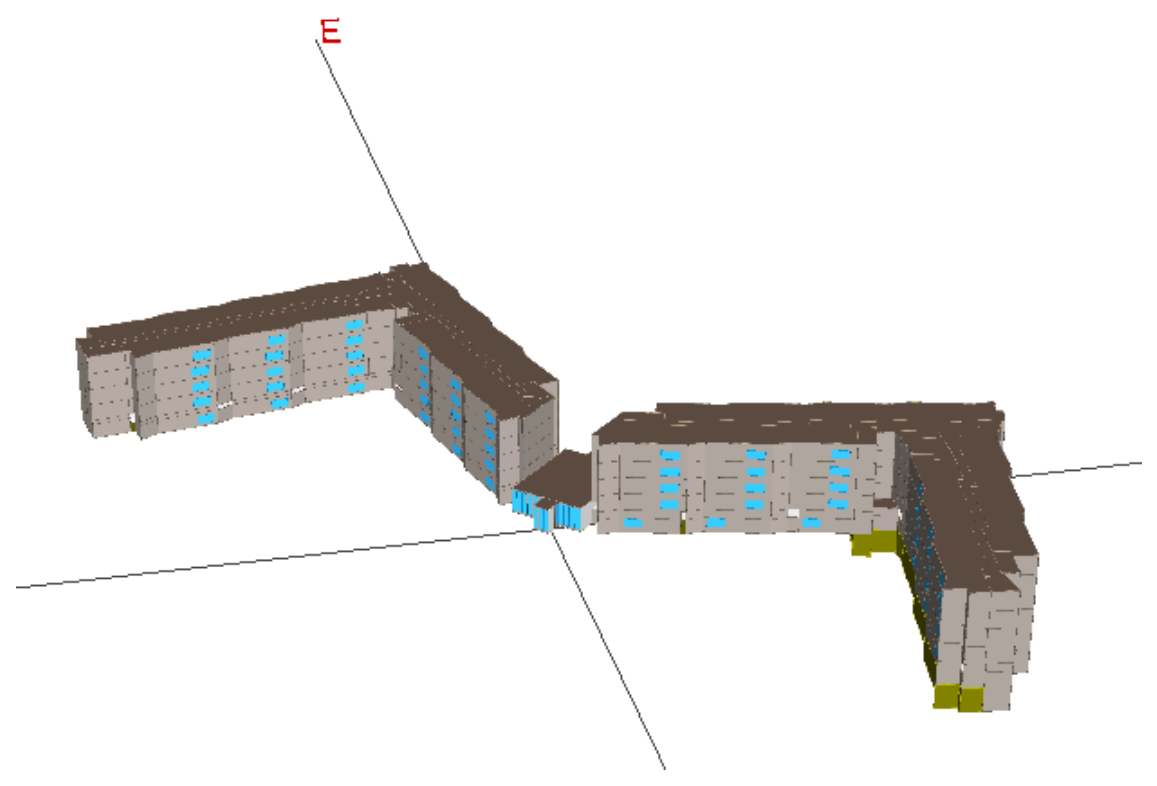

Fig. 41. Images of Liberty Terrace: (a) actual building and (b) a three-dimensional rendering of the eQUEST energy model of the building.

\subsection{Model Calibration}

The objective of model calibration was to ensure that the space heating and cooling loads predicted by the model match those calculated from the measured data, so that a valid comparison of the energy performance of the installed system could be made against a simulated baseline system. Actual weather data was obtained for Albany International Airport (7 miles north of the building) for 2012, the year for which measured data was available. Several parameters of the original eQUEST energy model were finetuned during the calibration process, including the equipment power density, occupancy, and space temperature range in the service zones. In addition, the occupancy schedule of the building was changed to represent the unoccupied period during the summer.

The model calibration process includes three steps: 1) vary the selected parameters; 2) run simulations, and 3) compare the simulation-predicted results with the corresponding measured data. This process is iterated until a good match between the two data sets is reached. The simulation-predicted heating and cooling loads and those derived from the measured data (as explained previously) were aggregated to allow comparisons on an hourly, daily, and monthly basis to inform the calibration process. With the calibrated model, the simulation-predicted hourly heating and cooling loads matched reasonable well with the measured loads (Fig. 42). Comparing the measured and predicted monthly heating and cooling loads (Fig. 43), the calibrated model achieved a NMBE (normalized mean bias error) of 5\% and a CVRMSE (root mean square error) of 9.9\%. This calibration result meets the compliance requirements of ASHRAE Guideline 14 (ASHRAE 2002), which requires that "the computer model shall have an NMBE of 5\% and a CVRMS of $15 \%$ relative to monthly calibration data." 

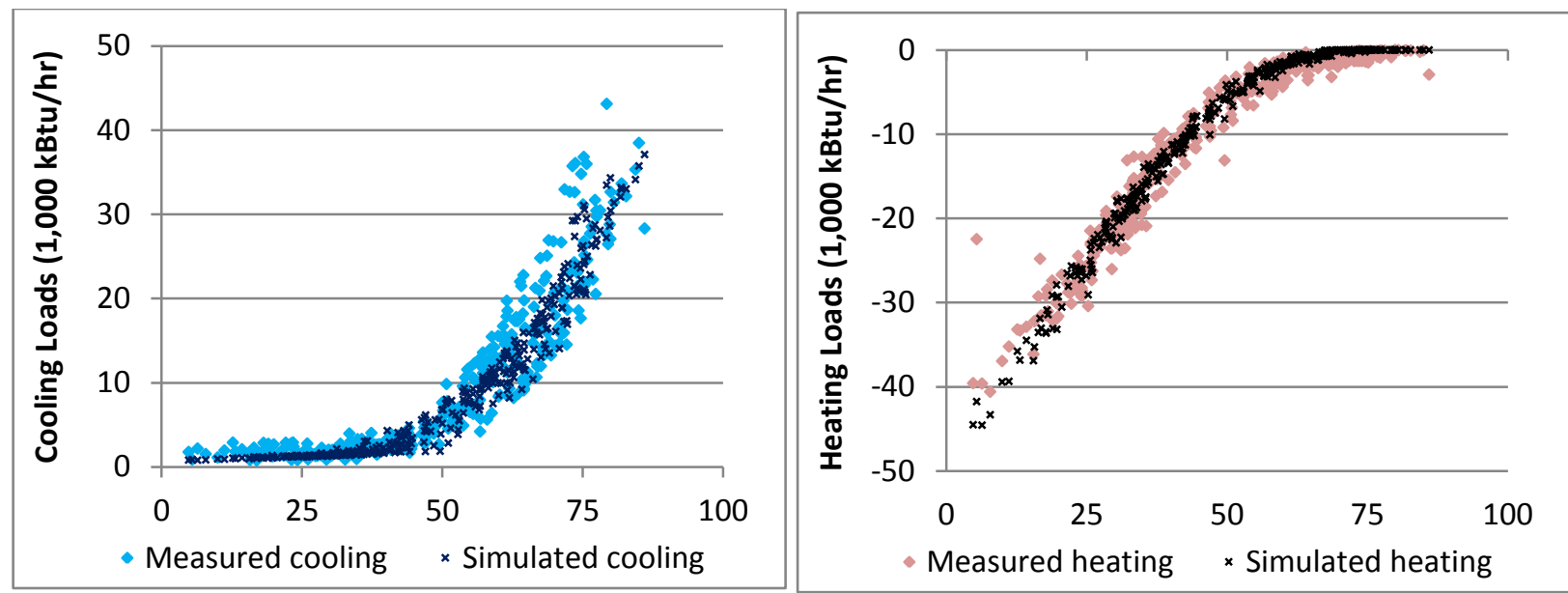

Fig. 42. Measured and predicted hourly heating and cooling loads.
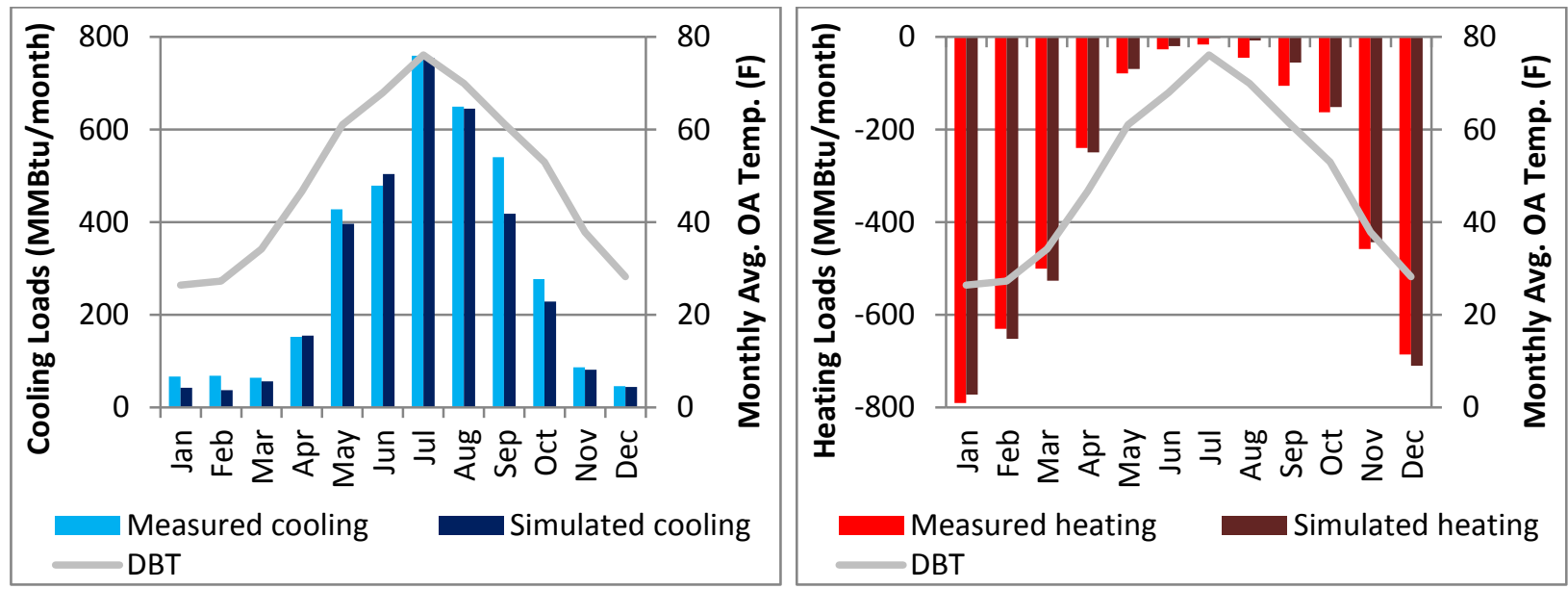

Fig. 43. Measured and predicted monthly heating and cooling loads.

\subsection{Baseline HVAC System}

A packaged terminal heat pump (PTHP) system was chosen as the baseline for this study since it was the original design for this residence hall. Each PTHP system provides space heating and space cooling for a room or zone. It is usually mounted in a through-the-wall configuration. Figure 44 is a schematic chart of a typical PTHP system, which is excerpted from the DOE-2 user manual (LBNL and JJH 2006). As shown in Fig. 44, a PTHP system consists of a refrigerant compressor, an air-cooled condenser, and a fan, which reject heat to the outdoors, and an evaporator coil and a fan to circulate the room air through the unit. There is usually a small outside air opening to satisfy minimum ventilation requirements, but no economizer. In the simulated PTHP, space heating is provided solely by the heat pump when the ambient temperature is not lower than $40^{\circ} \mathrm{F}$ and it is supplemented by electric resistance heating when ambient temperature becomes lower. The simulated baseline PTHP system provides space heating and space cooling to the entire building and it is also an all-electric system. 


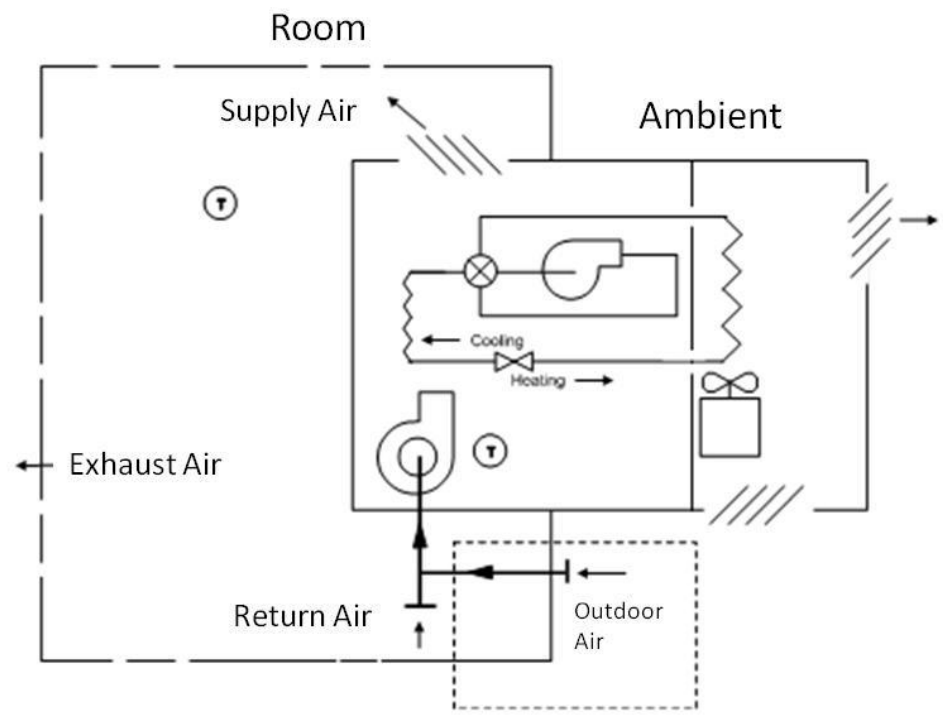

Fig. 44. Schematic of a typical packaged terminal heat pump. (Source: Lawrence Berkeley National Laboratory and James J. Hirsch \& Associates. 2006. DOE-2.2 Documentation Volume 3: Topics)

Principal design parameters of the simulated baseline PTHP system are summarized in Table 2. The simulated PTHPs serving the living suites provide a constant amount of (unconditioned) OA to each living suite to satisfy minimum ventilation requirements. Same as the simulated GSHP system, there is no OA ventilation in the common areas. PTHP system in each living suite and the common area is auto-sized by eQUEST according to the heating and cooling loads predicted by the calibrated model.

Table 2. Principal design parameters of the simulated baseline PTHP system

\begin{tabular}{lll}
\hline Component & Capacity & Efficiency \\
\hline PTHP & $1-2$ tons & Cooling: 13 EER (Approx. 12 SEER ${ }^{a}$ ) \\
& & Heating : 2.7 COP (Approx. 7.4 $\mathrm{HSPF}^{b}$ ) \\
Electric resistance & $70 \%$ of heat pump capacity & 0.98 \\
Supply fan & $400-800 \mathrm{ft}^{3} / \mathrm{min}, 0.25$ in. ESP & 0.52 (total efficiency) \\
\hline
\end{tabular}

${ }^{a}$ Minimum cooling efficiency for air-cooled, through-the-wall, electrically operated unitary and applied heat pumps (ASHRAE Standard 90.1- 2004).

${ }^{b}$ Minimum heating efficiency for air-cooled, through-the-wall, electrically operated unitary and applied heat pumps (ASHRAE Standard 90.1-2004).

${ }^{c}$ ESP is the external static pressure, represented in inches of water column.

\subsection{Comparison between Demonstrated GSHP System and Baseline PTHP System}

Using the calibrated computer model and the measured 2012 weather data, the full-year performance of the demonstrated GSHP system and the baseline PTHP system were predicted. Simulation results show that both systems can maintain the indoor temperature of the building at the same set points $\left(78^{\circ} \mathrm{F}\right.$ for cooling and $70^{\circ} \mathrm{F}$ for heating) when it is occupied ( 24 hours per day all year long). Both systems are allelectric.

The simulation-predicted annual electricity consumptions of these two all-electric system are listed in Table 3. The equivalent site and source energy consumption and carbon emissions were also calculated; 
these are listed in the same table. The power consumption data of the GSHP system includes the measured pumping power consumption before the control for the primary-loop pump was fixed.

Table 3. Energy consumptions and carbon emissions of the as-built GSHP and the baseline PTHP system (pumping power of the GSHP system is measured before the primary-loop pump control is fixed)

\begin{tabular}{|l|c|c|c|c|c|}
\hline & $\begin{array}{c}\text { Electric } \\
\text { consumption } \\
(\mathbf{k W h})\end{array}$ & $\begin{array}{c}\text { Building peak } \\
\text { electric demand } \\
(\mathbf{k W})\end{array}$ & $\begin{array}{c}\text { Site energy } \\
\text { (MBTU) }\end{array}$ & $\begin{array}{c}\text { Source energy } \\
\text { (MBTU) }\end{array}$ & $\begin{array}{c}\text { Carbon } \\
\text { emissions (Mt) }\end{array}$ \\
\hline Baseline PTHP & $2,227,100$ & 1258 & 7,601 & 26,171 & 1,758 \\
\hline GSHP & $1,143,100$ & 430 & 3,901 & 13,433 & 902 \\
\hline Savings/reductions & $1,084,000$ & 828 & 3,700 & 12,738 & 856 \\
\hline Percentage change (\%) & $\mathbf{4 9 \%}$ & $\mathbf{6 6 \%}$ & $\mathbf{4 9 \%}$ & $\mathbf{4 9 \%}$ & $\mathbf{4 9 \%}$ \\
\hline
\end{tabular}

All conversion factors for calculating the source energy consumption and carbon emissions in New York State are listed in Table 4, which is adopted from a report published by the National Renewable Energy Laboratory (Deru and Torcellini 2007).

Table 4. Conversion factors for source energy consumption and carbon emissions in New York State

\begin{tabular}{lll}
\hline Source energy factor for electricity delivered to building & 3.443 & $\mathrm{kWh} / \mathrm{kWh}$ \\
Total emission factors for delivered electricity & 1.74 & $\mathrm{lb} / \mathrm{kWh}$ \\
\hline
\end{tabular}

As shown in Table 3, compared with the PTHP system, the GSHP system reduces electric energy consumption by $49 \%$ (an annual savings of 1,084,000 kWh electricity). Since both the baseline and the GSHP systems are all-electric, the $49 \%$ savings/reduction is also for the site energy, source energy, and equivalent $\mathrm{CO}_{2}$ emissions. In addition, the GSHP system cuts the building's peak electric demand by $66 \%$ $(828 \mathrm{~kW})$.

Results for the HVAC-related electric end use of the baseline FTHP system and the as-built GSHP system are shown in Fig. 45. In addition, the simulated end-use power consumptions for the following two alternative GSHP systems are also shown in Fig. 45.

- Alternative GSHP system \#1: with one central variable-speed pump for the entire system

- Alternative GSHP system \#2: with one central variable-speed pump for the entire system, and without using ERV for each WAHP (i.e., unconditioned OA is introduced to the building directly)

As Fig. 45 shows, although all the GSHP systems use more pumping power than the baseline PTHP, they eliminate the huge power consumption for supplemental heating, which contributes $68 \%$ to the HVACrelated power consumption of the PTHP system. A properly operated central variable pump (alternative \#1) reduces pumping power by $74 \%$ and does not change the power consumption of any other end use. As a result, the pumping power fraction is reduced from the original $29 \%$ to only $10 \%$ of total GSHP system power consumption. The reduced pumping power further cuts the building's peak electric demand by 38 $\mathrm{kW}$ compared with the as-built GSHP system. Furthermore, if all the ERVs are not used (alternative \#2), the fan power consumption is reduced by $70 \%$, but it increases the power consumption for space heating. It also slightly increases the pumping energy but decreases the energy use for space cooling. It should be 
noted that in such a cold climate, it may not be acceptable to dump fresh OA directly into the conditioned space without first tempering (neutralizing) it. So, the ERVs may be required to temper the fresh air. However, the operation of the ERVs shall be refined to avoid unnecessary OA ventilation when the suite/apartment is not occupied. In addition, since the enthalpy wheel in the ERV has high air flow resistance and thus its operation results in significant fan power consumption, it shall be deactivated and bypassed when the enthalpy differential between the OA and the exhaust air is too small to justify the power consumption resulting from running the enthalpy wheel. In this case, a variable speed fan shall be used for the ERV so that it can deliver a constant amount of OA at different external static pressures.

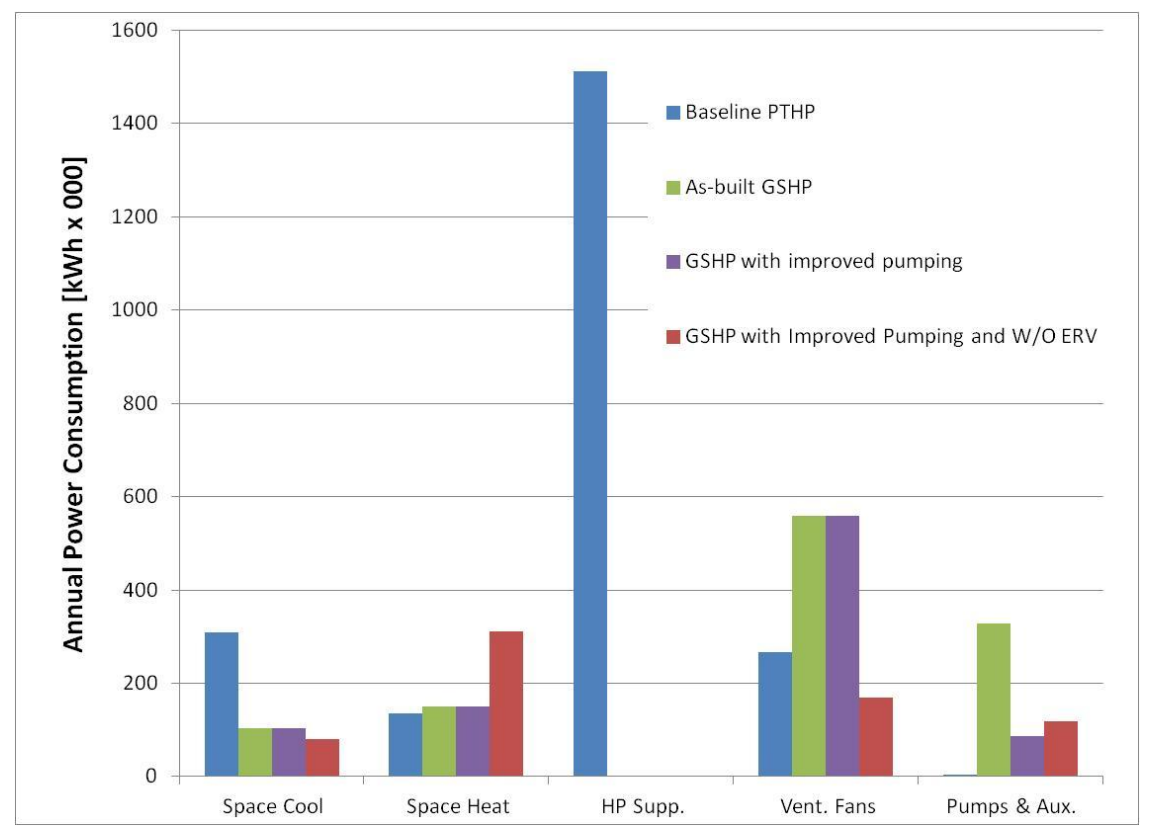

Fig. 45. Simulation results for electric end use of the baseline PTHP system and the as-built GSHP system, as well as two alternative GSHP systems.

The overall power consumption of the two alternatives is also compared with that of the baseline PTHP system. The results indicate that alternative GSHP systems \#1 and \#2 further increase the energy savings to $60 \%$ and $69 \%$, respectively.

\section{ANALYSIS OF COST EFFECTIVENESS}

The cost effectiveness of the demonstrated GSHP system was evaluated using a simple payback period, which is the ratio of the cost premium for the GSHP system to the annual operating cost savings it achieves.

\subsection{Cost Premium}

The GSHP system cost premium is the difference between the installed cost of the GSHP system and the baseline PTHP system. Table 5 summarizes the itemized installed cost of the demonstrated GSHP system, which was provided by the grantee. The total installed cost of the GSHP system is $\$ 5,709,435$. The estimated cost for the baseline PTHP system is $\$ 1,115,254$, which is determined with the typical installed cost of decentralized unitary HVAC equipment (RSMeans 2010) and the same 412 ton cooling capacity 
as the GSHP system. In addition, the cost for "general conditions" listed in Table 5 was assumed the same as that for installing the baseline PTHP system. The resulting cost premium of the GSHP system is $\$ 4,594,182$.

Table 5. Itemized installed cost of the demonstrated GSHP system

\begin{tabular}{ll}
\hline Cost items & Cost \\
\hline Well field & $\$ 2,665,883$ \\
Heat pump and terminal unit & $\$ 2,783,199$ \\
General conditions & $\$ 260,353$ \\
Total & $\mathbf{\$ 5 , 7 0 9 , 4 3 5}$ \\
\hline
\end{tabular}

Notes:

- "Well field" includes all the labor and material costs for drilling vertical bores, mobilizing/ excavating/back-filling the borehole field, and the piping system of the ground heat changer.

- "Heat pump and terminal unit" includes all the labor and material cost of heat pump units, the associated ductwork and piping system.

- "General conditions" includes all the labor and material cost associated with administration and management for the GSHP system installation.

Given the 412 ton installed cooling capacity of the GSHP system and the $184,533 \mathrm{ft}^{2}$ floor space, the installed cost can be normalized as $\$ 13,858$ per installed cooling ton, or $\$ 30.9 / \mathrm{ft}^{2}$ of conditioned floor space.

Since this is an ARRA-funded demonstration project, prevailing wage was required for all laborers involved. This may have resulted in higher labor cost than that for ordinary GSHP installations.

\subsection{Operating Cost Savings}

The operating costs of the GSHP system and the baseline PTHP system are calculated based on the predicted annual electric consumption and the local utility rate for electricity. According to the University at Albany, the price of electricity used on campus is $\$ 0.092 / \mathrm{kWh}$. Based on this electricity rate, and the predicted annual energy consumption (listed in Table 4), annual energy costs for operating the GSHP and the baseline PTHP systems are calculated to be $\$ 105,165$ and $\$ 204,893$, respectively. The annual energy cost savings achieved by the GSHP system is $\$ 99,728$, which is a $49 \%$ cost savings compared with the energy cost of the baseline PTHP system. If the energy cost of the alternative GSHP system design \#2 $(\$ 62,698)$ is used, the energy cost savings will increase to $\$ 142,195$.

\subsection{Simple Payback}

Based on the calculated cost premium $(\$ 4,594,182)$ and the predicted annual operating cost savings $(\$ 99,728)$ of the GSHP system, the simple payback period for the GSHP system is 46 years. The payback will drop to 32 years if the alternative GSHP system design \#2 had been implemented. 


\section{CONCLUSIONS}

This section summarizes the conclusions drawn from this case study, including the performance of the GSHP system based on measured and calculated data, benefits achieved by the GSHP system compared with the baseline system, and the cost effectiveness of the demonstrated GSHP system. In addition, lessons learned regarding performance data collection and analysis, as well as areas that need further improvement, are summarized.

\subsection{Performance, Energy Savings, Cost Effectiveness}

Based on our analysis of the measured and calculated data, the following conclusions can be drawn with regard to the performance of the demonstrated GSHP system:

- The ground-loop supply fluid temperature ranged from $47.5^{\circ} \mathrm{F}$ to $78.5^{\circ} \mathrm{F}$, with an average temperature of $60.3^{\circ} \mathrm{F}$. While the ambient temperature varied from $-2.2^{\circ} \mathrm{F}$ to $96.1^{\circ} \mathrm{F}$, the groundloop temperature is within a range favorable for efficient GSHP system operation. As a result, the WAHP units have good efficiency, with COP ranging from 3.8 to 5.7 and EER ranging from 12 to 29. The average combined EER and COP of the WAHP units during the one-year data collection period are 19.7 and 4.3, respectively.

- The pumps in the primary loop were oversized, resulting in a high ratio (17.8 hp/100 tons) between the installed pump power and the total cooling capacity of this system. In addition, although the secondary-loop pumps did vary speed in response to the fluctuating heating and cooling demands, these pumps ran at around $60 \%$ of full speed even with no heat pump running. This indicates that either the minimum bypass flow, or the loop pressure differential set point, or both, needs to be adjusted to reduce the excessive pumping and/or excessive pressure at low-load conditions. The original control for the primary-loop pump was not fit for the GSHP system, and it wasted significant pumping power. After implementing the new control stagey in 2014, which adjusts primary-loop flow based on the heating/cooling demand in the secondary loop, power consumption by the primary pump is reduced significantly (a 93\% reduction in the same 56-day period before and after the new control). The reduced pumping power also resulted in lower entering fluid temperature to the WAHPs, which increases their operating cooling efficiency by $7 \%$. As a result, the cumulative power consumption of the building during the same 56-day period in 2013 and 2014 was reduced by $15 \%$, from 331,052 kWh (in 2013) to 280,224 kWh (in 2014).

- The annual COP and EER of the GSHP system in 2013 (excluding the DOAS) are calculated as 2.5 and 10.1, respectively, which are significantly lower than the average COP and EER of the WAHP units. It is due to the excessive pumping power consumption, especially the primary loop pump.

- Simulations of the demonstrated GSHP system and a baseline PTHP system were performed using a calibrated computer model of the building. The simulation results indicate that the as-built GSHP system reduces electric energy consumption by $49 \%$ (an annual savings of 1,084,000 kWh of electricity) compared with the PTHP system. Since both the baseline and the GSHP systems are all-electric, the savings in electricity also means $49 \%$ savings/reduction in site energy, source energy, and equivalent $\mathrm{CO}_{2}$ emissions. The energy savings and emission reductions would have been increased to $69 \%$ if the variable-speed pumping system were controlled properly and the ERVs were not used. 
- The installed cost of the demonstrated GSHP system is $\$ 5,709,435$, which is normalized as $\$ 13,858$ per installed cooling ton, or $\$ 30.9 / \mathrm{ft}^{2}$ of the conditioned building floor space. The installed cost includes expenses unique to the ARRA-funded demonstration project that are not common in ordinary HVAC projects, such as the prevailing wage requirements for all laborers involved in this project. Based on the calculated cost premium $(\$ 4,594,182)$ and the predicted annual operating cost savings $(\$ 99,728)$ of the GSHP system, the simple payback period for the GSHP system is 46 years. The payback will drop to 32 years if the alternative GSHP system design \#2 had been implemented.

\subsection{Lessons Learned}

\subsubsection{Performance Data Collection}

Sub-metering for electrical load of HVAC equipment was not implemented due to scheduling problems: the project was almost at its end before the control contractor was asked to install instruments to monitor the electrical load of the HVAC equipment. The installation was not possible because the HVAC equipment was not segregated in a way that would allow electrical monitoring. Proper planning up front would make this an achievable goal.

\subsubsection{System Design and Control}

\section{Pumping system}

Configuration and control of the pumping system can significantly affect the power consumption and efficiency of the GSHP system. Since the fluid temperature leaving a GHX varies depending on its loading history, it is not realistic to maintain a constant leaving fluid temperature in the GHX (e.g., the undisturbed ground temperature) by only adjusting the pump speed. For the primary and secondary loop configuration, a two-step control strategy that maintains the secondary-loop supply temperature within $1^{\circ} \mathrm{F}$ from the primary-loop supply temperature has been demonstrated as an effective way for reducing pumping power in the primary loop without sacrificing the operating efficiency of the heat pumps. In fact, with this control strategy, the primary-secondary loop performs more like a single loop with a central variable-speed pump station. To fully realize the energy-saving potential of the variable-speed pump, the minimum flow rate of a pumping system must be as low as possible. The reduced pumping power also means less heat rejection load to the GHX, which in turn results in higher cooling efficiency of the heat pump due to the lower leaving fluid temperature from the GHX.

\section{$\underline{\text { OA ventilation system }}$}

For a DOAS with variable-speed fan, its cooling capacity shall be automatically adjusted to match the variable air flow. Otherwise, the air flow rate of the DOAS can only be adjusted in a small range to prevent the cooling coil from freezing. If the cooling capacity cannot be automatically adjusted to match the air flow rate, multiple DOASs of various sizes shall be used to supply variable OA flow to satisfy different OA ventilation demands. This will not only reduce power consumption for OA ventilation but also prevent overcooling the space.

Although an ERV can pre-heat or pre-cool the OA with heat or cool recovered from the exhaust air, the OA temperature leaving the ERV is not controllable and it floats with the ambient temperature. When the OA supply is through the return air of the WAHP, the fan of the WAHP shall be turned on only when the WAHP unit is actively conditioning the space (in the "AUTO" mode). This will reduce the cold draft through the ductwork. However, to ensure sufficient OA ventilation, the ERV must be able to deliver enough OA to the space (ideally through an opening at an unoccupied area) when the WAHP is off. The 
operation of the ERVs shall be refined to avoid unnecessary OA ventilation when the suite/apartment is not occupied. In addition, since the enthalpy wheel in the ERV has high air flow resistance and thus its operation results in significant fan power consumption, it shall be deactivated and bypassed when the enthalpy differential between the OA and the exhaust air is too small to justify the power consumption resulting from running the enthalpy wheel. In this case, a variable speed fan shall be used for the ERV so that it can deliver a constant amount of OA at different external static pressures. 


\section{REFERENCES}

ASHRAE (American Society of Heating, Refrigeration, and Air-conditioning Engineer). 2014. "ASHRAE Guideline 14-2014 - Measurement of Energy and Demand Savings."

Deru, M., and P. Torcellini. 2007. Source Energy and Emission Factors for Energy Use in Buildings. NREL/TP-550-38617, National Renewable Energy Laboratory, Golden, Colo.

Lnu, I. 2014. Email communications with the university energy officer at University at Albany.

Lawrence Berkeley National Laboratory and James J. Hirsch \& Associates. 2006. DOE-2.2 Documentation, Volume 3: Topics.

Liu, X., and G. Hellström. 2008. "Enhancement of an integrated simulation tool for ground source heat pump system design and energy analysis," in Proceedings of the $10^{\text {th }}$ International Thermal Energy Storage Conference, Stockton, NJ, June 2008.

RSMeans, 2010. Mechanical Cost Data. A Division of Reed Construction Data, Constriction Publisher \& Consultants, 63 Smiths Lane, Kingston, MA 02364-3008.

Walburger, A. and S. Perriello. 2013. Monitoring Plan and Data Summary for ARRA GSHP Demonstration Project Site 21-University at Albany. CDH Energy Corp. 
APPENDIX A. LIST OF THE CAPACITY AND EFFICIENCY OF INSTALLED WAHP UNITS

\begin{tabular}{|c|c|c|c|c|c|c|c|c|c|}
\hline \multirow[t]{2}{*}{ HP tag } & \multirow[t]{2}{*}{ Model } & \multirow{2}{*}{$\begin{array}{l}\text { Air flow } \\
\text { (cfm) }\end{array}$} & \multirow{2}{*}{$\begin{array}{c}\text { Blower } \\
\text { size } \\
\text { (hp) }\end{array}$} & \multirow{2}{*}{$\begin{array}{l}\text { Water side } \\
\text { flow } \\
\text { (gpm) }\end{array}$} & \multicolumn{2}{|c|}{ Cooling capacity @ 55 EWT } & \multirow{2}{*}{$\begin{array}{l}\text { Cooling EER } \\
\text { @ } 55 \text { FEWT } \\
\text { (Btu/Wh) }\end{array}$} & \multirow{2}{*}{$\begin{array}{c}\text { Heating capacity } \\
\text { @ } 55 \text { EWT } \\
\text { (Total MBtu/h) }\end{array}$} & \multirow{2}{*}{$\begin{array}{c}\text { Heating COP @ } \\
55 \text { FEWT } \\
\text { (Btu/Btu) }\end{array}$} \\
\hline & & & & & (Total MBtu/h) & (Sensible MBtu/h) & & & \\
\hline A003 & WCCW4019 & 700 & 0.33 & 5.5 & 23.7 & 17.2 & 23.0 & 18.2 & 4.15 \\
\hline A012 & WCCW4030 & 1,000 & 0.50 & 7.4 & 30.5 & 22.1 & 23.1 & 27.2 & 4.18 \\
\hline A103 & WCCW4024 & 850 & 0.33 & 6.0 & 26.9 & 19.6 & 22.3 & 20.8 & 4.05 \\
\hline A104 & WCCW4019 & 630 & 0.33 & 5.3 & 23.4 & 16.3 & 23.1 & 20.6 & 4.05 \\
\hline $\mathrm{A} 105 \mathrm{~A}$ & WCCW4019 & 700 & 0.33 & 4.0 & 23.1 & 17.0 & 21.9 & 17.1 & 3.72 \\
\hline $\mathrm{A} 106 \mathrm{~B}$ & WCCW4009 & 275 & 0.13 & 2.0 & 9.8 & 6.9 & 21.1 & 9.0 & 3.69 \\
\hline A107A & WCCW4036 & 1,100 & 0.50 & 7.5 & 35.9 & 25.8 & 22.6 & 31.8 & 4.01 \\
\hline A107B & WCCW4036 & 1,100 & 0.50 & 7.5 & 35.9 & 25.8 & 22.6 & 31.8 & 4.01 \\
\hline A108 & WCCW4015 & 630 & 0.33 & 3.8 & 17.4 & 10.5 & 32.9 & 13.8 & 4.34 \\
\hline A111 & WCCW4009 & 275 & 0.13 & 2.0 & 9.8 & 6.9 & 21.1 & 9.0 & 3.69 \\
\hline A113 & WCCW5012 & 400 & 0.13 & 3.0 & 13.5 & 9.4 & 18.6 & 12.4 & 3.55 \\
\hline A116 & WCCW4024 & 900 & 0.33 & 6.0 & 27.1 & 20.2 & 22.3 & 21.6 & 4.07 \\
\hline $\mathrm{A} 118$ & WCCW5012 & 390 & 0.13 & 3.0 & 13.6 & 9.4 & 18.6 & 12.4 & 3.55 \\
\hline A120 & WCCW4019 & 630 & 0.33 & 4.0 & 22.8 & 16.1 & 22.1 & 17.4 & 4.05 \\
\hline A121 & WCCW4019 & 630 & 0.33 & 3.8 & 22.7 & 16.0 & 21.9 & 17.3 & 4.04 \\
\hline A123 & WVHC1009 & 300 & 0.06 & 2.5 & 9.6 & 7.3 & 21.4 & 8.4 & 4.34 \\
\hline A124 & WVFW1024 & 950 & 0.33 & 6.0 & 25.7 & 20.8 & 29.3 & 20.3 & 4.66 \\
\hline A126 & WVFW1024 & 950 & 0.33 & 6.0 & 25.7 & 20.8 & 29.3 & 20.3 & 4.66 \\
\hline $\mathrm{A} 127$ & WVFW1024 & 950 & 0.33 & 6.0 & 25.7 & 20.8 & 29.3 & 20.3 & 4.66 \\
\hline A128 & WVFW1024 & 950 & 0.33 & 6.0 & 25.7 & 20.8 & 29.3 & 20.3 & 4.66 \\
\hline A130 & WCCW5012 & 390 & 0.13 & 3.0 & 13.6 & 9.4 & 18.6 & 12.4 & 3.55 \\
\hline A131 & WVFW1024 & 950 & 0.33 & 6.0 & 25.7 & 20.8 & 29.3 & 20.3 & 4.66 \\
\hline A202 & WCCW5012 & 400 & 0.13 & 3.0 & 13.7 & 9.5 & 18.7 & 12.5 & 3.58 \\
\hline A203 & WVFW1024 & 950 & 0.33 & 6.0 & 25.7 & 20.8 & 29.3 & 20.3 & 4.66 \\
\hline A204 & WVFW1024 & 950 & 0.33 & 6.0 & 25.7 & 20.8 & 29.3 & 20.3 & 4.66 \\
\hline A205 & WVFW1024 & 950 & 0.33 & 6.0 & 25.7 & 20.8 & 29.3 & 20.3 & 4.66 \\
\hline A206 & WVFW1024 & 950 & 0.33 & 6.0 & 25.7 & 20.8 & 29.3 & 20.3 & 4.66 \\
\hline A207 & WVFW1024 & 950 & 0.33 & 6.0 & 25.7 & 20.8 & 29.3 & 20.3 & 4.66 \\
\hline
\end{tabular}




\begin{tabular}{|c|c|c|c|c|c|c|c|c|c|}
\hline \multirow[t]{2}{*}{ HP tag } & \multirow[t]{2}{*}{ Model } & \multirow{2}{*}{$\begin{array}{c}\text { Air flow } \\
\text { (cfm) }\end{array}$} & \multirow{2}{*}{$\begin{array}{l}\text { Blower } \\
\text { size } \\
\text { (hp) }\end{array}$} & \multirow{2}{*}{$\begin{array}{l}\text { Water side } \\
\text { flow } \\
\text { (gpm) }\end{array}$} & \multicolumn{2}{|c|}{ Cooling capacity @ 55 EWT } & \multirow{2}{*}{$\begin{array}{l}\text { Cooling EER } \\
\text { @ } 55 \text { FEWT } \\
\text { (Btu/Wh) }\end{array}$} & \multirow{2}{*}{$\begin{array}{c}\text { Heating capacity } \\
@ 55 \text { EWT } \\
\text { (Total MBtu/h) }\end{array}$} & \multirow{2}{*}{$\begin{array}{c}\text { Heating COP @ } \\
55 \text { FEWT } \\
\text { (Btu/Btu) }\end{array}$} \\
\hline & & & & & (Total MBtu/h) & (Sensible MBtu/h) & & & \\
\hline A208 & WVFW1024 & 950 & 0.33 & 6.0 & 25.7 & 20.8 & 29.3 & 20.3 & 4.66 \\
\hline $\mathrm{A} 210$ & WVFW1024 & 950 & 0.33 & 6.0 & 25.7 & 20.8 & 29.3 & 20.3 & 4.66 \\
\hline A212 & WMHW1009 & 355 & 0.03 & 2.0 & 10.1 & 7.5 & 24.1 & 8.5 & 3.84 \\
\hline A213 & WCCW4015 & 630 & 0.33 & 3.8 & 17.4 & 10.5 & 32.9 & 13.8 & 4.34 \\
\hline A214 & WVFW1024 & 950 & 0.33 & 6.0 & 25.7 & 20.8 & 29.3 & 20.3 & 4.66 \\
\hline A215 & WVHC1009 & 300 & 0.06 & 2.5 & 9.6 & 7.3 & 21.4 & 8.4 & 4.34 \\
\hline A216 & WVFW1024 & 950 & 0.33 & 6.0 & 25.7 & 20.8 & 29.3 & 20.3 & 4.66 \\
\hline A217 & WVFW1024 & 950 & 0.33 & 6.0 & 25.7 & 20.8 & 29.3 & 20.3 & 4.66 \\
\hline A218 & WVFW1024 & 950 & 0.33 & 6.0 & 25.7 & 20.8 & 29.3 & 20.3 & 4.66 \\
\hline A219 & WVFW1024 & 950 & 0.33 & 6.0 & 25.7 & 20.8 & 29.3 & 20.3 & 4.66 \\
\hline A220 & WCCW5012 & 400 & 0.13 & 3.0 & 13.9 & 9.5 & 18.7 & 12.5 & 3.58 \\
\hline A221 & WVFW1024 & 950 & 0.33 & 6.0 & 25.7 & 20.8 & 29.3 & 20.3 & 4.66 \\
\hline A302 & WCCW5012 & 400 & 0.13 & 3.0 & 13.7 & 9.5 & 18.7 & 12.5 & 3.58 \\
\hline A303 & WVFW1024 & 950 & 0.33 & 6.0 & 25.7 & 20.8 & 29.3 & 20.3 & 4.66 \\
\hline A304 & WVFW1024 & 950 & 0.33 & 6.0 & 25.7 & 20.8 & 29.3 & 20.3 & 4.66 \\
\hline A305 & WVFW1024 & 950 & 0.33 & 6.0 & 25.7 & 20.8 & 29.3 & 20.3 & 4.66 \\
\hline A306 & WVFW1024 & 950 & 0.33 & 6.0 & 25.7 & 20.8 & 29.3 & 20.3 & 4.66 \\
\hline A307 & WVFW1024 & 950 & 0.33 & 6.0 & 25.7 & 20.8 & 29.3 & 20.3 & 4.66 \\
\hline A308 & WVFW1024 & 950 & 0.33 & 6.0 & 25.7 & 20.8 & 29.3 & 20.3 & 4.66 \\
\hline A310 & WVFW1024 & 950 & 0.33 & 6.0 & 25.7 & 20.8 & 29.3 & 20.3 & 4.66 \\
\hline A312 & WMHW1009 & 355 & 0.03 & 2.0 & 10.1 & 7.5 & 24.1 & 8.5 & 3.84 \\
\hline A313 & WCCW4015 & 630 & 0.33 & 3.8 & 17.4 & 10.5 & 32.9 & 13.8 & 4.34 \\
\hline A314 & WVFW1024 & 950 & 0.33 & 6.0 & 25.7 & 20.8 & 29.3 & 20.3 & 4.66 \\
\hline A315 & WVHC1009 & 300 & 0.06 & 2.5 & 9.6 & 7.3 & 21.4 & 8.4 & 4.34 \\
\hline A316 & WVFW1024 & 950 & 0.33 & 6.0 & 25.7 & 20.8 & 29.3 & 20.3 & 4.66 \\
\hline A317 & WVFW1024 & 950 & 0.33 & 6.0 & 25.7 & 20.8 & 29.3 & 20.3 & 4.66 \\
\hline A318 & WVFW1024 & 950 & 0.33 & 6.0 & 25.7 & 20.8 & 29.3 & 20.3 & 4.66 \\
\hline A319 & WVFW1024 & 950 & 0.33 & 6.0 & 25.7 & 20.8 & 29.3 & 20.3 & 4.66 \\
\hline A320 & WCCW5012 & 400 & 0.13 & 3.0 & 13.7 & 9.5 & 18.7 & 12.5 & 3.58 \\
\hline A321 & WVFW1024 & 950 & 0.33 & 6.0 & 25.7 & 20.8 & 29.3 & 20.3 & 4.66 \\
\hline
\end{tabular}




\begin{tabular}{|c|c|c|c|c|c|c|c|c|c|}
\hline \multirow[t]{2}{*}{ HP tag } & \multirow[t]{2}{*}{ Model } & \multirow{2}{*}{$\begin{array}{c}\text { Air flow } \\
\text { (cfm) }\end{array}$} & \multirow{2}{*}{$\begin{array}{l}\text { Blower } \\
\text { size } \\
\text { (hp) }\end{array}$} & \multirow{2}{*}{$\begin{array}{l}\text { Water side } \\
\text { flow } \\
\text { (gpm) }\end{array}$} & \multicolumn{2}{|c|}{ Cooling capacity @ 55 EWT } & \multirow{2}{*}{$\begin{array}{l}\text { Cooling EER } \\
\text { @ } 55 \text { FEWT } \\
\text { (Btu/Wh) }\end{array}$} & \multirow{2}{*}{$\begin{array}{c}\text { Heating capacity } \\
@ 55 \text { EWT } \\
\text { (Total MBtu/h) }\end{array}$} & \multirow{2}{*}{$\begin{array}{c}\text { Heating COP @ } \\
55 \text { FEWT } \\
\text { (Btu/Btu) }\end{array}$} \\
\hline & & & & & (Total MBtu/h) & (Sensible MBtu/h) & & & \\
\hline A402 & WCCW5012 & 400 & 0.13 & 3.0 & 13.7 & 9.5 & 18.7 & 12.5 & 3.58 \\
\hline A403 & WVFW1024 & 950 & 0.33 & 6.0 & 25.7 & 20.8 & 29.3 & 20.3 & 4.66 \\
\hline A404 & WVFW1024 & 950 & 0.33 & 6.0 & 25.7 & 20.8 & 29.3 & 20.3 & 4.66 \\
\hline A405 & WVFW1024 & 950 & 0.33 & 6.0 & 25.7 & 20.8 & 29.3 & 20.3 & 4.66 \\
\hline A406 & WVFW1024 & 950 & 0.33 & 6.0 & 25.7 & 20.8 & 29.3 & 20.3 & 4.66 \\
\hline A407 & WVFW1024 & 950 & 0.33 & 6.0 & 25.7 & 20.8 & 29.3 & 20.3 & 4.66 \\
\hline A408 & WVFW1024 & 950 & 0.33 & 6.0 & 25.7 & 20.8 & 29.3 & 20.3 & 4.66 \\
\hline A410 & WVFW1024 & 950 & 0.33 & 6.0 & 25.7 & 20.8 & 29.3 & 20.3 & 4.66 \\
\hline A412 & WMHW1009 & 355 & 0.03 & 2.0 & 10.1 & 7.5 & 24.1 & 8.5 & 3.84 \\
\hline A413 & WCCW4015 & 630 & 0.33 & 3.8 & 17.4 & 10.5 & 32.9 & 13.8 & 4.34 \\
\hline A414 & WVFW1024 & 950 & 0.33 & 6.0 & 25.7 & 20.8 & 29.3 & 20.3 & 4.66 \\
\hline A415 & WVHC1009 & 300 & 0.06 & 2.5 & 9.6 & 7.3 & 21.4 & 8.4 & 4.34 \\
\hline A416 & WVFW1024 & 950 & 0.33 & 6.0 & 25.7 & 20.8 & 29.3 & 20.3 & 4.66 \\
\hline A417 & WVFW1024 & 950 & 0.33 & 6.0 & 25.7 & 20.8 & 29.3 & 20.3 & 4.66 \\
\hline A418 & WVFW1024 & 950 & 0.33 & 6.0 & 25.7 & 20.8 & 29.3 & 20.3 & 4.66 \\
\hline A419 & WVFW1024 & 950 & 0.33 & 6.0 & 25.7 & 20.8 & 29.3 & 20.3 & 4.66 \\
\hline A420 & WCCW5012 & 400 & 0.13 & 3.0 & 13.7 & 9.5 & 18.7 & 12.5 & 3.58 \\
\hline A421 & WVFW1024 & 950 & 0.33 & 6.0 & 25.7 & 20.8 & 29.3 & 20.3 & 4.66 \\
\hline A502 & WCCW5012 & 400 & 0.13 & 3.0 & 13.7 & 9.5 & 18.7 & 12.5 & 3.58 \\
\hline A503 & WVFW1024 & 950 & 0.33 & 6.0 & 25.7 & 20.8 & 29.3 & 20.3 & 4.66 \\
\hline A504 & WVFW1024 & 950 & 0.33 & 6.0 & 25.7 & 20.8 & 29.3 & 20.3 & 4.66 \\
\hline A505 & WVFW1024 & 950 & 0.33 & 6.0 & 25.7 & 20.8 & 29.3 & 20.3 & 4.66 \\
\hline A506 & WVFW1024 & 950 & 0.33 & 6.0 & 25.7 & 20.8 & 29.3 & 20.3 & 4.66 \\
\hline A507 & WVFW1024 & 950 & 0.33 & 6.0 & 25.7 & 20.8 & 29.3 & 20.3 & 4.66 \\
\hline A508 & WVFW1024 & 950 & 0.33 & 6.0 & 25.7 & 20.8 & 29.3 & 20.3 & 4.66 \\
\hline A510 & WVFW1024 & 950 & 0.33 & 6.0 & 25.7 & 20.8 & 29.3 & 20.3 & 4.66 \\
\hline A512 & WMHW1009 & 355 & 0.03 & 2.0 & 10.1 & 7.5 & 24.1 & 8.5 & 3.84 \\
\hline A513 & WCCW4015 & 630 & 0.33 & 3.8 & 17.4 & 10.5 & 32.9 & 13.8 & 4.34 \\
\hline A514 & WVFW1024 & 950 & 0.33 & 6.0 & 25.7 & 20.8 & 29.3 & 20.3 & 4.66 \\
\hline A515 & WVHC1009 & 300 & 0.06 & 2.5 & 9.6 & 7.3 & 21.4 & 8.4 & 4.34 \\
\hline
\end{tabular}




\begin{tabular}{|c|c|c|c|c|c|c|c|c|c|}
\hline \multirow[t]{2}{*}{ HP tag } & \multirow[t]{2}{*}{ Model } & \multirow{2}{*}{$\begin{array}{c}\text { Air flow } \\
\text { (cfm) }\end{array}$} & \multirow{2}{*}{$\begin{array}{l}\text { Blower } \\
\text { size } \\
\text { (hp) }\end{array}$} & \multirow{2}{*}{$\begin{array}{l}\text { Water side } \\
\text { flow } \\
\text { (gpm) }\end{array}$} & \multicolumn{2}{|c|}{ Cooling capacity @ 55 EWT } & \multirow{2}{*}{$\begin{array}{l}\text { Cooling EER } \\
\text { @ } 55 \text { FEWT } \\
\text { (Btu/Wh) }\end{array}$} & \multirow{2}{*}{$\begin{array}{c}\text { Heating capacity } \\
@ 55 \text { EWT } \\
\text { (Total MBtu/h) }\end{array}$} & \multirow{2}{*}{$\begin{array}{c}\text { Heating COP @ } \\
55 \text { FEWT } \\
\text { (Btu/Btu) }\end{array}$} \\
\hline & & & & & (Total MBtu/h) & (Sensible MBtu/h) & & & \\
\hline $\mathrm{A} 516$ & WVFW1024 & 950 & 0.33 & 6.0 & 25.7 & 20.8 & 29.3 & 20.3 & 4.66 \\
\hline A517 & WVFW1024 & 950 & 0.33 & 6.0 & 25.7 & 20.8 & 29.3 & 20.3 & 4.66 \\
\hline A518 & WVFW1024 & 950 & 0.33 & 6.0 & 25.7 & 20.8 & 29.3 & 20.3 & 4.66 \\
\hline A519 & WVFW1024 & 950 & 0.33 & 6.0 & 25.7 & 20.8 & 29.3 & 20.3 & 4.66 \\
\hline A520 & WCCW5012 & 400 & 0.13 & 3.0 & 13.6 & 9.5 & 18.7 & 12.5 & 3.58 \\
\hline A521 & WVFW1024 & 950 & 0.33 & 6.0 & 25.7 & 20.8 & 29.3 & 20.3 & 4.66 \\
\hline B103 & WVFW1024 & 950 & 0.33 & 6.0 & 25.7 & 20.8 & 29.3 & 20.3 & 4.66 \\
\hline B104 & WVFW1024 & 950 & 0.33 & 6.0 & 25.7 & 20.8 & 29.3 & 20.3 & 4.66 \\
\hline B105 & WVFW1024 & 950 & 0.33 & 6.0 & 25.7 & 20.8 & 29.3 & 20.3 & 4.66 \\
\hline B106 & WVFW1024 & 950 & 0.33 & 6.0 & 25.7 & 20.8 & 29.3 & 20.3 & 4.66 \\
\hline B107 & WVFW1024 & 950 & 0.33 & 6.0 & 25.7 & 20.8 & 29.3 & 20.3 & 4.66 \\
\hline $\mathrm{B} 110$ & WCCW4019 & 700 & 0.33 & 5.5 & 23.7 & 17.4 & 23.0 & 18.2 & 4.15 \\
\hline $\mathrm{B} 112$ & WCCW5012 & 390 & 0.13 & 3.0 & 14.0 & 9.4 & 18.6 & 12.5 & 3.58 \\
\hline $\mathrm{B} 114$ & WCCW4109 & 630 & 0.33 & 4.0 & 22.8 & 16.1 & 22.1 & 17.4 & 4.05 \\
\hline B117 & WCCW4019 & 530 & 0.33 & 3.8 & 22.7 & 16.0 & 21.9 & 17.3 & 4.04 \\
\hline B118 & WVFW1024 & 950 & 0.33 & 6.0 & 25.7 & 20.8 & 29.3 & 20.3 & 4.66 \\
\hline B119 & WVHC1009 & 300 & 0.06 & 2.5 & 9.6 & 7.3 & 21.4 & 8.4 & 4.34 \\
\hline B120 & WVFW1024 & 950 & 0.33 & 6.0 & 25.7 & 20.8 & 29.3 & 20.3 & 4.66 \\
\hline B121 & WVFW1024 & 950 & 0.33 & 6.0 & 25.7 & 20.8 & 29.3 & 20.3 & 4.66 \\
\hline B122 & WVFW1024 & 950 & 0.33 & 6.0 & 25.7 & 20.8 & 29.3 & 20.3 & 4.66 \\
\hline B123 & WVFW1024 & 950 & 0.33 & 6.0 & 25.7 & 20.8 & 29.3 & 20.3 & 4.66 \\
\hline B124 & WVFW1024 & 950 & 0.33 & 6.0 & 25.7 & 20.8 & 29.3 & 20.3 & 4.66 \\
\hline B125 & WVFW1024 & 950 & 0.33 & 6.0 & 25.7 & 20.8 & 29.3 & 20.3 & 4.66 \\
\hline B126 & WCCW5012 & 400 & 0.13 & 3.0 & 13.9 & 9.5 & 18.7 & 12.5 & 3.58 \\
\hline B202 & WCCW5012 & 400 & 0.13 & 3.0 & 13.7 & 9.5 & 18.7 & 12.5 & 3.58 \\
\hline B203 & WVFW1024 & 950 & 0.33 & 6.0 & 25.7 & 20.8 & 29.3 & 20.3 & 4.66 \\
\hline B204 & WVFW1024 & 950 & 0.33 & 6.0 & 25.7 & 20.8 & 29.3 & 20.3 & 4.66 \\
\hline B205 & WVFW1024 & 950 & 0.33 & 6.0 & 25.7 & 20.8 & 29.3 & 20.3 & 4.66 \\
\hline B206 & WVFW1024 & 950 & 0.33 & 6.0 & 25.7 & 20.8 & 29.3 & 20.3 & 4.66 \\
\hline B207 & WVFW1024 & 950 & 0.33 & 6.0 & 25.7 & 20.8 & 29.3 & 20.3 & 4.66 \\
\hline
\end{tabular}




\begin{tabular}{|c|c|c|c|c|c|c|c|c|c|}
\hline \multirow[t]{2}{*}{ HP tag } & \multirow[t]{2}{*}{ Model } & \multirow{2}{*}{$\begin{array}{c}\text { Air flow } \\
\text { (cfm) }\end{array}$} & \multirow{2}{*}{$\begin{array}{l}\text { Blower } \\
\text { size } \\
\text { (hp) }\end{array}$} & \multirow{2}{*}{$\begin{array}{l}\text { Water side } \\
\text { flow } \\
\text { (gpm) }\end{array}$} & \multicolumn{2}{|c|}{ Cooling capacity @ 55 EWT } & \multirow{2}{*}{$\begin{array}{l}\text { Cooling EER } \\
\text { @ } 55 \text { FEWT } \\
\text { (Btu/Wh) }\end{array}$} & \multirow{2}{*}{$\begin{array}{c}\text { Heating capacity } \\
@ 55 \text { EWT } \\
\text { (Total MBtu/h) }\end{array}$} & \multirow{2}{*}{$\begin{array}{c}\text { Heating COP @ } \\
55 \text { FEWT } \\
\text { (Btu/Btu) }\end{array}$} \\
\hline & & & & & (Total MBtu/h) & (Sensible MBtu/h) & & & \\
\hline B208 & WVFW1024 & 950 & 0.33 & 6.0 & 25.7 & 20.8 & 29.3 & 20.3 & 4.66 \\
\hline B210 & WVFW1024 & 950 & 0.33 & 6.0 & 25.7 & 20.8 & 29.3 & 20.3 & 4.66 \\
\hline B212 & WMHW1009 & 355 & 0.03 & 2.0 & 10.1 & 7.5 & 24.1 & 8.5 & 3.84 \\
\hline B213 & WCCW4015 & 630 & 0.33 & 3.8 & 17.4 & 10.5 & 32.9 & 13.8 & 4.34 \\
\hline B214 & WVFW1024 & 950 & 0.33 & 6.0 & 25.7 & 20.8 & 29.3 & 20.3 & 4.66 \\
\hline $\mathrm{B} 215$ & WVHC1009 & 300 & 0.06 & 2.5 & 9.6 & 7.3 & 21.4 & 8.4 & 4.34 \\
\hline B216 & WVFW1024 & 950 & 0.33 & 6.0 & 25.7 & 20.8 & 29.3 & 20.3 & 4.66 \\
\hline B217 & WVFW1024 & 950 & 0.33 & 6.0 & 25.7 & 20.8 & 29.3 & 20.3 & 4.66 \\
\hline B218 & WVFW1024 & 950 & 0.33 & 6.0 & 25.7 & 20.8 & 29.3 & 20.3 & 4.66 \\
\hline B219 & WVFW1024 & 950 & 0.33 & 6.0 & 25.7 & 20.8 & 29.3 & 20.3 & 4.66 \\
\hline B220 & WVFW1024 & 950 & 0.33 & 6.0 & 25.7 & 20.8 & 29.3 & 20.3 & 4.66 \\
\hline B221 & WVFW1024 & 950 & 0.33 & 6.0 & 25.7 & 20.8 & 29.3 & 20.3 & 4.66 \\
\hline B222 & WCCW5012 & 400 & 0.13 & 3.0 & 13.7 & 9.5 & 18.7 & 12.5 & 3.58 \\
\hline B302 & WCCW5012 & 400 & 0.13 & 3.0 & 13.7 & 9.5 & 18.7 & 12.5 & 3.58 \\
\hline B303 & WVFW1024 & 950 & 0.33 & 6.0 & 25.7 & 20.8 & 29.3 & 20.3 & 4.66 \\
\hline B304 & WVFW1024 & 950 & 0.33 & 6.0 & 25.7 & 20.8 & 29.3 & 20.3 & 4.66 \\
\hline B305 & WVFW1024 & 950 & 0.33 & 6.0 & 25.7 & 20.8 & 29.3 & 20.3 & 4.66 \\
\hline B306 & WVFW1024 & 950 & 0.33 & 6.0 & 25.7 & 20.8 & 29.3 & 20.3 & 4.66 \\
\hline B307 & WVFW1024 & 950 & 0.33 & 6.0 & 25.7 & 20.8 & 29.3 & 20.3 & 4.66 \\
\hline B308 & WVFW1024 & 950 & 0.33 & 6.0 & 25.7 & 20.8 & 29.3 & 20.3 & 4.66 \\
\hline B310 & WVFW1024 & 950 & 0.33 & 6.0 & 25.7 & 20.8 & 29.3 & 20.3 & 4.66 \\
\hline B312 & WMHW1009 & 355 & 0.03 & 2.0 & 10.1 & 7.5 & 24.1 & 8.5 & 3.84 \\
\hline B313 & WCCW4015 & 630 & 0.33 & 3.8 & 17.4 & 10.5 & 32.9 & 13.8 & 4.34 \\
\hline B314 & WVFW1024 & 950 & 0.33 & 6.0 & 25.7 & 20.8 & 29.3 & 20.3 & 4.66 \\
\hline B315 & WVHC1009 & 300 & 0.06 & 2.5 & 9.6 & 7.3 & 21.4 & 8.4 & 4.34 \\
\hline B316 & WVFW1024 & 950 & 0.33 & 6.0 & 25.7 & 20.8 & 29.3 & 20.3 & 4.66 \\
\hline B317 & WVFW1024 & 950 & 0.33 & 6.0 & 25.7 & 20.8 & 29.3 & 20.3 & 4.66 \\
\hline B318 & WVFW1024 & 950 & 0.33 & 6.0 & 25.7 & 20.8 & 29.3 & 20.3 & 4.66 \\
\hline B319 & WVFW1024 & 950 & 0.33 & 6.0 & 25.7 & 20.8 & 29.3 & 20.3 & 4.66 \\
\hline B320 & WVFW1024 & 950 & 0.33 & 6.0 & 25.7 & 20.8 & 29.3 & 20.3 & 4.66 \\
\hline
\end{tabular}




\begin{tabular}{|c|c|c|c|c|c|c|c|c|c|}
\hline \multirow[t]{2}{*}{ HP tag } & \multirow[t]{2}{*}{ Model } & \multirow{2}{*}{$\begin{array}{c}\text { Air flow } \\
\text { (cfm) }\end{array}$} & \multirow{2}{*}{$\begin{array}{l}\text { Blower } \\
\text { size } \\
\text { (hp) }\end{array}$} & \multirow{2}{*}{$\begin{array}{l}\text { Water side } \\
\text { flow } \\
\text { (gpm) }\end{array}$} & \multicolumn{2}{|c|}{ Cooling capacity @ 55 EWT } & \multirow{2}{*}{$\begin{array}{l}\text { Cooling EER } \\
\text { @ } 55 \text { FEWT } \\
\text { (Btu/Wh) }\end{array}$} & \multirow{2}{*}{$\begin{array}{c}\text { Heating capacity } \\
@ 55 \text { EWT } \\
\text { (Total MBtu/h) }\end{array}$} & \multirow{2}{*}{$\begin{array}{c}\text { Heating COP @ } \\
55 \text { FEWT } \\
\text { (Btu/Btu) }\end{array}$} \\
\hline & & & & & (Total MBtu/h) & (Sensible MBtu/h) & & & \\
\hline B321 & WVFW1024 & 950 & 0.33 & 6.0 & 25.7 & 20.8 & 29.3 & 20.3 & 4.66 \\
\hline B322 & WCCW5012 & 400 & 0.13 & 3.0 & 13.7 & 9.5 & 18.7 & 12.5 & 3.58 \\
\hline B402 & WCCW5012 & 400 & 0.13 & 3.0 & 13.7 & 9.5 & 18.7 & 12.5 & 3.58 \\
\hline B403 & WVFW1024 & 950 & 0.33 & 6.0 & 25.7 & 20.8 & 29.3 & 20.3 & 4.66 \\
\hline B404 & WVFW1024 & 950 & 0.33 & 6.0 & 25.7 & 20.8 & 29.3 & 20.3 & 4.66 \\
\hline B405 & WVFW1024 & 950 & 0.33 & 6.0 & 25.7 & 20.8 & 29.3 & 20.3 & 4.66 \\
\hline B406 & WVFW1024 & 950 & 0.33 & 6.0 & 25.7 & 20.8 & 29.3 & 20.3 & 4.66 \\
\hline B407 & WVFW1024 & 950 & 0.33 & 6.0 & 25.7 & 20.8 & 29.3 & 20.3 & 4.66 \\
\hline B408 & WVFW1024 & 950 & 0.33 & 6.0 & 25.7 & 20.8 & 29.3 & 20.3 & 4.66 \\
\hline B410 & WVFW1024 & 950 & 0.33 & 6.0 & 25.7 & 20.8 & 29.3 & 20.3 & 4.66 \\
\hline B412 & WMHW1009 & 355 & 0.03 & 2.0 & 10.1 & 7.5 & 24.1 & 8.5 & 3.84 \\
\hline B413 & WCCW4015 & 630 & 0.33 & 3.8 & 17.4 & 10.5 & 32.9 & 13.8 & 4.34 \\
\hline B414 & WVFW1024 & 950 & 0.33 & 6.0 & 25.7 & 20.8 & 29.3 & 20.3 & 4.66 \\
\hline B415 & WVHC1009 & 300 & 0.06 & 2.5 & 9.6 & 7.3 & 21.4 & 8.4 & 4.34 \\
\hline B416 & WVFW1024 & 950 & 0.33 & 6.0 & 25.7 & 20.8 & 29.3 & 20.3 & 4.66 \\
\hline B417 & WVFW1024 & 950 & 0.33 & 6.0 & 25.7 & 20.8 & 29.3 & 20.3 & 4.66 \\
\hline B418 & WVFW1024 & 950 & 0.33 & 6.0 & 25.7 & 20.8 & 29.3 & 20.3 & 4.66 \\
\hline B419 & WVFW1024 & 950 & 0.33 & 6.0 & 25.7 & 20.8 & 29.3 & 20.3 & 4.66 \\
\hline B420 & WVFW1024 & 950 & 0.33 & 6.0 & 25.7 & 20.8 & 29.3 & 20.3 & 4.66 \\
\hline B421 & WVFW1024 & 950 & 0.33 & 6.0 & 25.7 & 20.8 & 29.3 & 20.3 & 4.66 \\
\hline B422 & WCCW5012 & 400 & 0.13 & 3.0 & 13.7 & 9.5 & 18.7 & 12.5 & 3.58 \\
\hline B502 & WCCW5012 & 400 & 0.13 & 3.0 & 13.7 & 9.5 & 18.7 & 12.5 & 3.58 \\
\hline B503 & WVFW1024 & 950 & 0.33 & 6.0 & 25.7 & 20.8 & 29.3 & 20.3 & 4.66 \\
\hline B504 & WVFW1024 & 950 & 0.33 & 6.0 & 25.7 & 20.8 & 29.3 & 20.3 & 4.66 \\
\hline B505 & WVFW1024 & 950 & 0.33 & 6.0 & 25.7 & 20.8 & 29.3 & 20.3 & 4.66 \\
\hline B506 & WVFW1024 & 950 & 0.33 & 6.0 & 25.7 & 20.8 & 29.3 & 20.3 & 4.66 \\
\hline B507 & WVFW1024 & 950 & 0.33 & 6.0 & 25.7 & 20.8 & 29.3 & 20.3 & 4.66 \\
\hline B508 & WVFW1024 & 950 & 0.33 & 6.0 & 25.7 & 20.8 & 29.3 & 20.3 & 4.66 \\
\hline B510 & WVFW1024 & 950 & 0.33 & 6.0 & 25.7 & 20.8 & 29.3 & 20.3 & 4.66 \\
\hline B512 & WMHW1009 & 355 & 0.03 & 2.0 & 10.1 & 7.5 & 24.1 & 8.5 & 3.84 \\
\hline
\end{tabular}




\begin{tabular}{|c|c|c|c|c|c|c|c|c|c|}
\hline \multirow{2}{*}{ HP tag } & \multirow{2}{*}{ Model } & \multirow{2}{*}{$\begin{array}{l}\text { Air flow } \\
\text { (cfm) }\end{array}$} & \multirow{2}{*}{$\begin{array}{l}\text { Blower } \\
\text { size } \\
\text { (hp) }\end{array}$} & \multirow{2}{*}{$\begin{array}{l}\text { Water side } \\
\text { flow } \\
\text { (gpm) }\end{array}$} & \multicolumn{2}{|c|}{ Cooling capacity @ 55 EWT } & \multirow{2}{*}{$\begin{array}{l}\text { Cooling EER } \\
\text { @ 55 FEWT } \\
\text { (Btu/Wh) }\end{array}$} & \multirow{2}{*}{$\begin{array}{l}\text { Heating capacity } \\
@ 55 \text { EWT } \\
\text { (Total MBtu/h) }\end{array}$} & \multirow{2}{*}{$\begin{array}{c}\text { Heating COP @ } \\
55 \text { FEWT } \\
\text { (Btu/Btu) }\end{array}$} \\
\hline & & & & & (Total MBtu/h) & (Sensible MBtu/h) & & & \\
\hline B513 & WCCW4015 & 630 & 0.33 & 3.8 & 17.4 & 10.5 & 32.9 & 13.8 & 4.34 \\
\hline B514 & WVFW1024 & 950 & 0.33 & 6.0 & 25.7 & 20.8 & 29.3 & 20.3 & 4.66 \\
\hline B515 & WVHC1009 & 300 & 0.06 & 2.5 & 9.6 & 7.3 & 21.4 & 8.4 & 4.34 \\
\hline B516 & WVFW1024 & 950 & 0.33 & 6.0 & 25.7 & 20.8 & 29.3 & 20.3 & 4.66 \\
\hline B517 & WVFW1024 & 950 & 0.33 & 6.0 & 25.7 & 20.8 & 29.3 & 20.3 & 4.66 \\
\hline B518 & WVFW1024 & 950 & 0.33 & 6.0 & 25.7 & 20.8 & 29.3 & 20.3 & 4.66 \\
\hline B519 & WVFW1024 & 950 & 0.33 & 6.0 & 25.7 & 20.8 & 29.3 & 20.3 & 4.66 \\
\hline B520 & WVFW1024 & 950 & 0.33 & 6.0 & 25.7 & 20.8 & 29.3 & 20.3 & 4.66 \\
\hline B521 & WVFW1024 & 950 & 0.33 & 6.0 & 25.7 & 20.8 & 29.3 & 20.3 & 4.66 \\
\hline B522 & WCCW5012 & 400 & 0.13 & 3.0 & 13.7 & 9.5 & 18.7 & 12.5 & 3.58 \\
\hline C105 & WCCW4070 & 2,330 & 1.00 & 15.0 & 76.2 & 41.5 & 22.9 & 68.2 & 4.32 \\
\hline & Total & 151,210 & 54.1 & 975 & 4,260 & 3,321 & 27.8 & 3,425 & 4.50 \\
\hline
\end{tabular}




\section{APPENDIX B. ORIGINAL SPECIFICATION FOR PUMPING CONTROL}

Following information is from the original design document of the demonstrated GSHP system.

THE VFDS WILL RAMP UP OR DOWN BASED ON GSHP WELL FIELD TEMPERATURE DIFFERENTIAL AND GSHP WELL FIELD TEMPERATURE SET POINTS FOR GSHP WELL FIELD SUPPLY AND RETURN TEMPERATURES

WSHP BUILDING SIDE PUMPS ARE CONTROLLED TO MAINTAIN THE BUILDING LOOP BETWEEN TWO TEMPERATURES:

$\square$ COOLING: THE UPPER LIMIT IS THE GSHP DESIGN (HIGH LIMIT) ENTERING WATER TEMPERATURE FOR COOLING.

$\square$ HEATING: THE LOWER LIMIT IS THE GSHP DESIGN (LOW LIMIT) ENTERING WATER TEMPERATURE FOR HEATING.

THE PUMPS OPERATE IN PARALLEL TO MEET THE BUILDING LOAD. PUMP SEED IS MODULATED TO MAINTAIN THE DESIRED BUILDING LOOP TEMPERATURE DEPENDING ON BUILDING LOAD MEASURED BY THE GSHP LOOP DIFFERENTIAL TEMPERATURE. PUMP P-4 WILL RAMP FROM 20\% MINIMUM FLOW TO 100\% TO MEET TEMPERATURE SET POINT. IF P-4 IS NOT ABLE TO SATISFY THE LOAD, PUMP P-5 WILL ENERGIZE AND RAMP FROM 20\% TO 100\% UNTIL THE TEMPERATURE SET POINT IS MET. WHEN BOTH PUMPS ARE ENERGIZED, BOTH WILL RAMP UP AND DOWN AT THE SAME SPEED TO MEET TEMPERATURE SET POINT. AS THE BUILDING LOAD DECREASES AND THE GSHP LOOP DIFFERENTIAL TEMPERATURE DECREASES, PUMP P-6 WILL RAMP DOWN TO 20\% MINIMUM AND THEN TO OFF AS THE BUILDING LOAD AND THE GSHP LOOP DIFFERENTIAL TEMPERATURE DECREASES. PUMP P-5 WILL RAMP FROM 100\% TO 20\% MINIMUM FLOW TO MEET TEMPERATURE SET POINT.

ALL SET POINTS WILL BE OPERATOR ADJUSTABLE FROM THE BMS. 


\section{APPENDIX C. ADDITIONAL DATA FROM ON-SITE MEASUREMENTS}

(1) Fan power of the GSHP unit in a typical suite:

- 206 VAC, 1.9 amps, 200 watts (in ventilation mode)

- 206 VAC, 4.5 amps, 930 watts (single-stage compressor in cooling mode)

(2) Circulation pumps

- $\quad$ Measured ground loop pumping power of operating pumps (Pump $1 \& 2$ ON, Pump 3 OFF)

\begin{tabular}{|l|r|r|r|r|}
\hline Pump \#1 & & & & \\
\hline Speed (command) & Auto & $75 \%$ & $50 \%$ & $10 \%$ \\
\hline Speed (acutal) & $97 \%$ & $76 \%$ & $51 \%$ & $20 \%$ \\
\hline Amps (Avg) & 20.47 & 11.10 & 2.73 & 1.25 \\
\hline Power (kW) & 14.2 & 6.6 & 1.42 & 0.6 \\
\hline & & & & \\
\hline Pump \#2 & & & & \\
\hline Speed (command) & Auto & & & \\
\hline Speed (acutal) & $90 \%$ & & & \\
\hline Amps (Avg) & 16.50 & & & \\
\hline Power (kW) & 11.5 & & & \\
\hline
\end{tabular}

